\title{
THE EFFECTS OF WATER DEVELOPMENT UPON POPULATIONS OF GAMBEL'S QUAIL IN SOUTHWESTERN UTAH
}

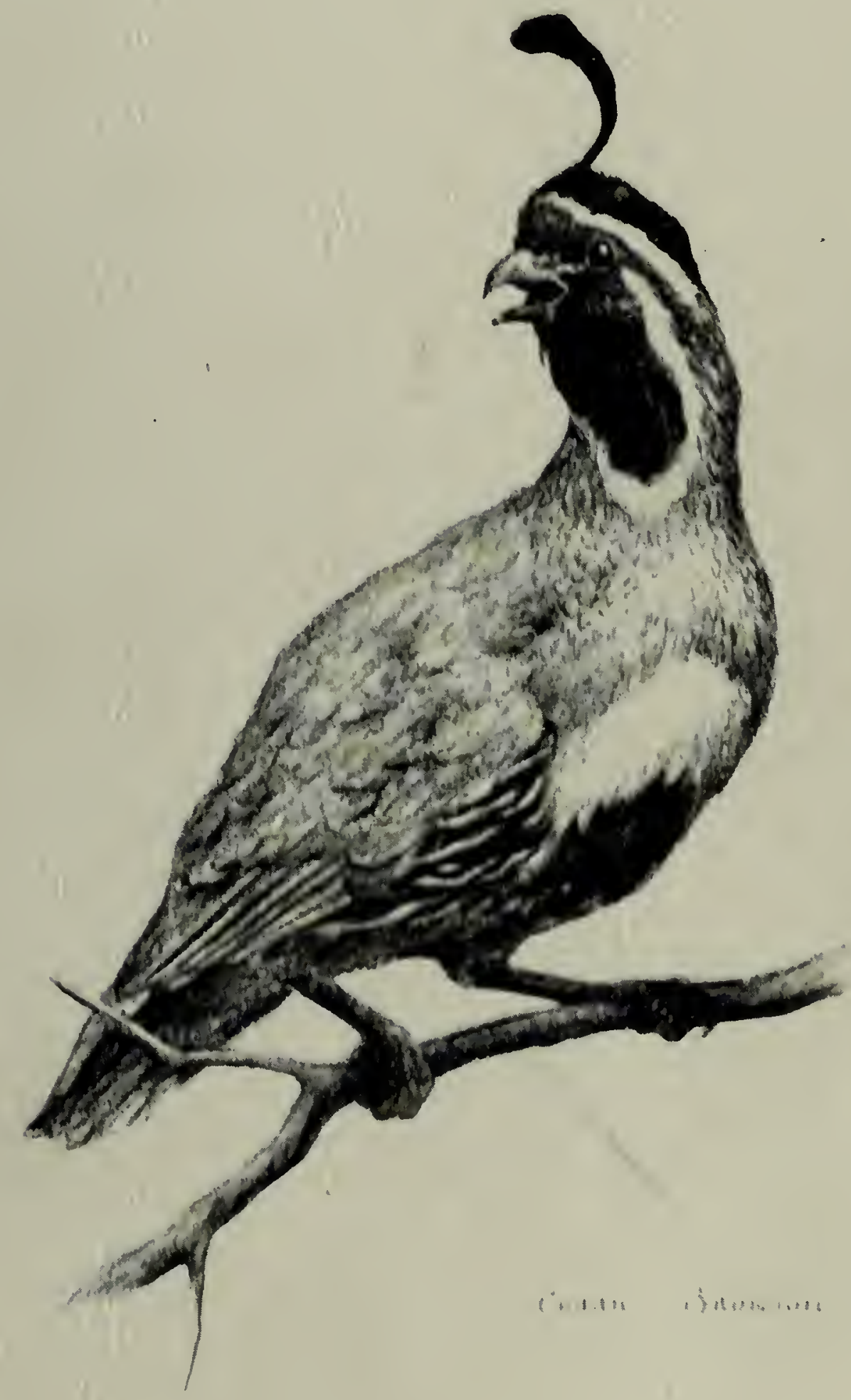

PUBLICATION NO. 65-5

Federal Aid Project W-103-R

UTAH STATE DEPARTMENT OF FISH AND GAME 
HAROID B. LEE LIBRARY

BRIGHAW YU_G LIIVERSITY

PROVO, UTAH 
THE EFFECTS OF WATER DEVELOPMENT UPON POPULATIONS OF GAMBEL'S QUAIL

IN SOUTHWESTERN UTAH

\section{By}

Darrell H. Nish

PUBLICATION NO. 65-5

Job Completion Report

for

Federal Aid Project W-103-R

December 31, 1964

UTAH STATE DEPARTMENT OF FISH AND GAME

HAROLD S . CRANE, DIRECTOR 


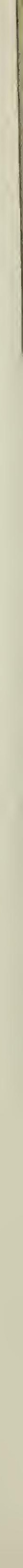


State of $\mathrm{U}$ T A H

Project No. W-103-R-3

Name :

The Effects of Water Development Upon Populations of Gambel's Quail in Southwestern Utah

Job No. $\mathrm{F}-1$

Title: Final Report

Period Covered: June 15, 1961 to June 30, 1964

Abstract:

Research was conducted from 1961-64 to determine the effects of water on Gambel's quail with regard to population density, survival of young and distribution and movements. Work was also done on habitat evaluation, testing trend techniques and recording life history information.

Quail tended to concentrate in the vicinity of water even during the period from September to June when they were not observed to drink it. Deprivation of water noticeably altered distribution patterns.

Movements were effected by water to the extent that during the water-critical period from June to September quail made frequent, possibly daily, trips to water. Extreme movements of two and three miles were noted following water deprivation. Twenty percent of marked quail observed had apparently changed catchments. The mean movements of hunter-harvested and marked quail were 1.0 and 0.63 miles respectively.

There was inconclusive evidence that quail utilizing water experienced greater survival and population densities than those living in waterless areas.

Five vegetation types were described but the ecotonal nature of the study area obscured boundary lines between types. In order of greatest quail use they included the mixed-shrub, mountain-shrub, black-brush, creosote-brush-- bur-sage and pinyon-juniper.

Protective cover for quail was usually provided by desertalmond. This shrub occurred along the margins of the larger dry washes and influenced quail abundance and distribution to a greater extent than water.

The diet of quail was largely a function of availability although preferences were apparent.

Although water was found to influence quail, its practical value for improving hunting was questioned. During this study, drinking water was not limiting population increase. Quail numbers declined each year despite the presence of water. As a result, hunting was poor and few people were attracted to 
$\|$ 
the area. The possibility exists that during years of high population the concentrating and possibly increasing effect of water may substantially improve hunter success. Only additional research will determine this satisfactorily. It was recommended that no further water development be done unless future research reveals greater benefits than found during this study.

No conclusions were made concerning the relative accuracy of the trend techniques because of only two years data being available. It appeared however, that the long-period waterhole counts provided the most information on reproductive success in addition to indicating population trend.

Life history information confirmed findings of other workers and added no new knowledge of this species.

Recommendations outlining future research needs were also presented.

The attached report was prepared and presented as a thesis for a Master of Science Degree in Wildlife Biology at Utah State University. Formal publication of this report is planned.

Prepared by: Darrell H. Nish

Date: December 31, 1964
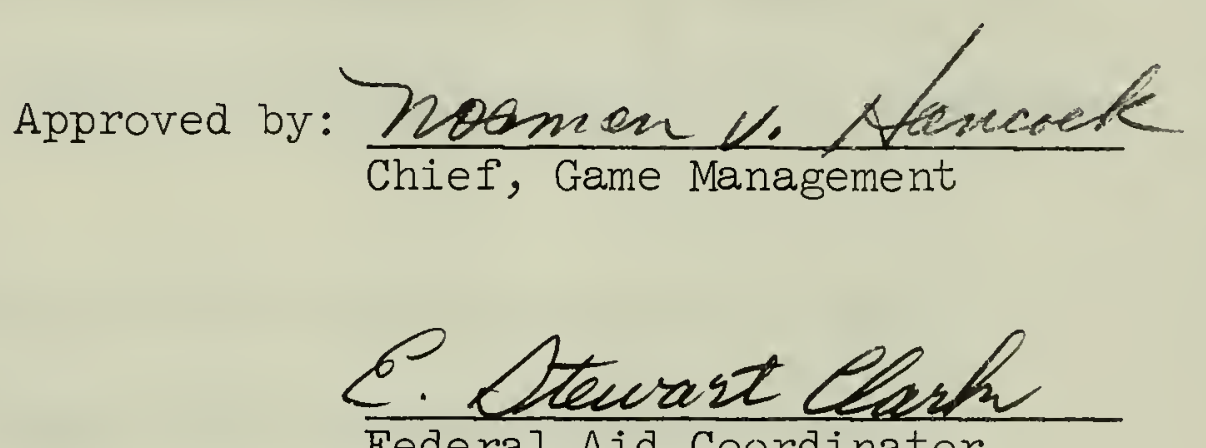
Digitized by the Internet Archive in 2011 with funding from Brigham Young University 


\section{ACKNOWLEDGMENTS}

My deepest gratitude is extended to the State of Utah Department of Fish and Game for allowing me to conduct this research. Sincere thanks are given Mr. Norman V. Hancock and Mr. Clifton M. Greenhalgh for assistance and advice. I am especially grateful to Mr. William J. Bailey, Jr. for his guidance, encouragement and critical review of this thesis. Appreciation is extended to personnel of the Southern Region for their efforts in my behalf.

My major professor, Dr. Jessop B. Low, Leader of the Utah Cooperative Wildlife Research Unit, provided constant encouragement and guidance throughout the study period. To him and other members of my graduate committee, Dr. Allen W. Stokes, Prof. Merrill H. Gunnell and Dr. D.R. Franklin, I express my appreciation.

Prof. Arthur H. Holmgren, Curator of the Intermountain Herbarium, contributed much by identifying the many plant specimens collected.

I am grateful to $\mathrm{Mr}$. Levi Snow of st. George, Utah for permitting me to use the Terry Ranch as a base for field work and for many other kindnesses.

Finally I express sincere appreciation and gratitude to my wife LaDean for her unfailing faith and support, and for the many hours she devoted to typing the manuscript.

Darrell H. Nish 

TABLE OF CONTENTS

INTRODUCTION

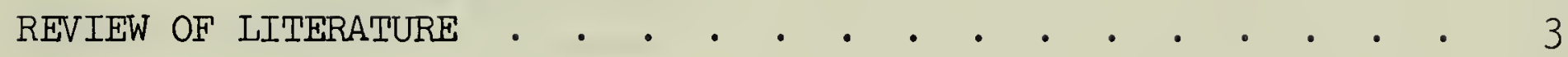

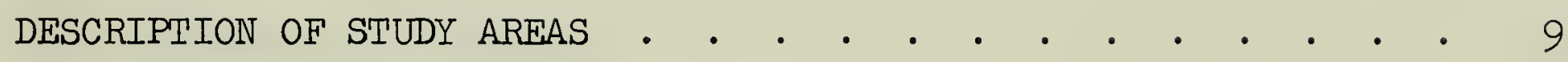

General study area • • • • • • • • • . . . . . 9

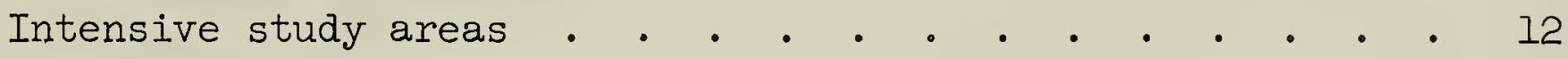

Developed areas . . . . . . . . . . . . . 13

Waterless areas . . . . . . • . • . . . . 15

Quail watering devices . . . . . . . . . . . . 18

Stock-watering tanks . . . . . . . . . . . . 18

Quail fountains . . . . . . . . . . . . 18

Water catchments . . . . . . . . . . . 18

PROCEDURES

Quail population density . . . . . . . . . . . . 24

Line-transect counts . . . . . . . . . . . . 24

Call counts . . . . . . . . . . . . . . 25

Roadside counts . . . . . . . . • . . . 28

Long -period waterhole counts . . . . . . . . 28

Hunter checking stations . • . • . • • • . . 29

Survival of young quail • • • • • • • • • • • 29

Distribution of quail . . . . . . . . . . . . 30

Quail movements • • • . . • . • . . . . • . 31

Habitat evaluation . • . . . • . . . . . . . 34

Intensive study areas . . . • . . . . . . 34

General study areas . . . . . • • • . . . . 35

Life history information . • • • • • • • • • • 35

RESULTS • • • • • • • • • • • • • • • • • • • 37

Quail population density . • • • • • • • • • • • 37

Line-transect counts . . . . . . . . . . 37

Call counts . . . . . . . . . . . . . 43 
$+2$ 
Roadside counts . • . . . . . . . • . . 443

Long-period waterhole counts . . . . . . . . 47

Hunter success . . . . . . . . • . . . . 47

Comparison of indexes . . . . . . . . . . . . 47

Survival of young quail • • • • • • • • • • • . 51

Intensive study areas . . . . • • . . • . . 51

General study area . . . . . . • . . . . 52

Distribution of quail . • . . . . . . . . . . . 59

Intensive study areas . . . . . . . . . . . 59

General study area . . . . . . . . . . . 61

Call counts. . . . . . . . . . . . . . 62

Quail movements • • • • • • • • • • . . . 62

Trapping success . . . . . . . . . . 62

Band returns . . . . . . . . . . . . 66

Marked quail observations . . . . . . . . 68

Retrapped quail . . . . . . • •. . . 69

Longevity . . . . . . . . . . . . . . . 69

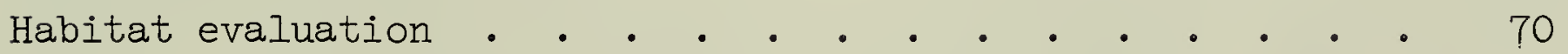

Intensive study areas . . . . . . . . . . 70

General study area . . . . . . . . . 80

Habitat quality . • . . . • . . . • . 87

Food habits . . . . . . . . . • • • . . 90

Life history information • • • • • • • • • • • 97

Nesting • • • • • • • • • • • • • • • . 97

Age ratios . . . . . . . . . . . . . . . 98

Sex ratios • . • . • . • . . . • • • . . 98

Harvest . . . . . • . . . . . • . . . . 98

Quail weights . • . • . . . • • . . . • 99

Quail watering habits . . . . . . . . 100

DISCUSSION AND CONCLUSIONS • • • • • • • • • • • • • • . 102

Effects of water on quail . . . . . . . . . . 102

Population density . • . . . . . . . . . 102

Survival of young quail . . . . . . . . . 103

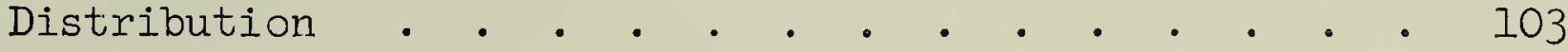

Movements . . . . . . . . . . . . . 104

Habitat evaluation . . . . . . . . . . . . . 105

Food habits . . . . . . . . . . . . . . 107

Value of water development . . . . . . . . . . 108 
Evaluation of trend techniques . . . . . . . . 110

Life history information . . . . . . . . . . . Ill

RECOMMENDATIONS • • • • • • • • • • • • • • • . • 113

SUMMARY • • • • • • • • • • • • • • • • • 115

LITERATURE CITED • • • • • • • • • • • • • . 118

APPENDIX • • • • • • • • • • • • • • • • • • . 121 


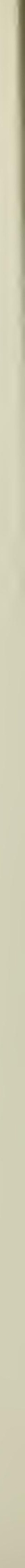




\section{LIST OF TABLES}

Table

1. Results of line-transect counts in areas $\mathrm{A}-1$ and $\mathrm{A}-2$, September, 1961 through September, 1963 . . . . . . 40

2. Results of line-transect counts in areas B-I and B-2, September, 1961 through September, 1963 . . . . . . . 41

3. Call count indexes determined for the general study area during 1962, 1963 and 1964 . . . . . . . . . 44

4. The effects of wind velocity on calling as indicated by pooling counts according to estimated velocity in 1962

5. Frequency of calling of individual male Gambel's quail during 1962 and 1963

6. Results of pre-breeding roadside counts of Gambel's quail for 1962, 1963 and 1964 . . . . . . . . . 48

7. Results of post-breeding roadside counts of Gambel's quail for 1962 and 1963 . . . . . . . . . . . 48

8. Results of long-period waterhole counts for 1962 and 1963

9. Quail hunter success in the Beaver Dam Mountain area during 1961

10. Quail hunter success in the Beaver Dam Mountain area during 1962

11. Quail hunter success in the Beaver Dam Mountain area during 1963

12. Comparison of estimated population decline as determined by call counts, roadside counts, long-period waterhole counts and hunter success from 1962 to 1963 . . . . . 50

13. Summary of Gambel's quail monthly brood size and age ratios showing their gradual decline through the summer months, 1962 

Table

Page

14. Summary of Gambel's quail monthly brood size and age ratios showing their gradual decline through the summer months, 1963

15. Relative proportions of juvenile quail in the hunters' bag on succeeding week-ends during the 1961 hunting season . . 58

16. Relative proportions of juvenile quail in the hunters' bag during succeeding periods of the 1962 hunting season . . . 58

17. Number of quail observed at varying distances from water in intensive study areas $\mathrm{A}-1$ and $\mathrm{A}-2$ during each of the seven census periods . . . . . . . . . . . 60

18. Mean number of quail heard calling for stations pooled according to distance from free water . • . . . . . . 65

19. Mean number of quail heard calling for stations pooled on the basis of habitat quality . . . . . . . . 65

20. Summary of trapping success during 1961, 1962 and 1963 • 67

21. Relative coverage of shrubs, cacti and yucca in areas $A-1$ and $A-2$ as determined by line-intercept transect and rectangular plot vegetation analysis in 1962 and 1963

22. Relative density (plants per square foot) of forbs and grasses in areas $\mathrm{A}-1$ and $\mathrm{A}-2$ as determined by rectangular plot vegetation analysis in 1962, 1963 and 1964. .

23. Relative coverage of shrubs, cacti and yucca in areas $B-I$ and B-2 as determined by line-intercept transect and rectangular plot vegetation ana.lysis in 1962 and 1963

24. Relative density (plants per square foot) of forbs and grasses in areas $\mathrm{B}-1$ and $\mathrm{B}-2$ as determined by rectangular plot vegetation analysis in 1962, 1963 and 1964 . .

25. Relative quail use of watering devices in the various vegetation types in the Beaver Dam Mountain area during 1962 and 1963

26. Food items found in 44 quail crops collected from cultivated areas along the Beaver Dam Wash during the fall of 1962

27. Food items found in 84 quail crops collected on the west slope of the Beaver Dam Mountains during the fall of 1962

28. Relative utilization of plant foods by quail collected from intensive study areas $A-1$ and $A-2$ during the fall of 1962 
29. Locations of intensive study areas $A-1, A-2, B-1$ and $B-2$ as determined by examination of sectionalized aerial photographs

30. Survival of young quail as indicated by pooled monthly age ratios in areas $A-I$ and $A-2,1962$ and 1963 . . . . . . 123

31. Survival of young quail as indicated by pooled monthly age ratios in areas $\mathrm{B}-1$ and $\mathrm{B}-2,1962$ and 1963 . . . . . 123

32. Summary of brood and age-ratio counts pooled with respect to time and distance from drinking water during 1962 and 1963 • • • • . • • • • • • • • • • • • • • 124

33. Summary of hunter band returns for quail banded during the period from June 15, 1961 to June 30, 1964 . . . . . 125

34. Summary of marked quail observations for the period June 15, 1961 to June 30, 1964 in the general study area . . . . 127

35. A comparison of maximum and minimum temperatures (degrees Fahrenheit) and precipitation for intensive study areas A-I and A-2 during the period from June, 1962 - August, 1963 - 130

36. A comparison of maximum and minimum temperatures (degrees Fahrenheit) and precipitation for intensive study areas B-I and B-2 during the period from June, 1962 - August, 1963 - 131

37. List of plant species identified in the general study area during the period from June 15, 1961 - June 30, 1964 • . . 132 



\section{LIST OF FIGURES}

Figure

Page

1. Location of the general study area in Washington County, Utah • • • . . . . • • . . • . . . . . . . 10

2. View of the bajada on the west slope of the Beaver Dam Mountains, Washington County, Utah . . . . . . . . . 11

3. Location of intensive study areas $\mathrm{A}-1$ and $\mathrm{A}-2$ on the west slope of the Beaver Dam Mountains . . . . . . . . 14

4. Jones Catchment No. 2 located at the center of replication I, intensive study area A-I, closed May 1, 1962 to prevent quail use . . . . . . . . . . . . . . . 16

5. Brick Wash Catchment located at the center of replication II, intensive study area A-I closed May I, 1962 to prevent quail

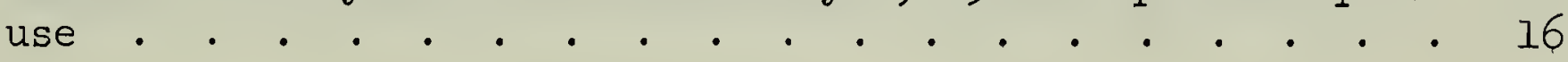

6. Location of intensive study areas $B-1$ and $B-2$ on the west slope of the Beaver Dam Mountains . . . . . . . . 17

7. Typical stock-watering tank on the west slope of the Beaver

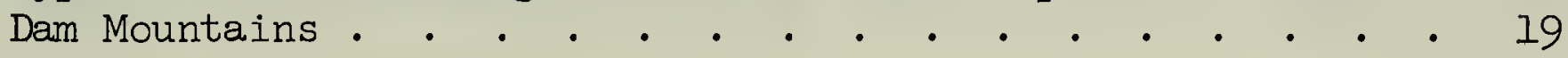

8. Newly constructed stock-watering tank showing quail ramp designed to prevent drowning of young quail . . . . . . 19

9. View of a quail fountain with tripod fence . . . . . . 20

10. Close-up of a quail fountain . • • • • • • . . . . 20

1l. California type water catchment • • • . • • • • . . 22

12. Concrete open-basin type water catchment . . . . • . . 23

13. Fiberglass open-bàsin type water catchment . . . . • . 23

14. Diagrammatic representation of line-transect pattern used during pre-development surveys, September, 1961 . • • 26

15. Diagrammatic representation of line-transect pattern used during April, 1962 and later counts . . . . . . . 26 

16. Route used for mating-call counts, pre-breeding and postbreeding roadside counts on the west slope of the Beaver Dam Mounta ins.

17. Collapsible wire-mesh funnel trap with plastic container of water used as bait at center . . . . . . . . . . . 32

18. Quail trap showing brush piled on top to provide shade . . 32

19. Quail with colored neck tag and band in place . . . . . 33

20. Population trend for areas $A-1$ and $A-2$ during the period from September, 1961 through September, 1963 . • . . . 38

21. Population trend for areas $B-1$ and $B-2$ during the period from September, 1961 through September, 1963

22. Pooled mean calls heard and quail calling per station showing the trend of calling during April and May, 1962 . . 45

23. Pooled mean calls heard and quail calling per station showing the trend of calling during April and May, 1963 • . 45

24. Mean calls heard and quail calling per station for each day's census during April and May, 1962

25. Mean calls heard and quail calling per station for each day's census during April and May, 1963

26. Graph showing the relationship between survival of young quail and distance from available water, 1962 . . . .

27. Graph showing the relationship between survival of young quail and distance from available water, 1963 . . . . 54

28. Relationship of mean brood size and age ratios to time, 1962

29. Relationship of mean brood size and age ratios to time, 1963 .

30. Distribution pattern of quail observed in the general study area during the period from July I, 1962 to June 30, 1963

31. Distribution pattern of quail observed in the general study area during the period from July 1, 1962 to June 30, 1963

32. The creosote-bush--bur-sage vegetation type . 

33. The mixed-shrub vegetation type . . . . . . . . . $\quad 84$

34. Typical clumps of desert-almond (prunus fasciculatus) lining the margin of a large dry wash on the west slope of the Beaver Dam Mountains

35. The black-brush vegetation type . . . . . . . . . 86

36. The mountain-shrub vegetation type . . . . . . . . . 88

37. The pinyon-juniper vegetation type . . • . . . . . . 88

38. Distribution of 81 quail coveys arriving at water during the morning hours of July and August, 1962 and 1963 . . . 101 


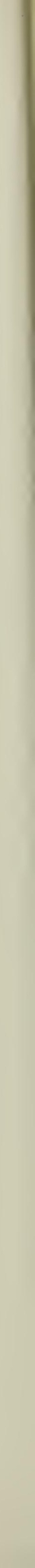




\section{INTRODUCTION}

The Gambel's quail (Lophortyx gambelii) has long been considered one of the outstanding game birds of the arid southwestern United States. Because of its importance, much research has been focused upon increasing its populations in the states where it occurs. Most of this research has been aimed at devising various methods of habitat improvement which would result in increased abundance and thus provide more and better quail. hunting. Since the Gambel's quail persists in a relatively xeric environment, many workers have assumed that water has probably been the single factor which has most limited population increase over most of its range. Consequently, large amounts of money have been spent to provide drinking water in dry areas, usually through the installation of rainwater catchments.

Gambel's quail in Utah are confined to the southwest corner of the State, primarily in Washington County. Though its range is not extensive it is sufficient to serve as an important game bird to the sportsmen of Utah. Because of the relative paucity of upland bird hunting in Utah, the importance of this quail becomes magnified, especially in the face of the rapidly expanding human population.

Because of this importance, Utah along with other western states began a limited water development program in the early 1950's. Fifteen rainwater catchments were installed in Washington County over a five-year period. Superficially it appeared that these catchments resulted in considerable increase in quail. However, research in other states during the past decade has cast a shadow of doubt over the value of water development for increasing desert quail populations. Though some of these studies 

have shown water development to be of value, others have not. None of this research has shown conclusively that water development has increased Gambel's quail populations. Most of it has consisted of an evaluation of water catchment use by quail and has not provided an objective comparison of areas with and without available drinking water.

Because of doubt implanted by past research, it was decided that before additional widespread water development could be justified in Utah a critical analysis of existing watering devices would be conducted. The present project was established in June, 1961 to investigate the influence of water availability upon Gambel's quail populations in Utah.

The objectives pursued by this research were: (I) to determine the influence of water availability upon quail population density, (2) to determine the effect of water upon the survival of young quail, (3) to ascertain how the presence of drinking water in the environment influences the distribution and movements of quail, (4) to evaluate the habitat of quail, (5) to initiate call counts, roadside counts and long-period waterhole counts to determine which is best suited for determining quail population trends in Utah, and (6) to collect pertinent life history information. 


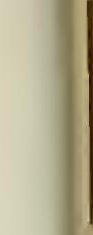


REVIEW OF LITERATURE

The value of water to desert-dwelling game birds has been a topic of considerable discussion among biologists in the southwestern United States for many years. The Gambel's quail has been one of the species on which much of this attention has been centered. A large proportion of the speculation concerning the value of drinking water to this and other species has been based upon subjective evaluation of occurrence of coveys in areas with or without water, and has not been substantiated by adequate research.

One of the earliest opinions expressed concerning the importance of water was that of Grinnell (1927). He observed that water was the factor which was limiting California quail in California, as a result of natural waters being used up by humanity. It was his opinion that the maximum distance which newly-hatched quail could travel to water was 400 yards. He said that nests were destined to failure or abandonment if located over this distance from available water sources.

Vorhies (1928) refuted Grinnell's (1927) supposition concerning the importance of drinking water on the basis of his observations of Gambel's and scaled quail (Callipepla squamata) at the Santa Rita Range Reserve near Tucson, Arizona. He cited several instances where quail were able to exist and reproduce without the benefits of free drinking water. Concerning the distribution of nests around water, he believed that nesting activity was greatest away from the "trampled" areas around stock tanks. With regard to the ability of newly-hatched chicks to subsist without water, he cited instances in poultry where just-hatched baby 
chicks were shipped without food or water for periods of 74 hours. In fact, the Department of Poultry Husbandry of the University of Arizona found that domestic chicks would live 11 days without either food or water. In his opinion hunting, not water, was the delimiting factor operating against quail in the arid Southwest.

McLean (1930) made the statement that "desert quail do come to water, at least when they can secure it, at regular hours, generally twice a day," but does not say whether they require water or not.

California was the first of the southwestern states to start a water development program. Glading (1947) stated that the summer population of valley quail in San Benito County "jumped" following water provision during the period from 1942-1946. Gambel's quail responded similarly in San Bernardino and Riverside counties from 1945 to 1946. Gorsuch (1934) commented after having visited "practically every general type of locality in which the bird occurs" that Gambel's quail do not require drinking water. He states that: ". . if the drinking of water were essential to their existence they could not live in many localities where they are abundant." He also observed from counting quail at stock water tanks, that only one-third of the quail coming to the tanks actually took a drink. He concluded that the biggest attraction to these birds was the mesquite beans and other seeds obtained from livestock droppings which were abundant in the vicinity of water. However, it should be noted that these counts were made in winter.

In a later review of the California development program, Ross (1951) stated as follows:

Trapping operations, bag checks, and general observations revealed that chick survival in areas where nesting was attempted at such distances from water as to prevent the young from reaching it within a few hours after hatching was very poor or in 

negative quantity. This was especially true when there were no late spring rains, and succulent annuals were lacking. Also noted was the fact that food supplies surrounding the few dependable water holes in the foothills were overutilized, often depleted during the summer months by tremendous concentrations of birds. As with any form of life, disease stalked the heels of famine, and populations frequently dropped sharply to low levels, from which recovery was slow and uncertain.

The establishment of new water holes in proximity to suitable food and cover plots was indicated then, in order to prevent unhealthy concentrations, to expand nesting areas and make possible a more even utilization of food supplies.

The development program has done much to extend the range of the quail and rabbit, and provide for more equitable utilization of food supplies; but the populations, especially so in the southeastern portion of the state, remain at the mercy of, and dependent upon precipitation.

MacGregor (1953) reporting on the results of a study of California

quail and water wherein experimental and control areas were used, summarized

the effects of water development in this manner:

The installation of water in dry areas has a manifold effect on the quail population. It attracts birds from surrounding areas, increases the range, survival, and the populations. Usually areas which have permanent water are heavily grazed by livestock, and the cover is over utilized and is poorer than on the lightly grazed dry areas. By making water available to quail in these dry areas where cover is in better condition, nesting success and survival is increased.

If the quail habitat exclusive of the lack of water is considered marginal the addition of water will have little effect on the quail population. Guzzlers on our desert ranges may produce many quail in favorable years but under the unfavorable conditions of recent years, results in many of these areas are disappointing.

Lowe (1955) commented on the occurrence of Gambel's quail on Tiburon

Island, Sonora, Mexico. He stated that it persisted there independent of free surface water, apparently fulfilling its moisture requirements from other sources, primarily succulent vegetation and moisture derived from metabolic processes. He concluded that "It is beyond reasonable doubt that the Gambel quail occurring on Tiburon Island do not require free surface water of any kind for their successful maintenance during the dry periods of the year." 

In his work on the watering patterns of various desert game animals in Arizona, Elder (1956) concluded that "From a practical management standpoint open water was considered an essential habitat requirement for . . Gambel's quail during the spring-summer and fall dry periods."

Wallmo (1956) stated that "The importance of free water to scaled quail is not fully understood." He said that most covey ranges are near livestock watering places, but cites an instance where coveys were found as much as seven miles from water.

Wright and Webb (1956) were of the opinion that catchments will increase the quail population of an area if both food and cover are available. They concluded that "The development of water to improve habitat conditions for wildlife in west-central Arizona is feasible and desirable. Food and shelter are available to support a larger population, but permanent water is not."

With regard to water development in New Mexico, Campbell (1960) concluded that: "Considering the low levels of utilization ordinarily found, and the high costs of construction and maintenance. . guzzlers are ineffective and impractical for quail management in New Mexico." He accounts for the differences in guzzler effectiveness between this state and others, where water developments were deemed of value, by variation in the seasonal distribution of rainfall. At the time when young quail are being produced in New Mexico, the normal rainfall pattern permits wide dispersal of the birds and allows them to take advantage of green succulence and insects, rather than concentrate in the vicinity of permanent water.

Concerning the water requirements of the Gambel's quail, Hungerford (1960) reported:

The calculated moisture requirement . . appears to be fulfilled by the measured moisture content of natural food items. These quail also have behavioral adaptions to conserve body moisture. 

With regard to the value of water development he states: "Gambel's quail can and do subsist well without free water in southern Arizona and rainwater catchments designed for this species alone are considered non-essential."

As a result of their work on the water economy of the California quail, Bartholomew and MacMillen (1961) summarized that: "Although very well suited for an arid existence, California Quail have not successfully inhabited deserts, probably because their limited mobility precludes periodic visits to distant water sources."

Gullion (1960) stated that the water relationships of the Gambel's quail in Nevada were as follows:

Observations . . . show that watering needs of Gambel's Quail cannot be described as a simple "they need drinking water" or "they do not." In the desert valley areas whe re the Desert Riparian and Thorn Shrub types occur, or where there are irrigated crops, or streams or waste waters are present, a combination of high humidity and fleshy plants provides the moisture needed for survival of this species, even during the hottest part of the year. In this situation desert quail, if necessary, can live their life-span without taking a drink of water.

On Nevada desert areas the critical period during which water may be an important factor limiting quail distribution extends from about the middle of June to mid-July.

It is during this period that the desert upland habitats which furnish adequate food supplies must have a proper distribution of water if Gambel's Quail are to make maximum use of this environment in Nevada. It is for this brief period of time that the development of artificial watering structures in areas of otherwise suitable habitat becomes a practical and useful game management technique.

Schemnitz (1961) stated that the scaled quail on his study area in the Oklahoma panhandle centered their activities around available waterholes. However, he did not know whether this concentration was a result of a need for water or other requirements such as food or cover.

The diversity of opinions expressed by previous workers, whethe $r$ based on objective or subjective determinations, points out the complexity of the relationships of various game birds to water in Southwestern deserts. 
It indicates that the value of water may vary with individual species or even with different populations of the same species which persist under differing climatic conditions. Above all it emphasizes the dearth of absolute knowledge on the subject of water relationships of game birds. 
DESCRIPTION OF STUDY AREAS

\section{General Study Area}

The general area of study was on the east and west slopes of the Beaver Dam Mountains in western Washington County, 30 miles west of the city of St. George. Its approximate boundaries included: the Arizona state line on the south, Nevada on the west; Beaver Dam Mountains to the east and Bull Valley Mountains on the north. It included an area of about 385 square miles, much of which was inhabited by quail (Fig. 1).

Topographically the area consisted of a dendritic pattern of dry desert washes of varying sizes descending from the mountainous areas westward to the Beaver Dam Wash and east and south to the Virgin River.

Geologically the area consisted of the mountain zone and the western bajada. The latter comprised most of the favorable quail habitat and was described by Christian (1962) as ranging in elevation from 2,100 to 5,000 feet, consisting of coarse, largely unconsolidated alluvium of a variety of rock types which gives the soil an excellent nutritional balance, and having a rocky, coarse textured gray soil which is low in organic matter (Fig. 2).

Climatically, the area has typically hot and dry summers with moderate to occasionally cold winters. The mean annual temperature for Littlefield, Arizona (10 miles south at 1800 feet elevation) during the period 1950-60 (based on a somewhat erratic record) was $65.3^{\circ} \mathrm{F}$. The mean annual precipitation for the same period was 5.8 inches. The mean, mean maximum and mean minimum temperature (degrees Fahrenheit) for the coldest and hottest 


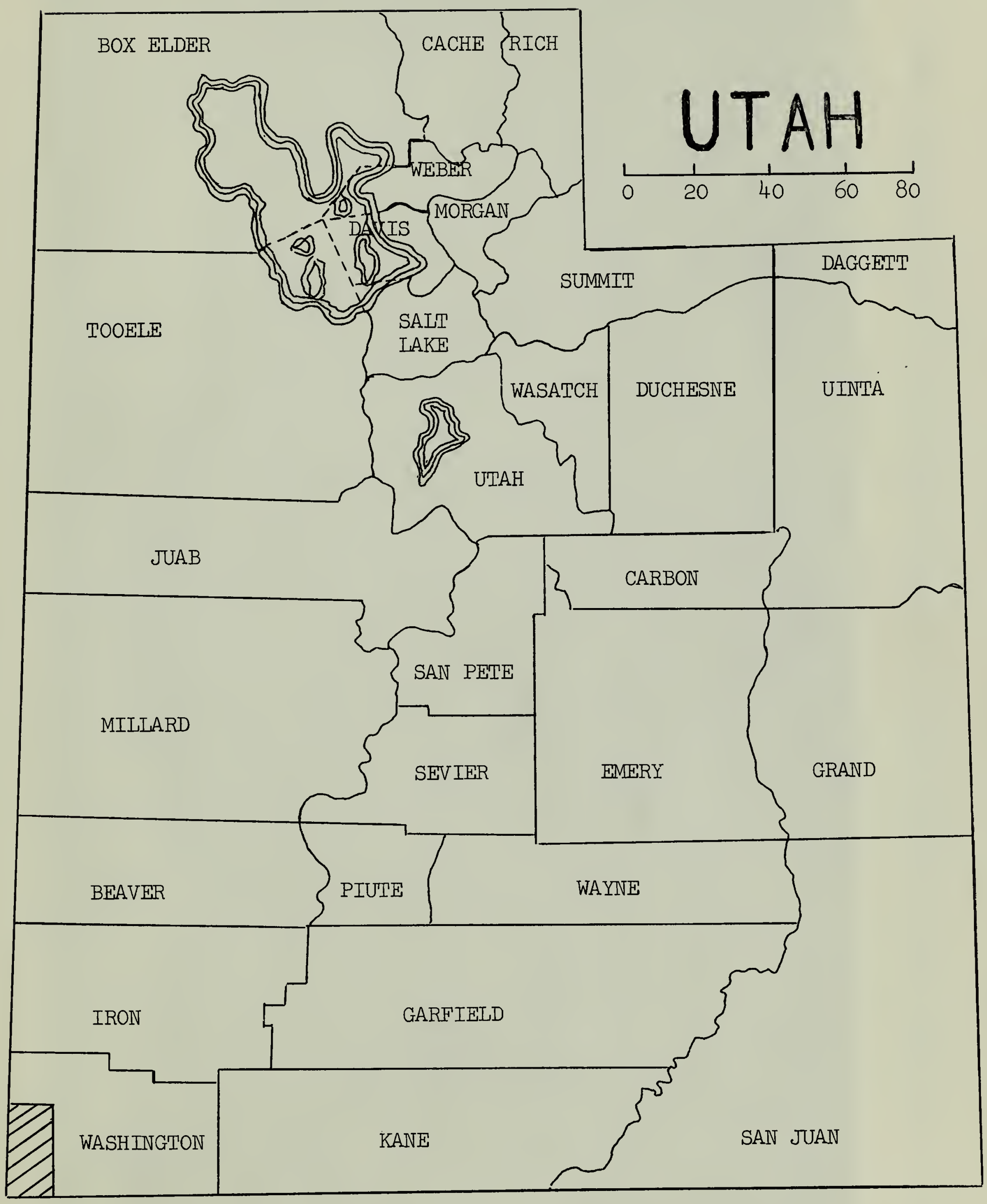

Figure 1. Location of the general study area in Washington County, Utah 


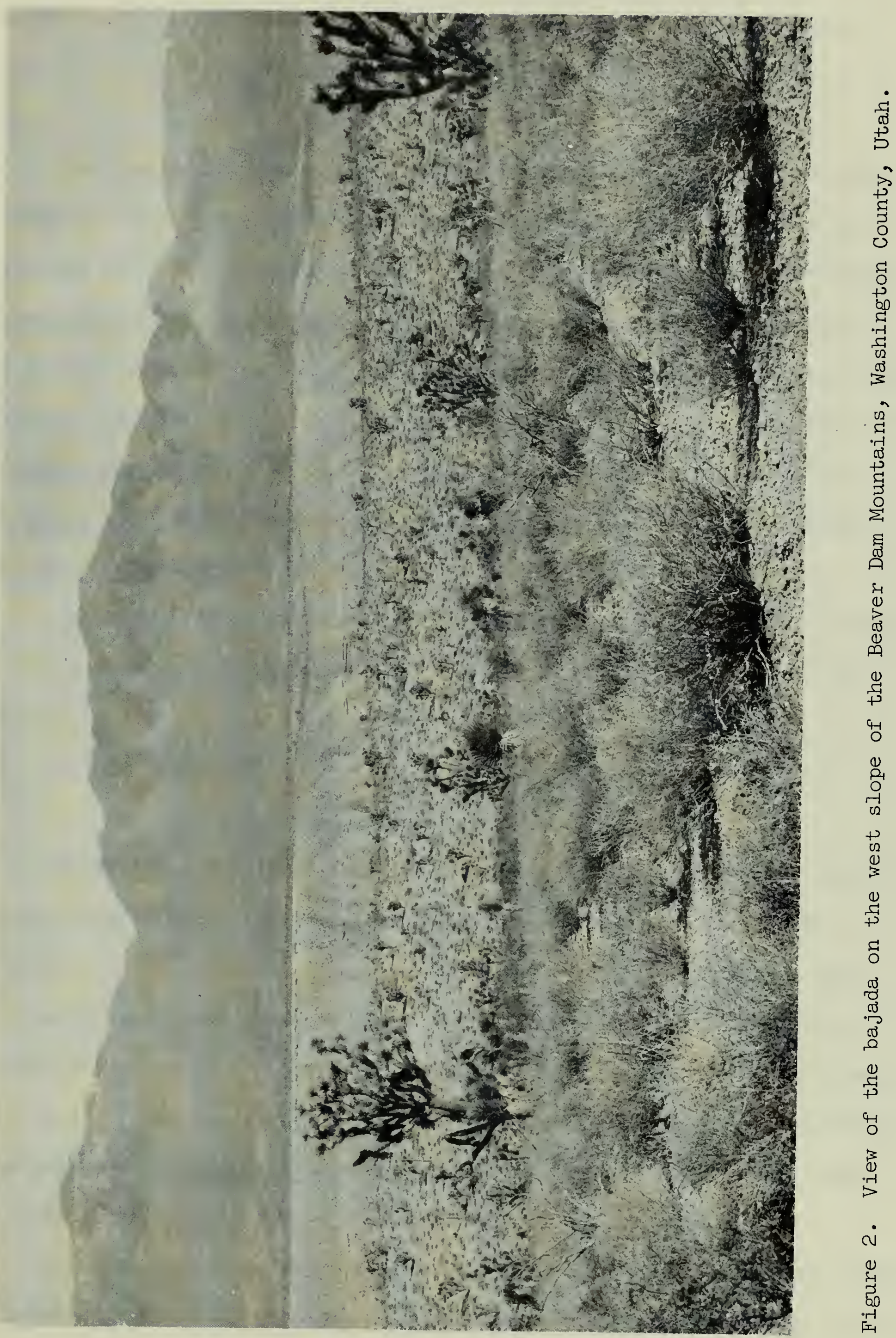


months were as follows: January $43.2^{\circ}, 55.8^{\circ}, 30.6^{\circ}$; July $86.1^{\circ}, 103.3^{\circ}$, and $68.9^{\circ}$. The prevailing winds were from the Mohave Desert area to the southwest.

The vegetation was varied, ranging from the creosote-bush--bur-sage association at low elevations to the pinyon-juniper belt at middle elevations and ponderosa pine in one locality at the top of the Beaver Dam Mountains. The ecotone between the pinyon-juniper and creosote-bush-bur-sage comprised virtually all of the favorable quail range on the western bajada. The most prominent plant species in this belt were the Joshua-tree (Yucca brevifolia), black-brush (Coleogyne ramosissima), creosote-bush (Larrea divaricata), bur-sage (Franseria dumosa), and turpentine-broom (Thamnosma montana).

Virtually all of the land in the general study area was public domain administered by the Bureau of Land Management of the Department of the Interior.

\section{Intensive Study Areas}

To evaluate the effects of water as objectively as possible, experimental and control areas were used. Two approaches were considered desirable: (I) to select two areas already developed with water, make preliminary surveys to determine relative abundance of quail and then close the water developments in one of the areas to determine the effects of this closure on the population and (2) select two areas without water, determine relative quail abundance, and then develop one of these areas to determine the effects on the quail population.

With these approaches in mind, four intensive study areas were chosen on the west slope of the Beaver Dam Mountains. Selection was made on the 
basis of apparent ecological similarity. Criteria used were as follows: (1) areas had to be similar with respect to vegetation composition, (2) topography and exposure had to be as nearly alike as possible, (3) water availability or removal from water had to be similar, and (4) a center-line wash with near equal amounts of favorable cover for quail was necessary for each area. To insure that the preceeding requirements were fulfilled as closely as possible, the areas were chosen in close proximity insofar as knowledge of the daily and seasonal cruising range of quail would allow. This juxta-position also facilitated sampling methods.

At the time of selection, two of the areas were developed with rainwater catchments which had been installed several years previous to this study. The other two areas were waterless.

\section{Developed areas}

These areas were designated as $\mathrm{A}-1$ and $\mathrm{A}-2$. Each contained two water catchments which had been functioning for six years or more and presumably maintained established populations of quail.

Exact locations of these areas are given in Table 29.

These areas measured one by two miles, and contained two one-squaremile replications. Area A-I was situated along Jones Wash and Brick Wash, and had Jones Catchment No. 2 at the center of replication number $I$ and Brick Wash Catchment at the center of replication number II. Area A-2 was situated along Gravel Canyon Wash and had Gravel Canyon Wash Catchments No. I and 2 at the center of replications number I and II respectively (Fig. 3). The elevation of area $A-1$ ranged from about 3,400-3,500 feet and A-2 from 3,300 to 3,700 feet.

The exposure of area A-I was to the west while A-2 faced to the s outhwest. 


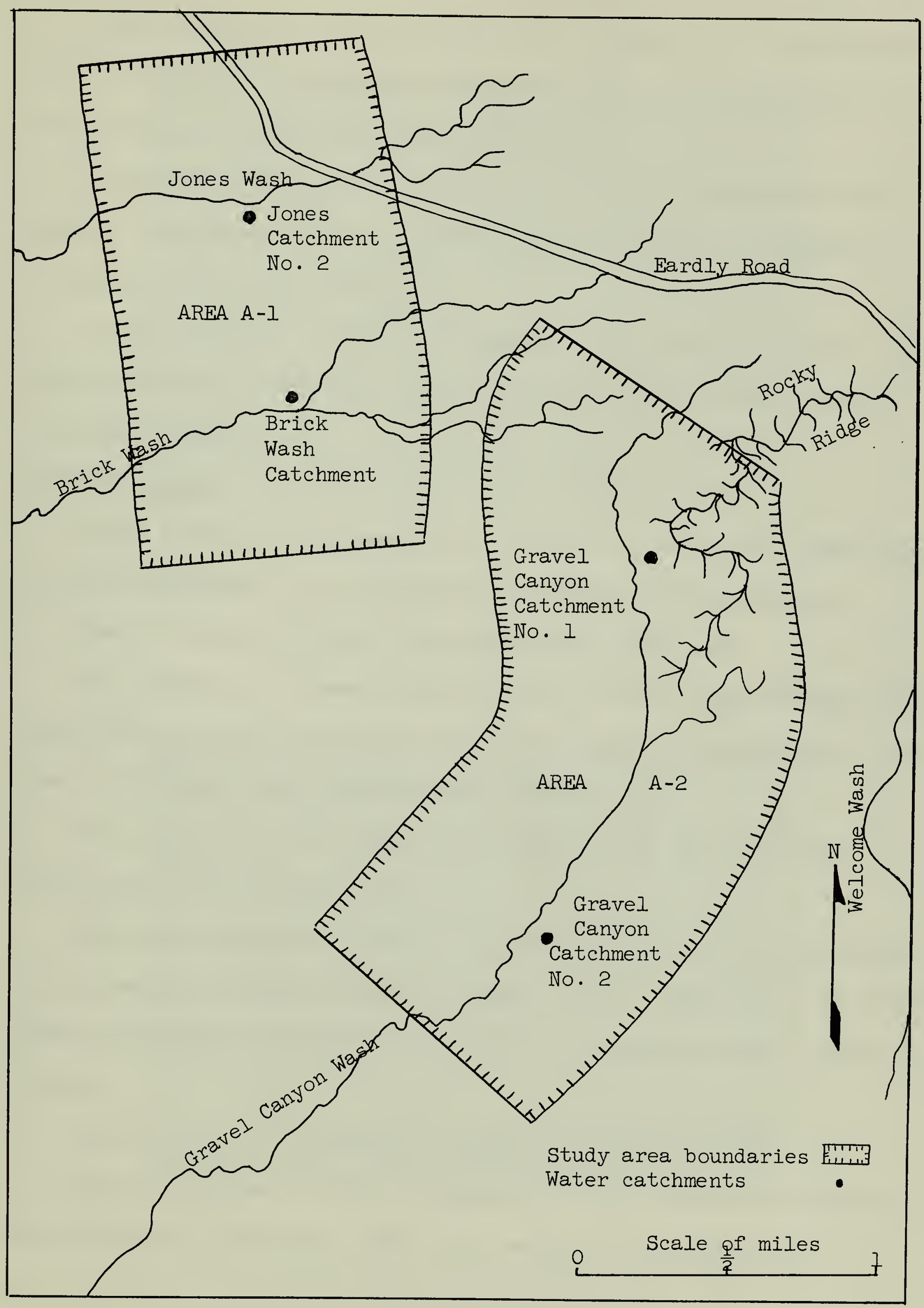

Figure 3. Location of intensive study areas $A-1$ and $A-2$ on the west slope of the Beaver Dam Mountains 

The topography of the two areas varied slightly. The center-line wash in area A-2 circumscribed a high rocky ridge in the upper half of replication I. Area A-2 was uniform throughout.

The vegetation was essentially similar to that described for the general study area. A more detailed account of vegetation composition is discussed in a later section.

After preliminary surveys in September, 1961 and April, 1962, the water catchments in area A-I were closed May 1,1962 to prevent quail use (Fig. 4 and 5).

\section{Waterless areas}

These areas were designated as $B-1$ and $B-2$. The nearest water sources at the commencement of this study were at least 1.5 miles distant.

Exact locations of these areas are given in Table 29.

The dimensions of these areas were one by three miles and they were subdivided into three one-square-mile replications. The center-line for area B-I was Vern's Wash and B-2 Reber Wash (Fig. 6).

The elevation of B-I ranged from 3,600 to 4,400 feet while B-2 varied from 3,500 to 4,000 feet.

The exposure and topography was essentially identical in both areas. Both center-line washes drained from east to west. That in B-I was slightly deeper and narrower in replications I and II but otherwise they were very similar.

The vegetation is discussed in detail in a later section. After preliminary surveys in September, 1961, three water catchments were installed in area B-2, one at the center of each replication. 


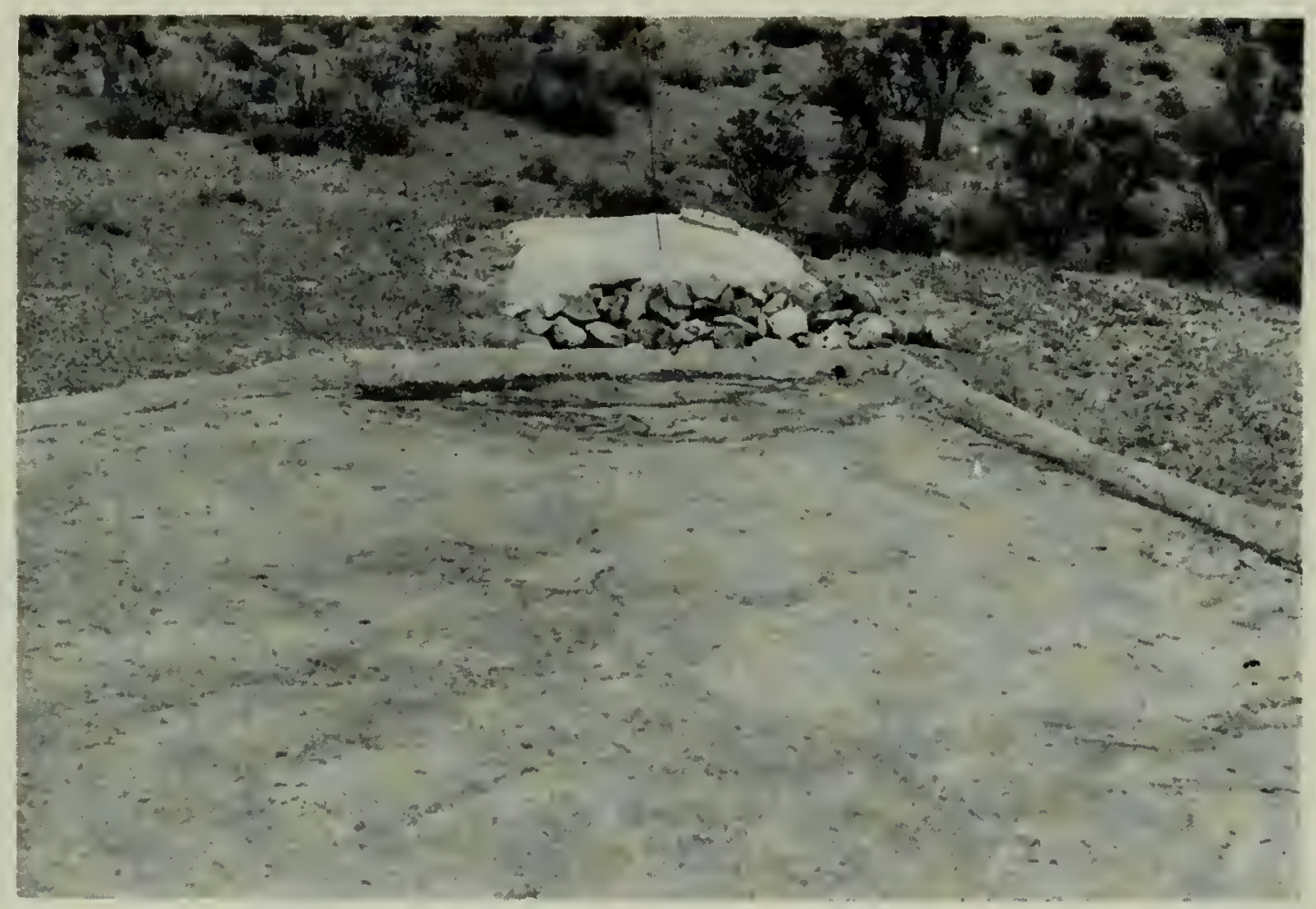

Figure 4. Jones Catchment No. 2 located at the center of replication $I$, intensive study area $\mathrm{A}-\mathrm{I}$, closed May 1, 1962 to prevent quail use.

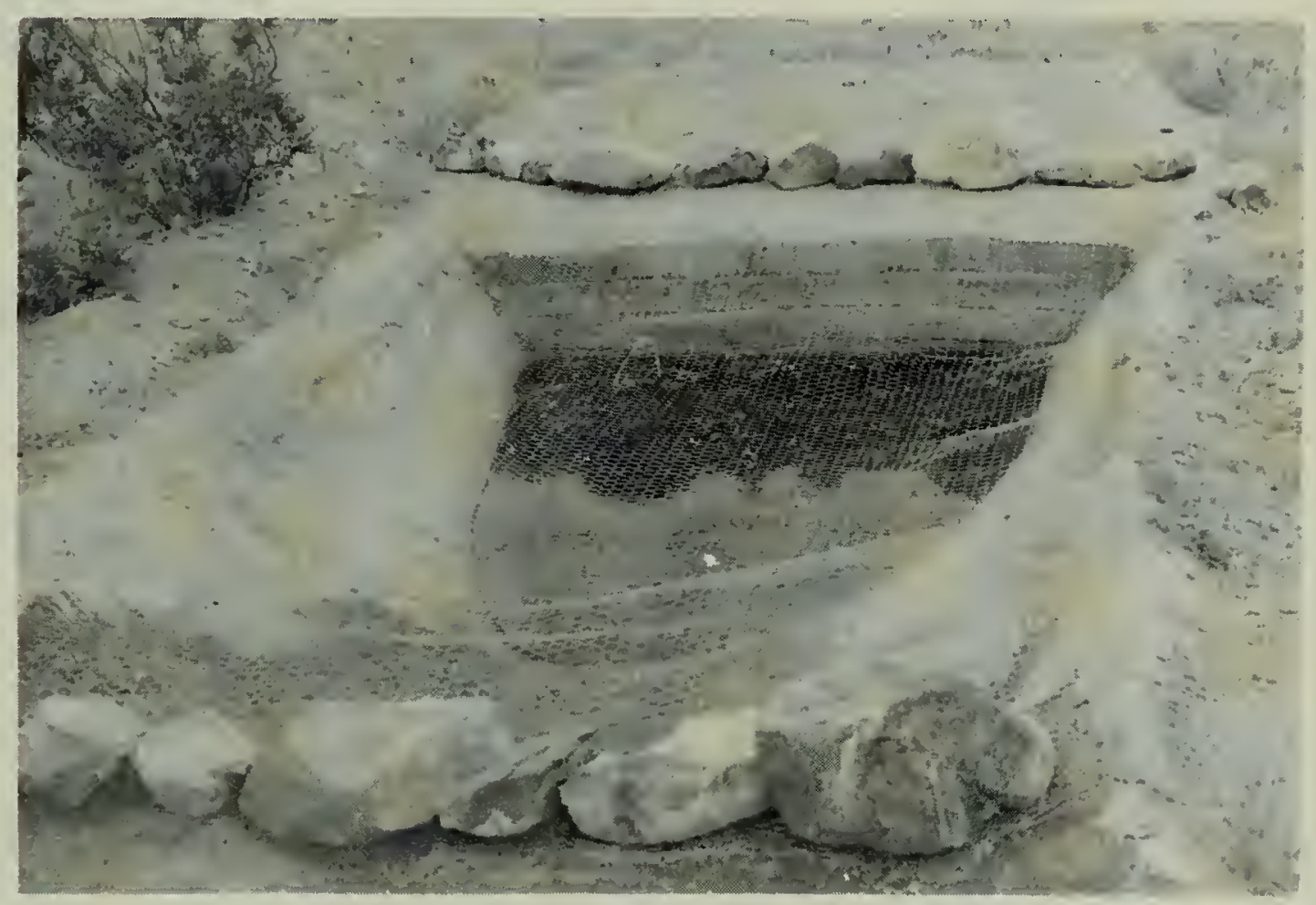

Figure 5. Brick Wash Catchment located at the center of replication II, intensive study area $\mathrm{A}-1$, closed May 1, 1962 to prevent quail use. 



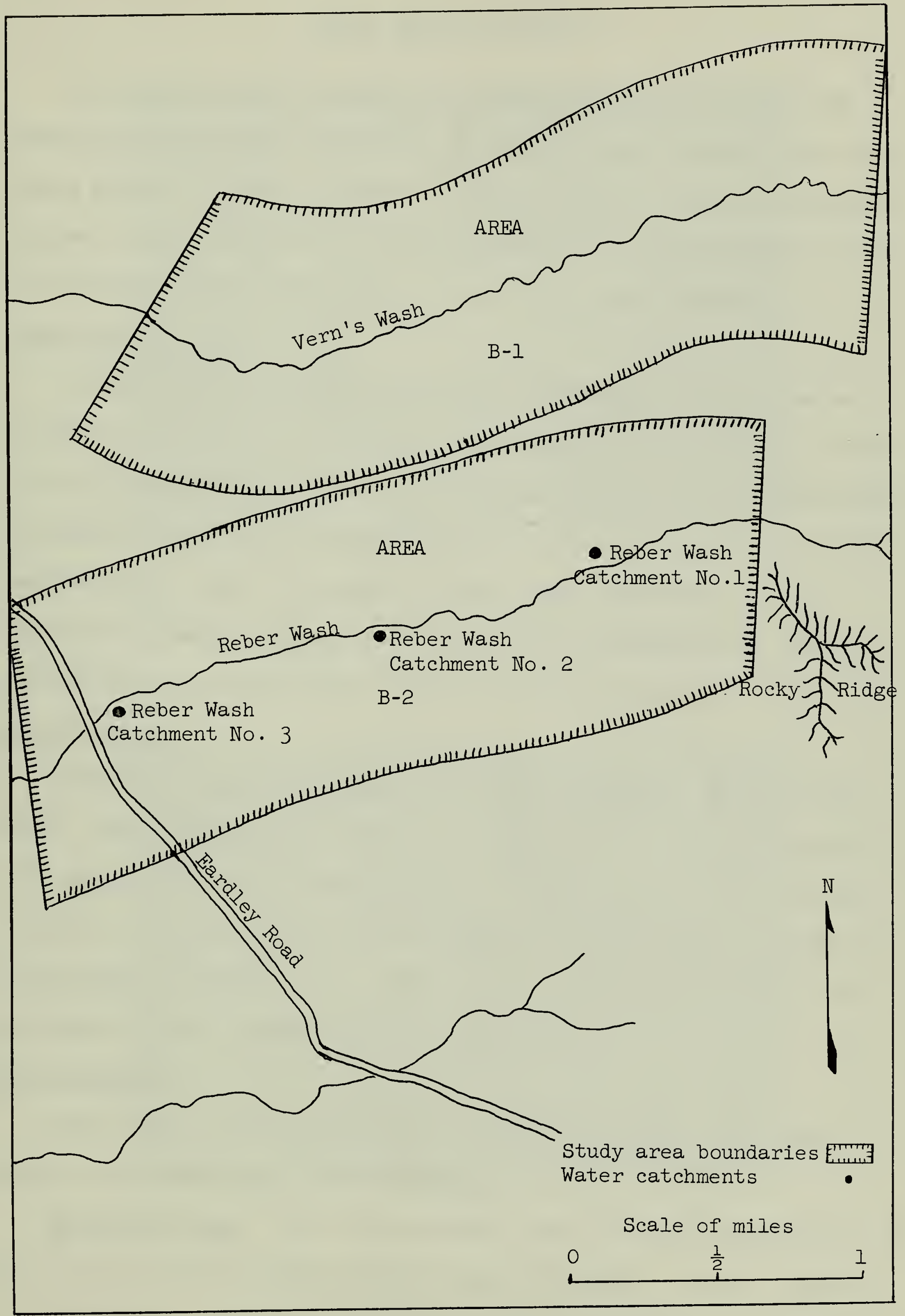

Figure 6. Location of intensive study areas $B-1$ and $B-2$ on the west slope of the Beaver Dam Mountains 


\section{Quail Watering Devices}

Water was available to quail on the west slope of the Beaver Dam Mountains from a number of sources. At the cultivated ranches, water was always present in small reservoirs and periodically in various irrigation ditches. Quail inhabiting the mountain area and bajada depended on water from stock-watering tanks, quail fountains, and water catchments. Stock-watering tanks

Virtually every natural spring in the Beaver Dam Mountain area was developed and piped into one or more stock-watering tanks (Fig. 7). Most of these maintained available water for quail during the hot summer months, but some went dry early each year. Few of those installed prior to 1963 contained quail ramps of any kind. During 1963, the Bureau of Land Management installed several new tanks which were equipped with ramps enabling quail to drink without danger of drowning (Fig. 8). Quail fountains

These were installed by the Fish and Game Department near two stock tanks. They consisted of a section of chimney flue placed in the ground at an angle, with a pipe supplying water from the nearby stock tank (Fig. 9 and 10). A fenced tripod prevented damage by large mammals. These devices always maintained water. They were intended to provide water for small quail unable to drink from the nearby tank.

Water catchments

Three types of water catchments have been installed in Washington County by the Department of Fish and Game.

California type. Five such catchments were installed during 1950. The basin, basin cover and apron were all made of concrete. In this type the entire basin was enclosed to retard evaporation and quail were required to pass through a narrow entrance to drink (Fig. II). Their capacity was 703 gallons. 



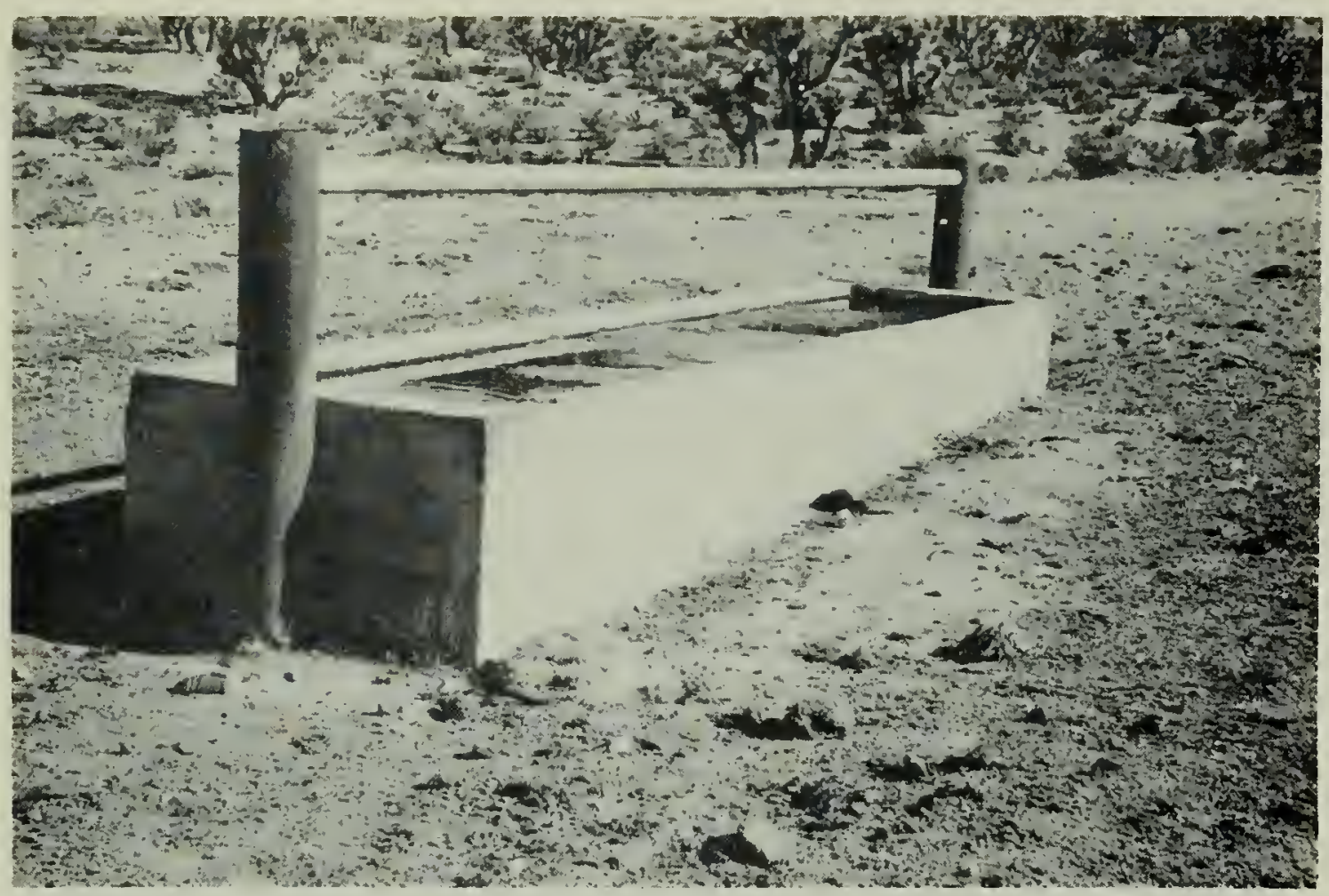

Figure 7. Typical stock-watering tank on the west slope of the Beaver Dam Mountains.

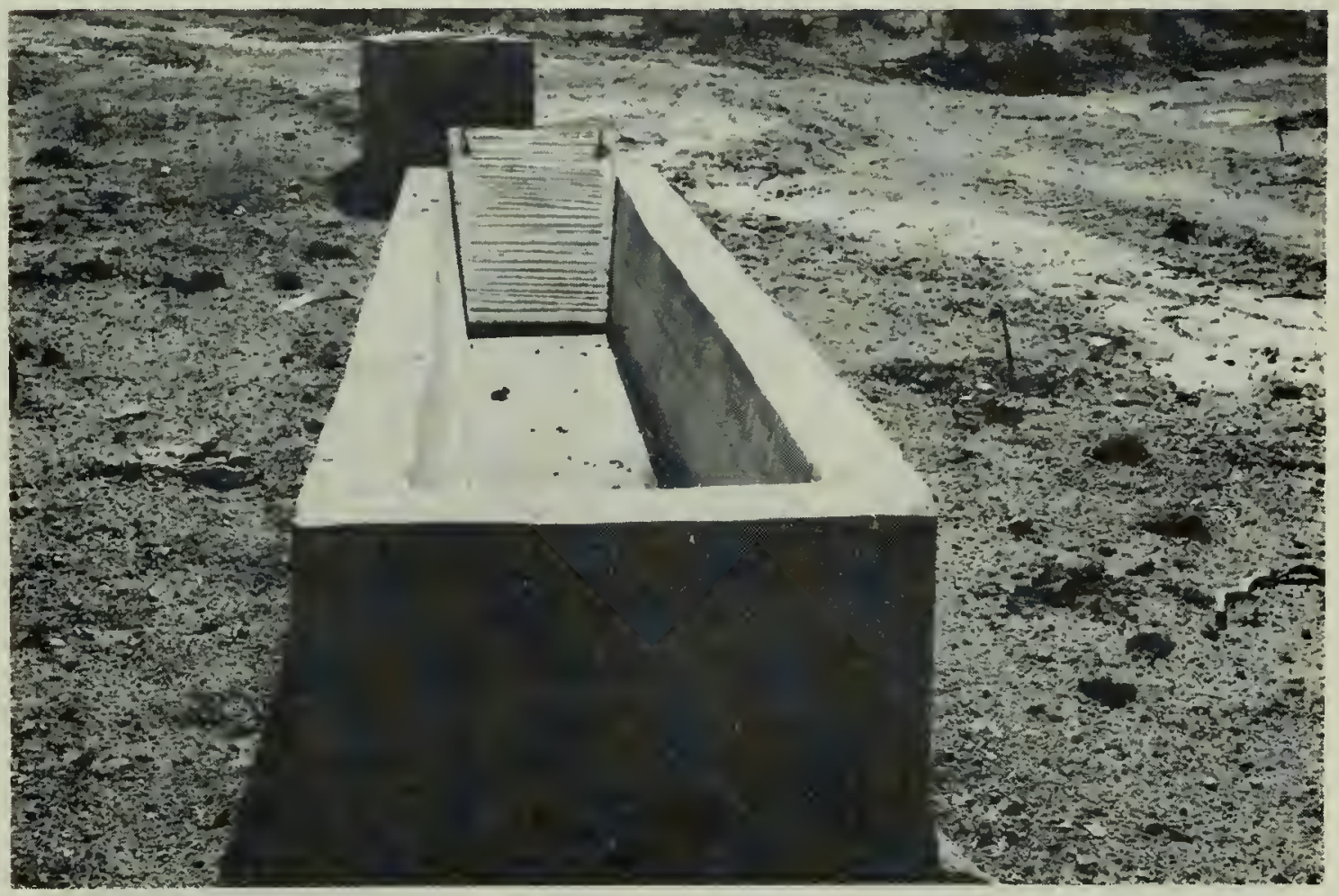

Figure 8. Newly constructed stock-watering tank showing quail ramp designed to prevent drowning of young quail. 


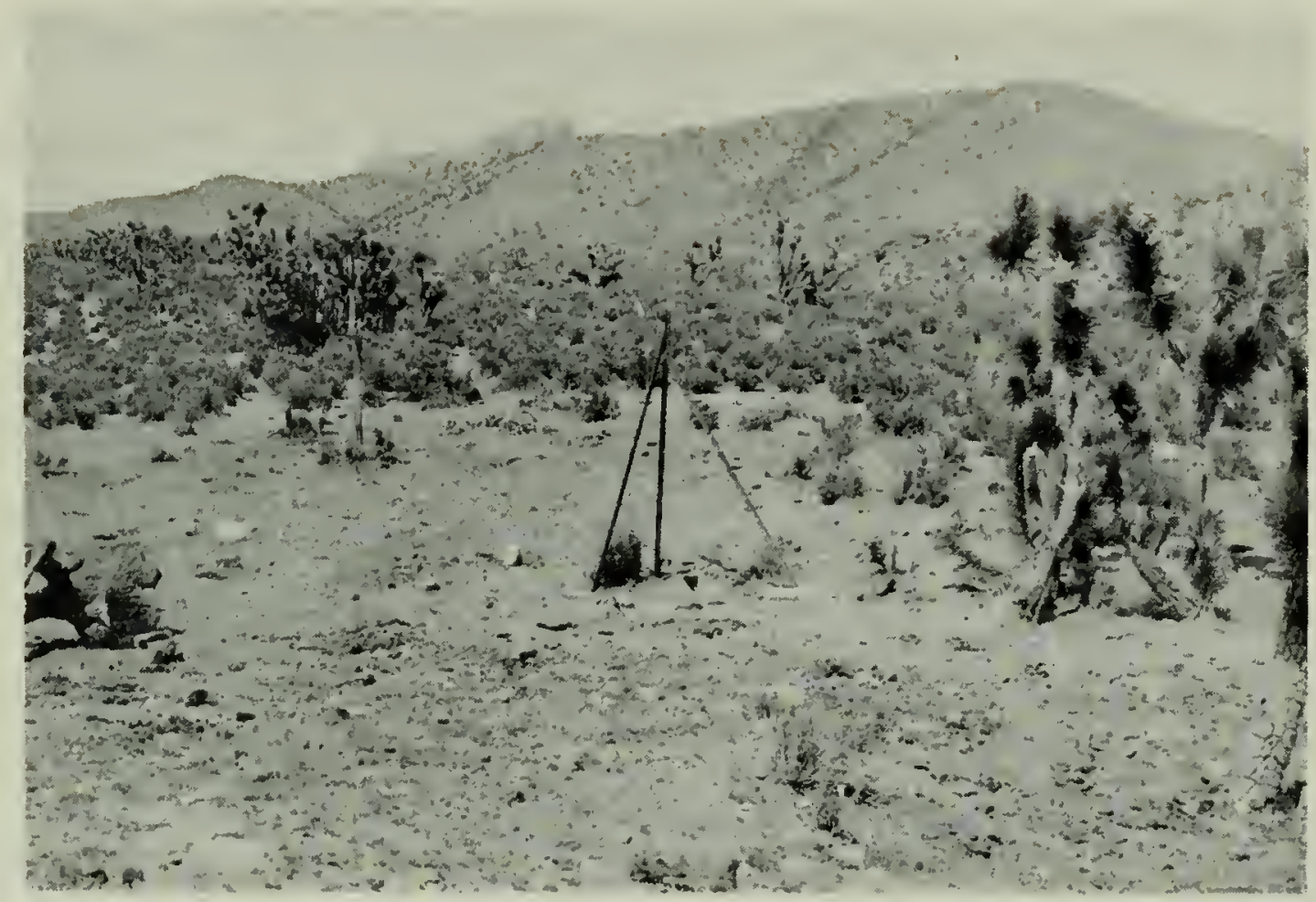

Figure 9. View of a quail fountain with tripod fence.

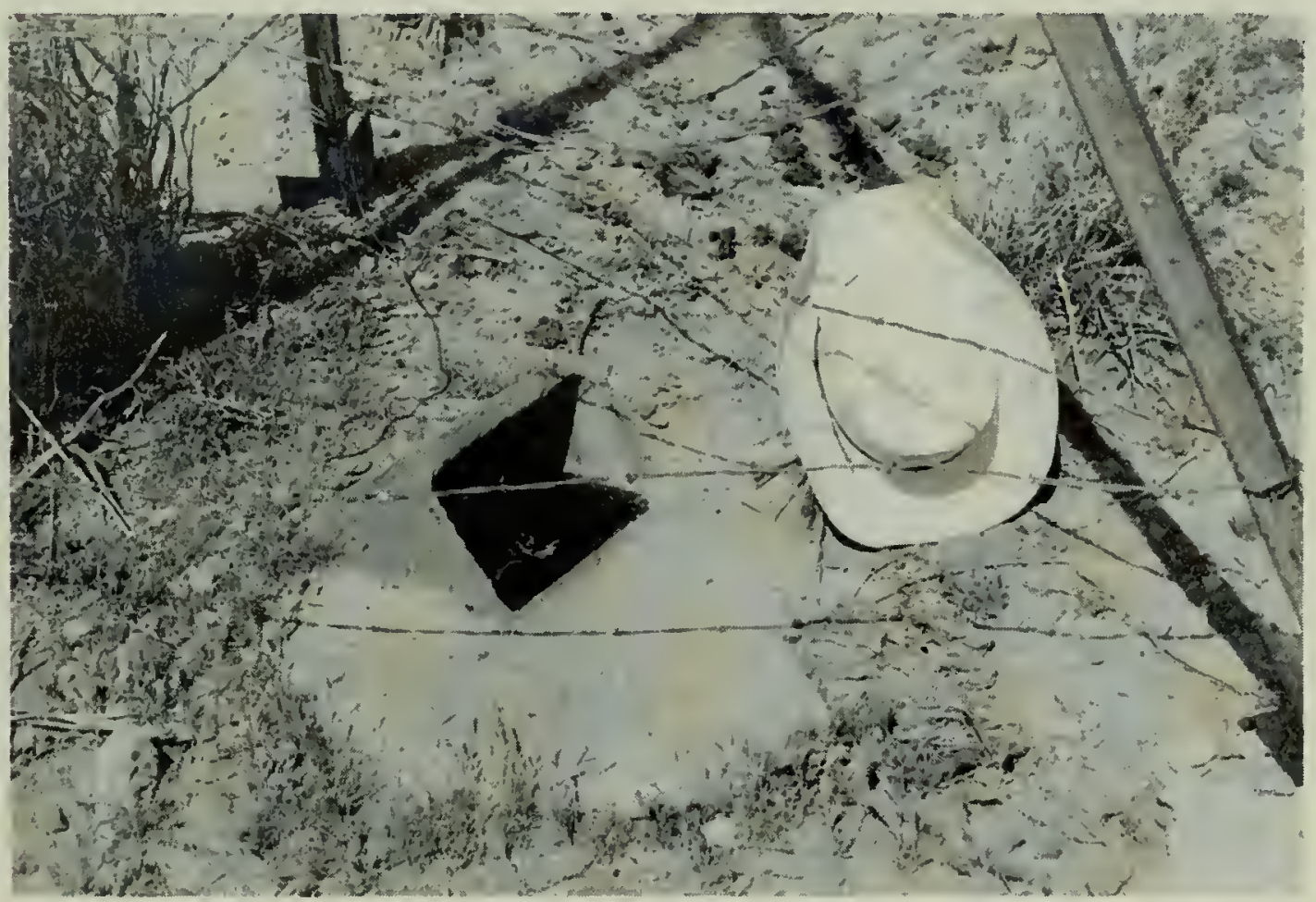

Figure 10. Close-up of a quail fountain. 

Concrete open-basin type. These were of concrete construction, but part of the storage basin had no cover enabling big game as well as quail to utilize them. This type was fenced to prevent livestock use (Fig. 12). Their capacity was about $750-1,000$ gallons

Fiberglass open-basin type. This type had a design similar to the concrete open-basin type, but had a fiberglass storage basin and "shedroof" apron constructed of corrugated metal on a wood frame work (Fig. 13). The capacity of this type was 1,000 gallons. 



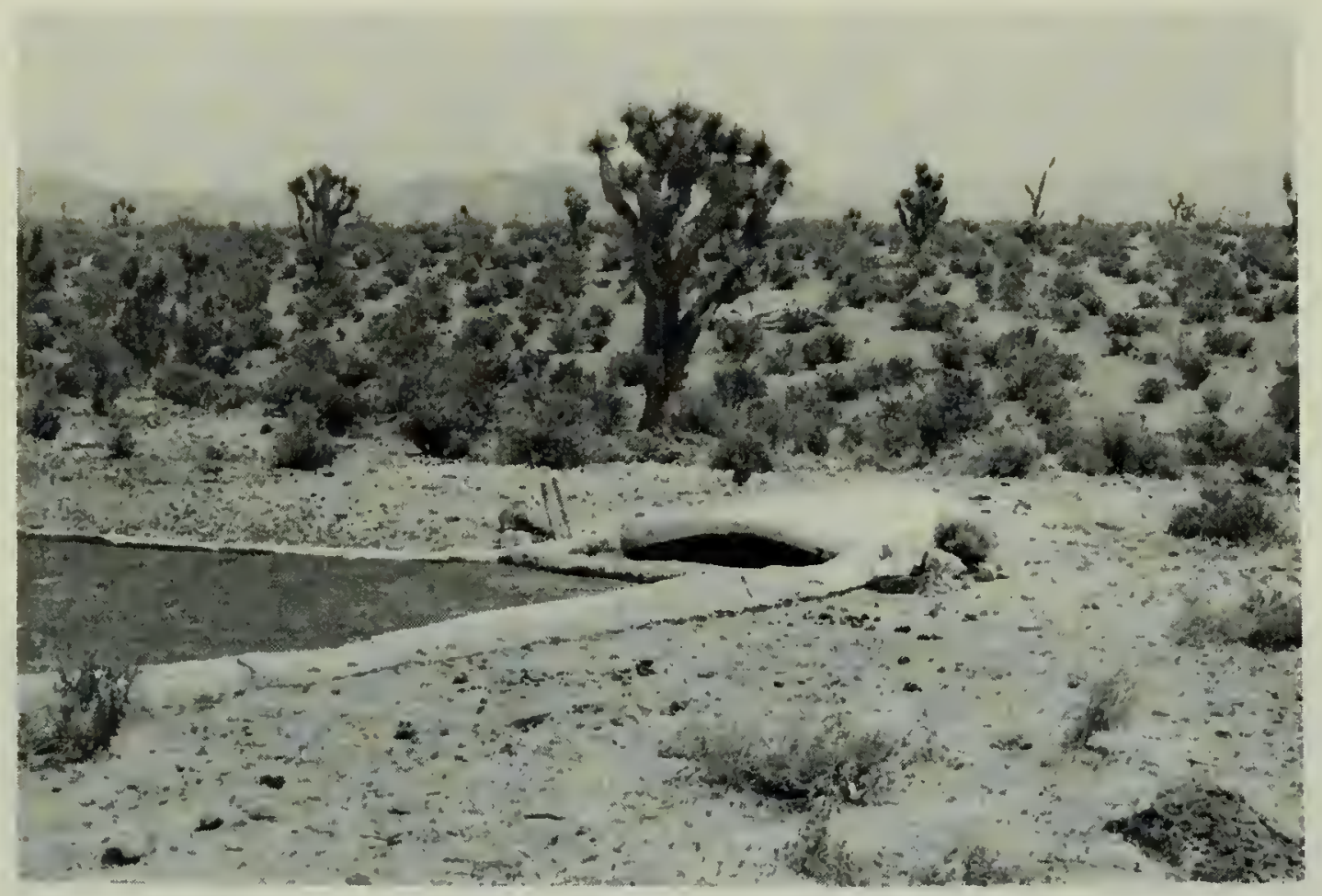

Figure 11. California type water catchment.

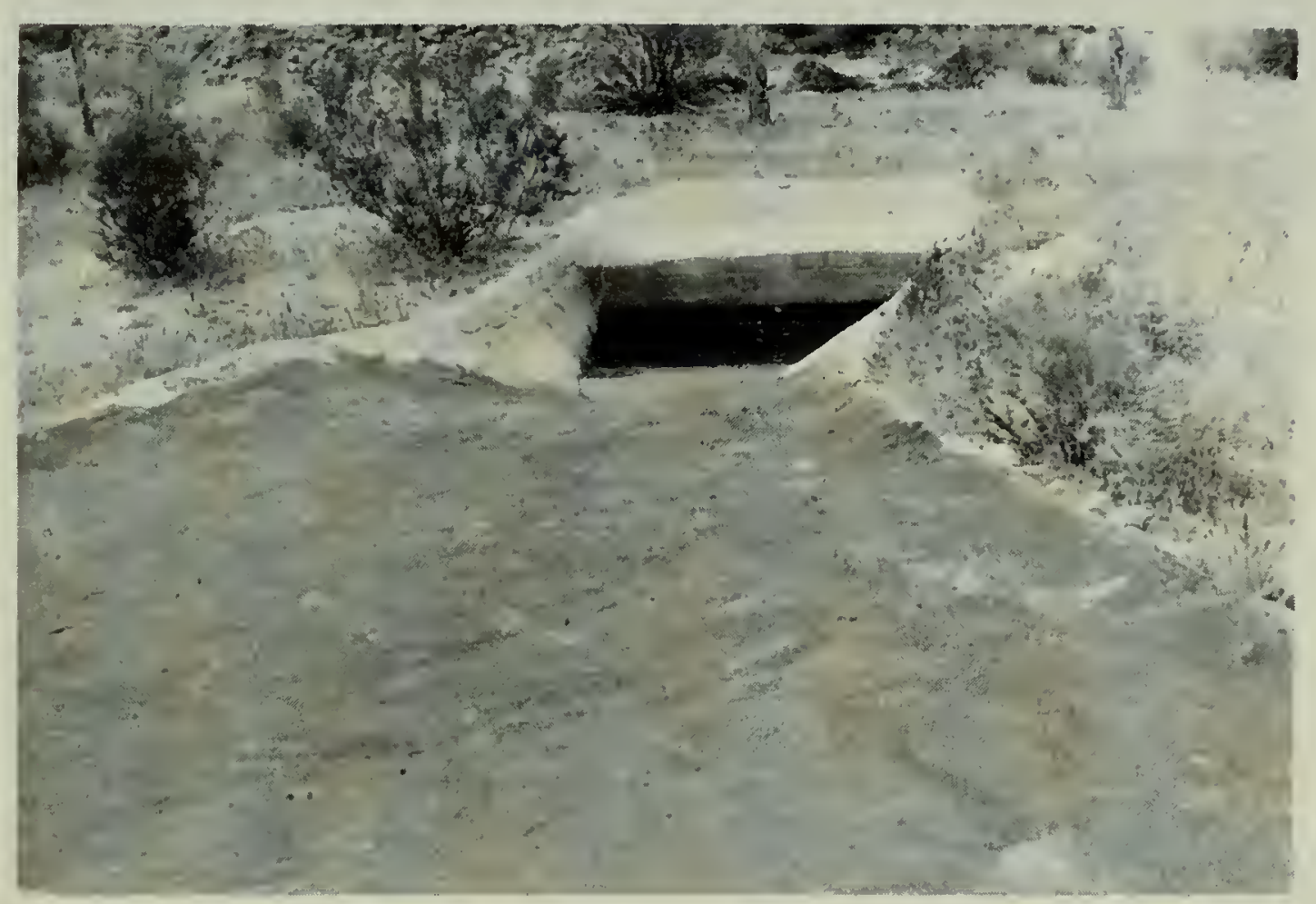

Figure 12. Concrete open-basin type water catchment. 


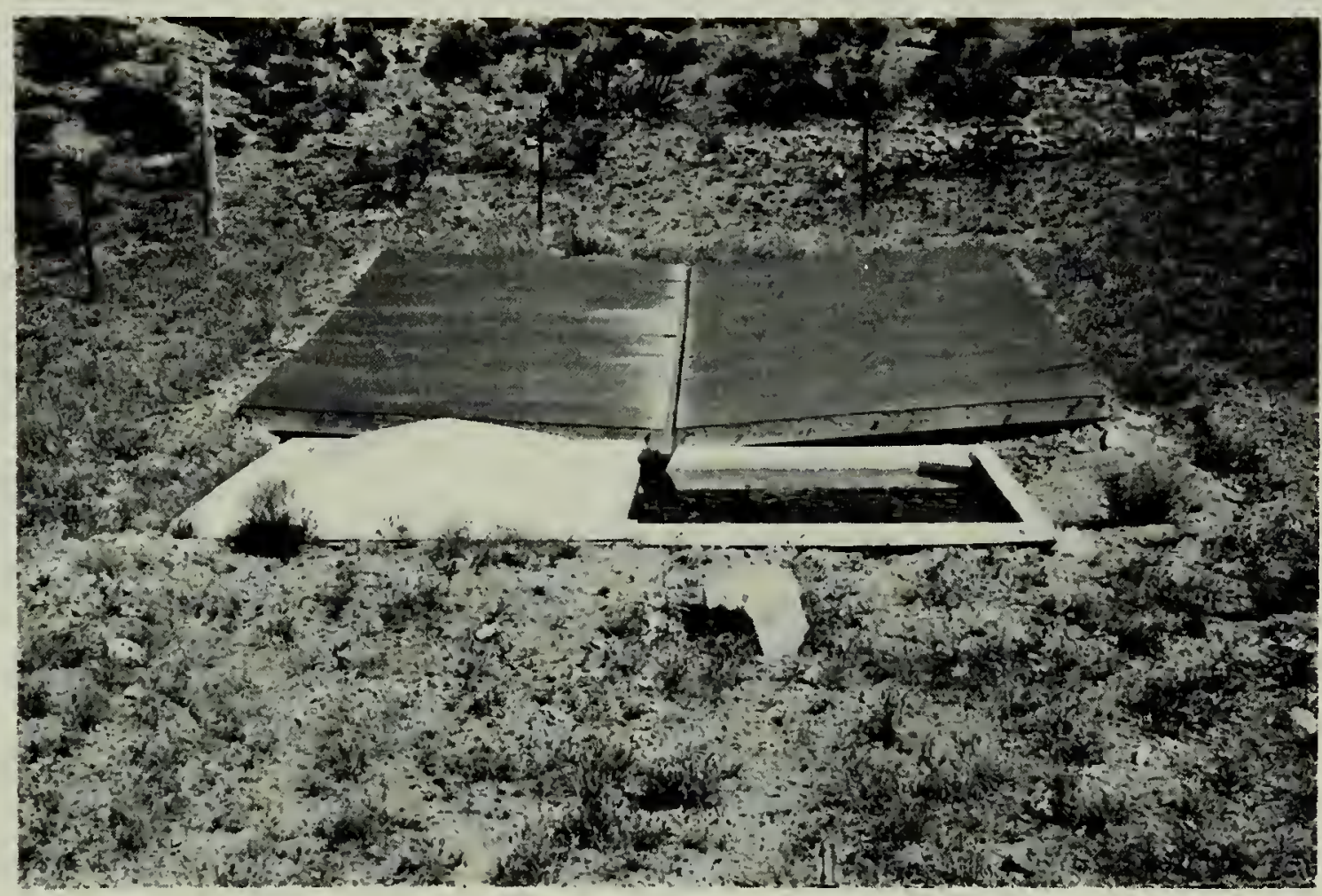

Figure 13. Fiberglass open-basin type water catchment. 


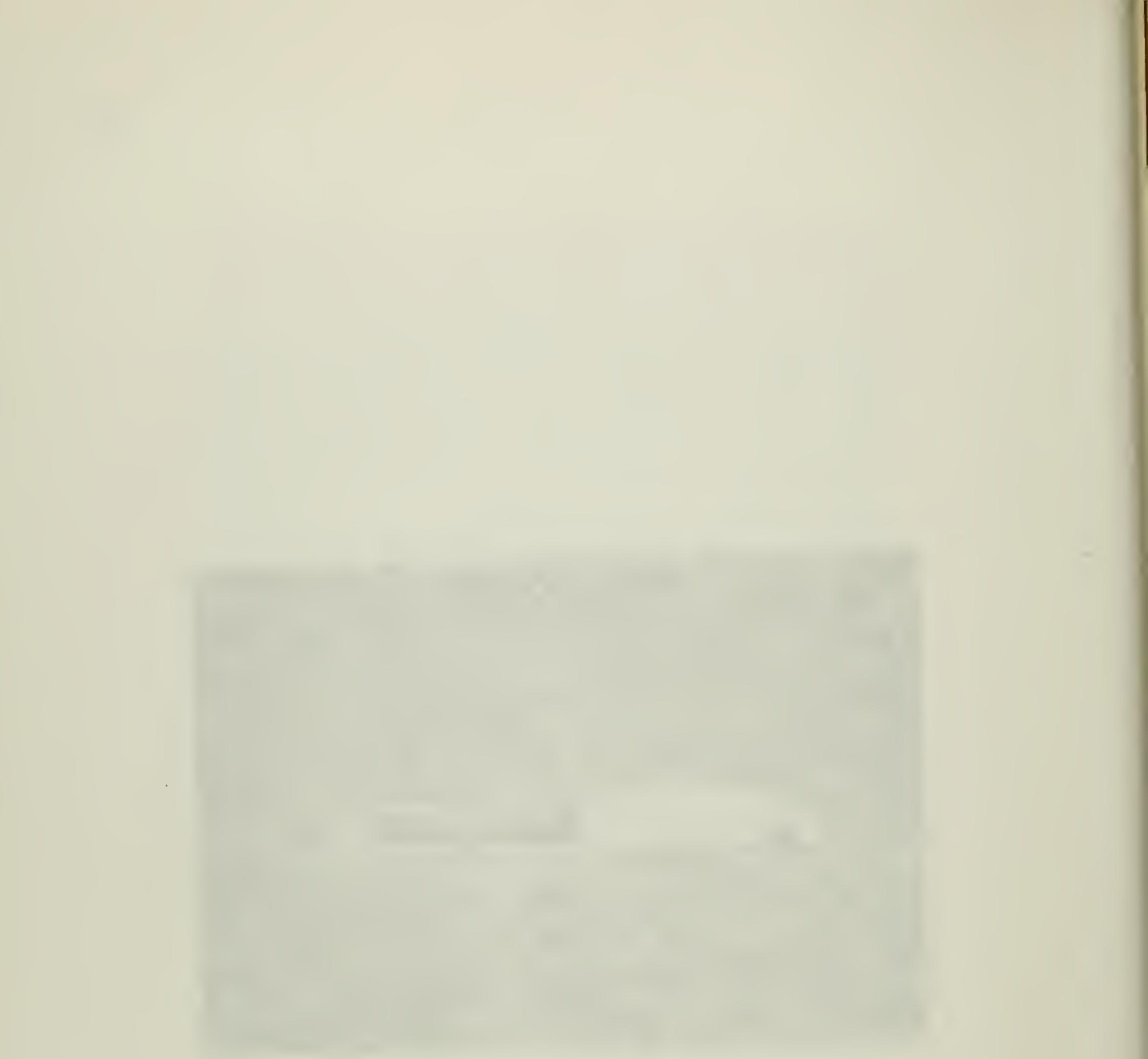




\section{PROCEDURES}

\section{Quail Population Density}

Indexes to population density were obtained for both the intensive and general study areas. In the intensive areas, line-transect counts were made to determine relative density. Call counts, roadside counts, long-period waterhole counts and hunter success were used over the general study area to determine population trends on an extensive basis. These latter counts will be continued for several years, after the termination of this study, by the Department of Fish and Game to determine which method most accurately measures population trend.

\section{Line-transect counts}

Line-transect counts were used for determining relative abundance of quail between intensive study areas. The index to population density was derived in quail-per-mile.

All counts were made on horseback because more miles of transect could be covered in a given period of time. Also it was possible to get closer to quail on a horse than on foot and thus more accurate counts were obtained.

Surveys were made during spring, early summer, and early fall. The spring counts were made during April just prior to nesting. The early summer counts were made in June of 1962 and July of 1963, after reproduction had occurred, and the early fall counts were made in September of each year prior to the hunting season.

During pre-development surveys one transect was set up in each replication of each area. Each transect consisted of two one-mile lines 

at right angles to and bisecting each other, forming a cross, the center of which was the center of the replication; the water catchment in $A-I$ and A-2 (Fig. 14).

For all post-development counts the sampling pattern was changed. Instead of using the cross and passing the catchment twice during each count, four one-mile transects were located at right angles to the centerline wash. They were set up systematically at one-quarter mile intervals in each replication (Fig. 15). This was done to avoid possible bias resulting from the concentration of quail around water in those areas with catchments, and to double sample size in each area.

Line-transect counts were made during both early morning and late evening. During each counting period, all transects in one replication of two study areas were censused. Starting points were alternated from area to area in succeding counts to reduce bias resulting from time lag. For example, if replication $I$ in area $A-I$ was counted first on a given morning, the next morning count on replication I began in area A-2. Also, if transect one in a given replication was counted first during one count, the next count on that replication began on transect four and proceeded in the opposite direction. A period of about three and one-half hours was required to complete a census. Each monthly census required about three weeks to complete. During this time, the transects in areas A-1 and $A-2$ were counted four times each, while those in $B-1$ and $B-2$ were replicated three times.

\section{$\underline{\text { Call }}$ counts}

Mating-call counts were used during April and May of 1962, 1963 and 1964. Fifteen call-count stations were established at one-mile intervals over a 14-mile route selected on the west slope of the Beaver Dam Mountains (Fig. 16). It extended over a large proportion of available habitat. 



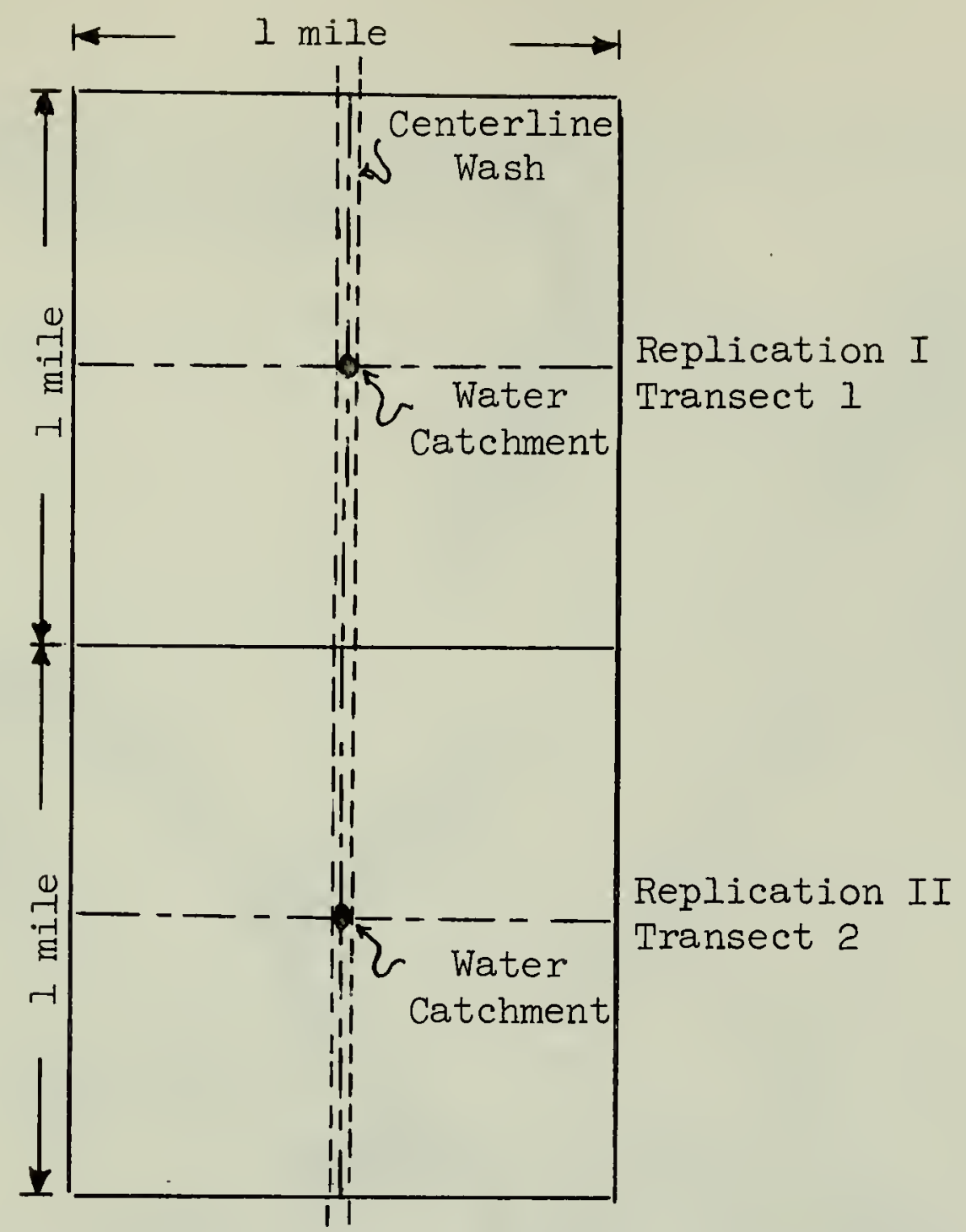

Figure 14. Diagrammatic representation of line-transect pattern used during pre-development surveys, September, 1961

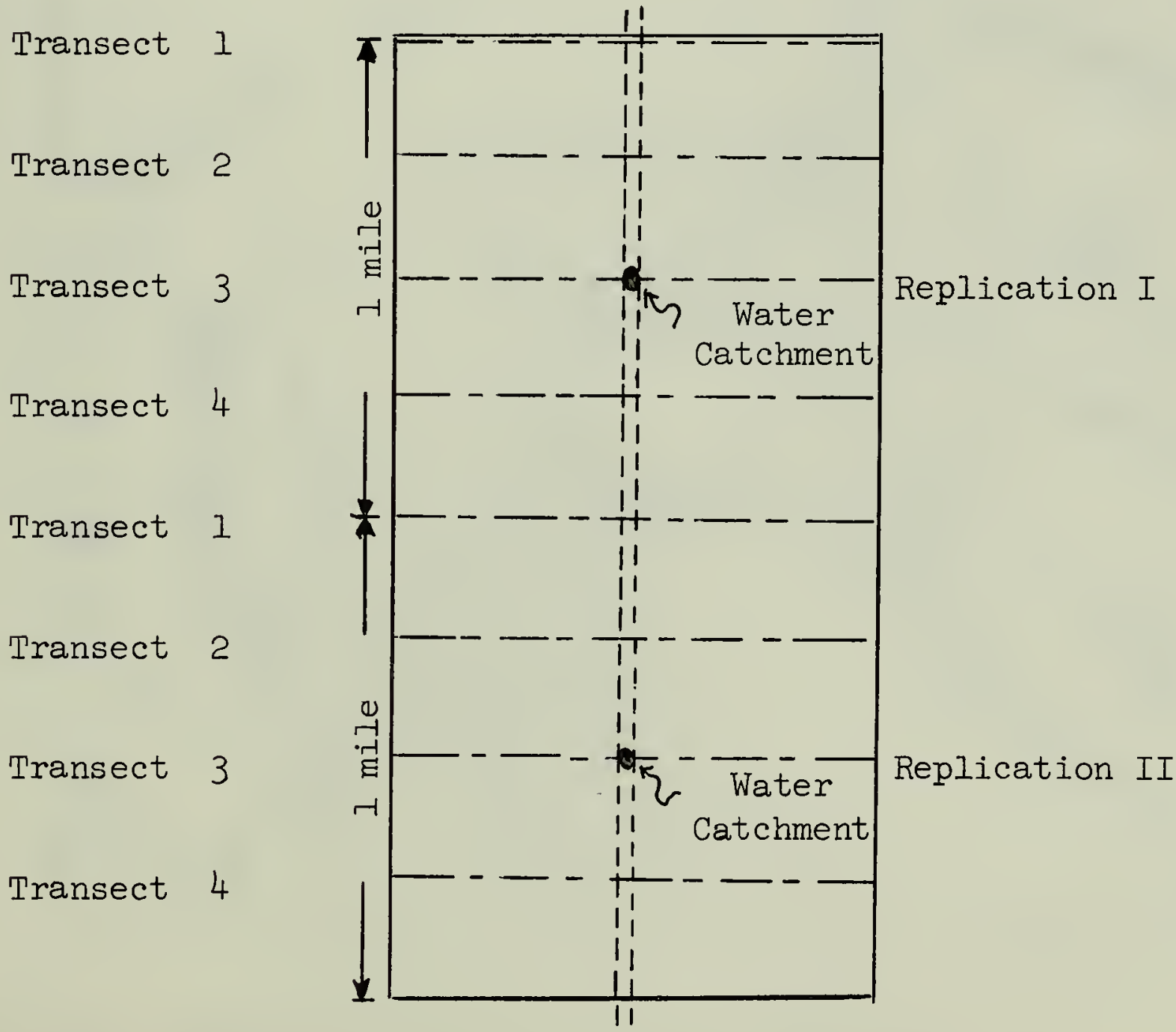

Figure 15. Diagrammatic representation of line-transect pattern used during April, 1962 and later counts 

$-27-$

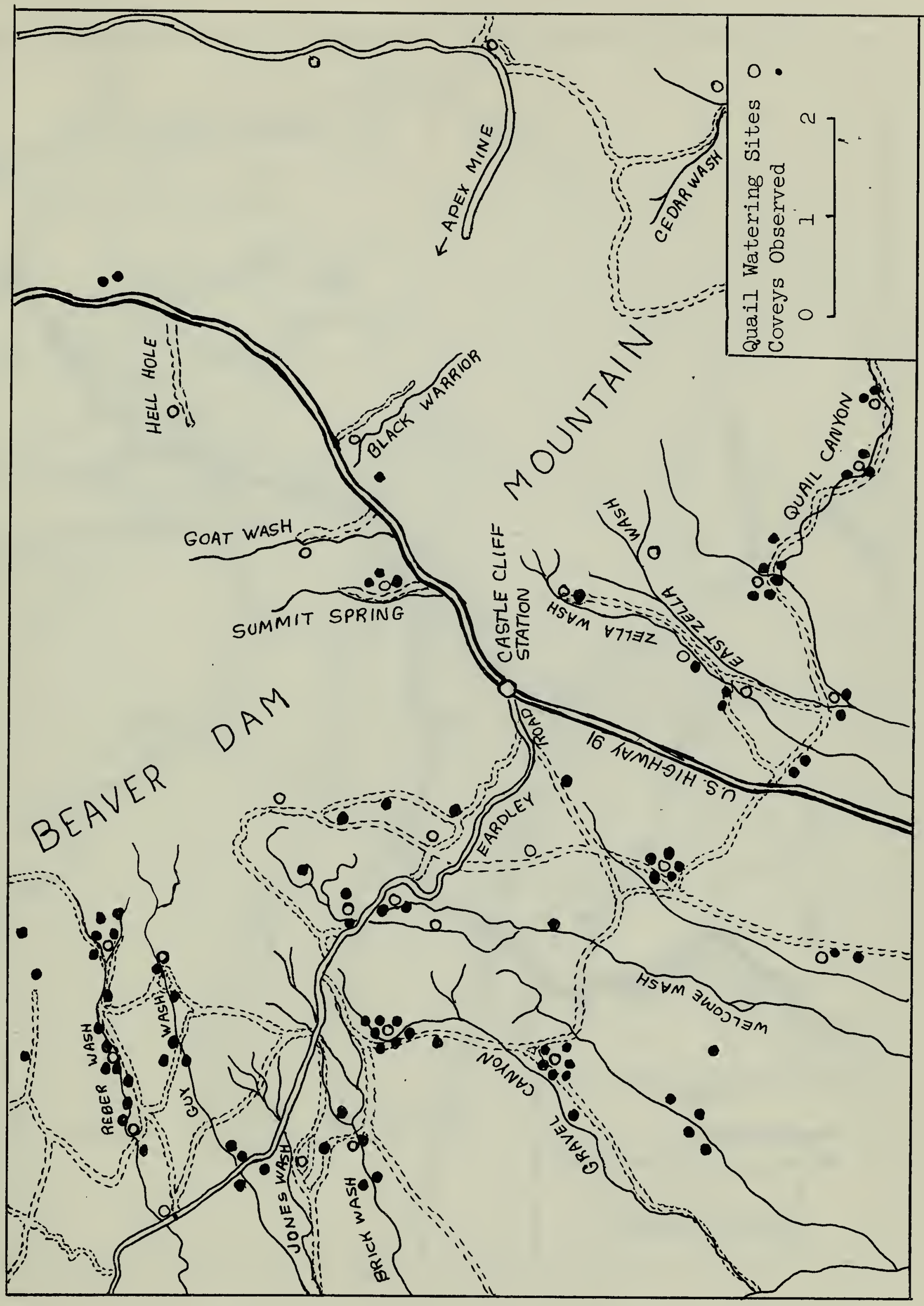

Figure El. General Distribution of Quail, 1962-63 



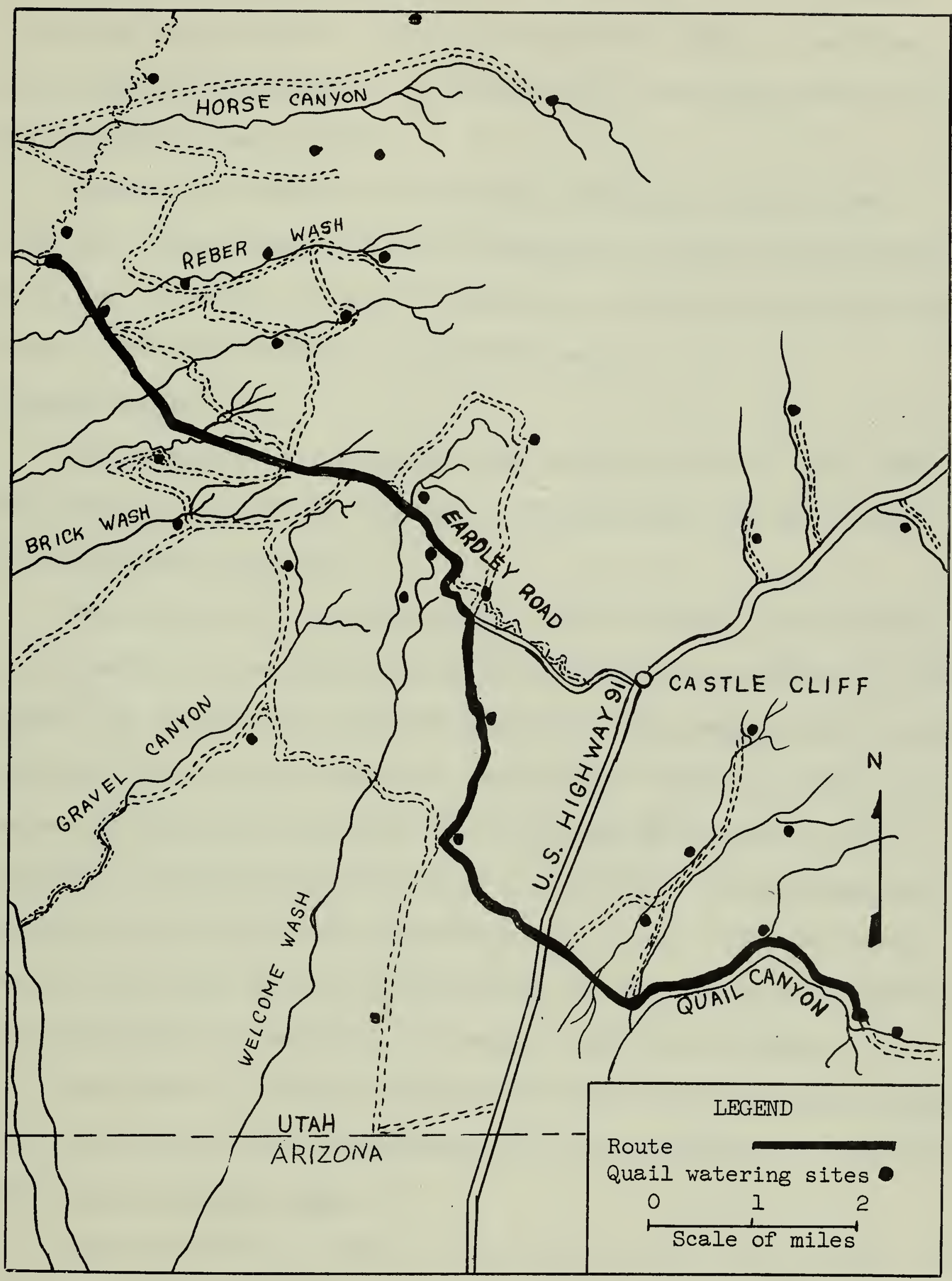

Figure 16. Route used for mating-call counts, pre-breeding and postbreeding roadside counts on the west slope of the Beaver Dam Mountains. 

Counts were started one-half hour before sunrise, and a two-minute count made at each station. Total calls heard and number of individual quail calling were recorded. In addition, wind velocity and disturbances were recorded at each station.

Indexes were determined in mean quail calling per station, mean calls per station, mean total quail calling for the route, and mean total calls for the route. The peak of calling for each year was also determined, as was the calling frequency of individual males. $\underline{\text { Roadside }} \underline{\text { counts }}$

Replicate roadside counts were made in April and May of 1962, 1963 and 1964 prior to hatching, and again during late July and early August of 1962 and 1963 (Fig. 16).

The count prior to hatching was to provide an index (quail-per-mile) to the potential breeding population and to determine the percent of quail paired. It is well known that during dry years many quail in desert areas remain in winter coveys through the spring months and fail to pair, consequently, many do not reproduce (Gallizioli and Smith, 1959). Thus a subsequent reduction probably occurs in the number of calling males even though the potential breeding population may be high. The relationship between this index, percent of quail paired and the call-count index each year should give an indication of expected reproductive success.

The purpose of the late summer roadside count was to determine production and provide an index (quail-per-mile) to the population at that time. Long-period waterhole counts

Waterhole counts were made at six watering sites. Two five-hour counts, starting one-half hour before sunrise, were made at each site during July and August of 1962 and 1963. The highest total count for each watering device was determined. The totals from all sites were combined to provide 

an index to be compared to future years. In addition, brood and ageratio data were recorded for determining production.

Hunter checking stations

During the hunting seasons of 1961 and 1962 a hunter checking station was operated in the general study area. The purpose of this station was to obtain data concerning hunter success which is to be used for future comparison of the various trend techniques. In addition, data on crippling loss, age ratios, sex ratios, and food habits were obtained.

In the fall of 1963 two voluntary stations were set up for collecting quail wings, data on hunter success and crippling loss. At these stations hunters were provided with envelopes having attached questionnaires which were filled out, wings placed therein, and dropped in a slotted box.

\section{Survival of Young Quail}

Brood and age-ratio data collected during line-transect counts, roadside counts, long-period waterhole counts, hunter checking stations, and general observations during routine work were analyzed to determine the influence of water on survival of young quail, and to show the relationship between brood size and age ratios, and time.

To determine relative survival between areas with and without free water, brood size and age ratios were pooled according to distance from free water and time. The categories used were: observations made one-half mile or less from free water and observations over one-half mile from water. These categories were then subdivided into two groups: those observed prior to June 30th and those recorded after that date. Two assumptions were made in this analysis: ( 1 ) June 30 th was the date when water presumably became a limiting factor. This was based on the fact that quail were first observed drinking water on approximately this date 

in both 1962 and 1963, and (2) most, if not all, quail observed over one-half mile from water were living independent of it. This assumption was based on work done in Arizona and Nevada on quail movements. In Arizona Greenwalt (1955) found that year to year movements of quail were limited to less than 550 yards. Within-year movements averaged 480 yards. Gullion (1954a) observed that in Nevada, under conditions of poor food availability, 79 percent of 1,010 retrapped quail were captured at their original trap sites, and that the average movements of the remaining 21 percent was only 2,610 feet. The average extreme daily movements were only 2,980 feet. Over a two-year period the average movements were only 2,760 feet. To show the relationship between brood size and age ratios, and time, all such data were pooled on a monthly basis and compared.

\section{Distribution of Quail}

Distribution was determined both on an intensive and extensive basis. In the intensive study areas quail distribution was determined from observations made during line-transect counts. Each quail observation made during these surveys was recorded as to location on the transect, and then classified with relation to water; or in areas without available water, with relation to the center of the replication.

On an extensive basis, a general pattern of distribution was derived by recording each quail observation (single or covey) and then plotting these on a map of the general study area.

Call-count data were pooled with relation to water and habitat quality to determine the effects of these two factors on quail distribution in spring. Habitat quality was determined subjectively, using the relative abundance of protective cover, black-brush and turpentine-broom as the basis for judgment. 



\section{Quail Movements}

Quail movements were determined by banding and marking. Quail were live trapped using either $4^{\prime} \times 6^{\prime} \times l^{\frac{1}{2}}{ }^{\prime}$ or $4^{\prime} \times 4^{\prime} \times 1^{\prime}$ collapsible, wiremesh, funnel-type traps.

Water was used as bait for practically all trapping in the vicinity of water catchments and proved to be effective. The procedures followed were: (I) a small plastic container was placed in the ground next to a catchment to serve as an alternative source of water; (2) after sign was observed indicating that quail were drinking from this pan (usually one or two days), the entrance to the catchment was closed to prohibit quail from arinking; (3) a funnel trap was placed over the pan with clumps of brush piled on it to provide shade. Quail showed no noticeably different reactions to traps without brush than they did those with large quantities to conceal them. Only enough brush was used to provide shade for entrapped quail (Fig. 17 and 18). When traps were not set, the water in the pan remained available to quail and was readily used by them. Traps were set only in the mornings and quail were not left in them over 3 or 4 hours to avoid ill effects of high ambient temperatures.

Quail were banded with numbered aluminum leg bands (National Band and Tag Company, size 7) and marked with colored plastic strips, safety-pinned to the spinal feather tract near the base of the neck, a method modified from that described by Nelson (1955). Different colored tags were used at various trapping sites (Fig. 19).

Observations of movement were obtained from a number of sources. Foremost among these were sight recoras obtained from routine work such as lineintersect counts, long-period waterhole counts, and roadside counts. Some records were obtained during routine travel about the areas, some from retrapped quail and others from hunter bag checks and band returns. 



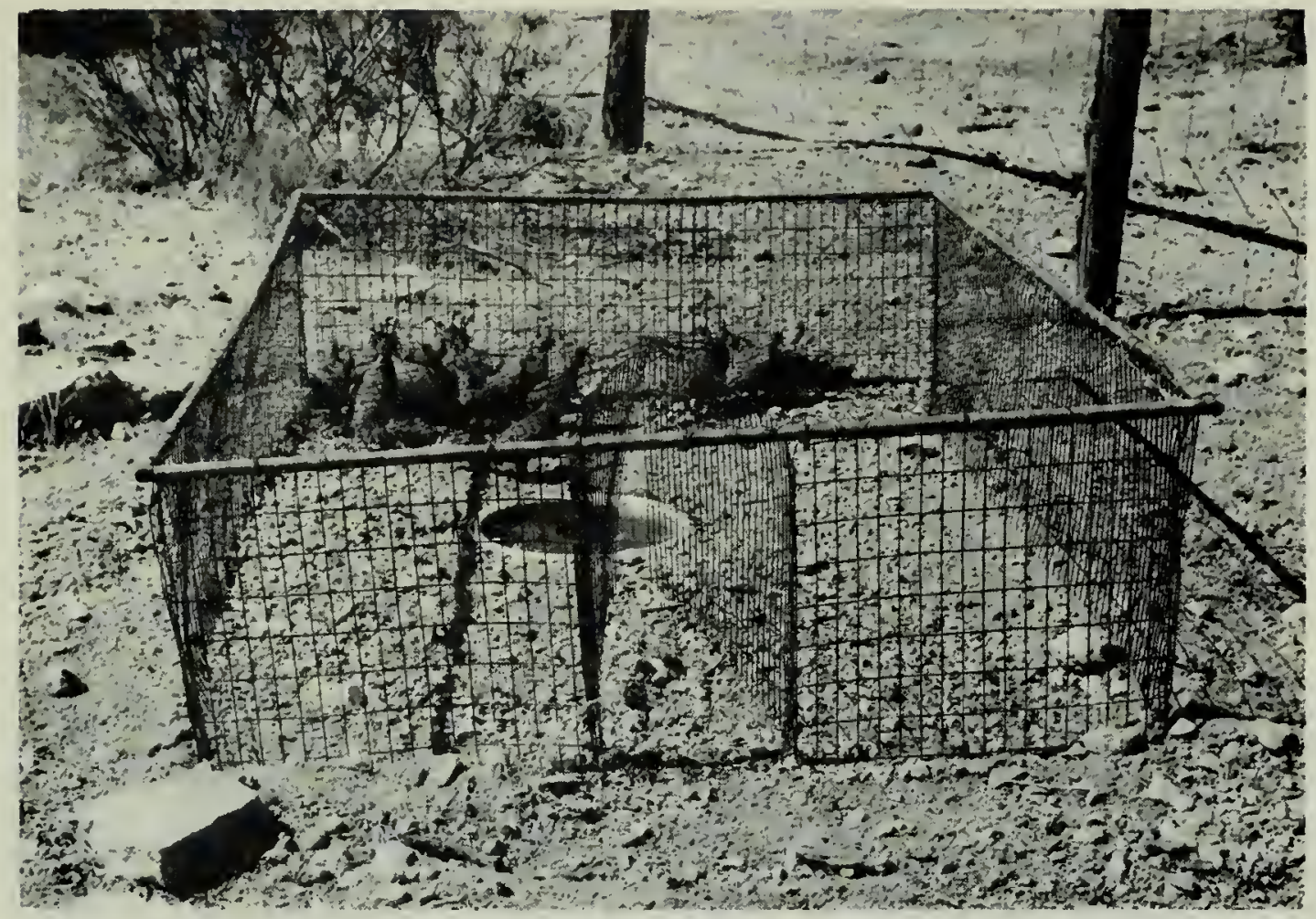

Figure 17. Collapsible wire-mesh funnel trap with plastic container of water used as bait at center.

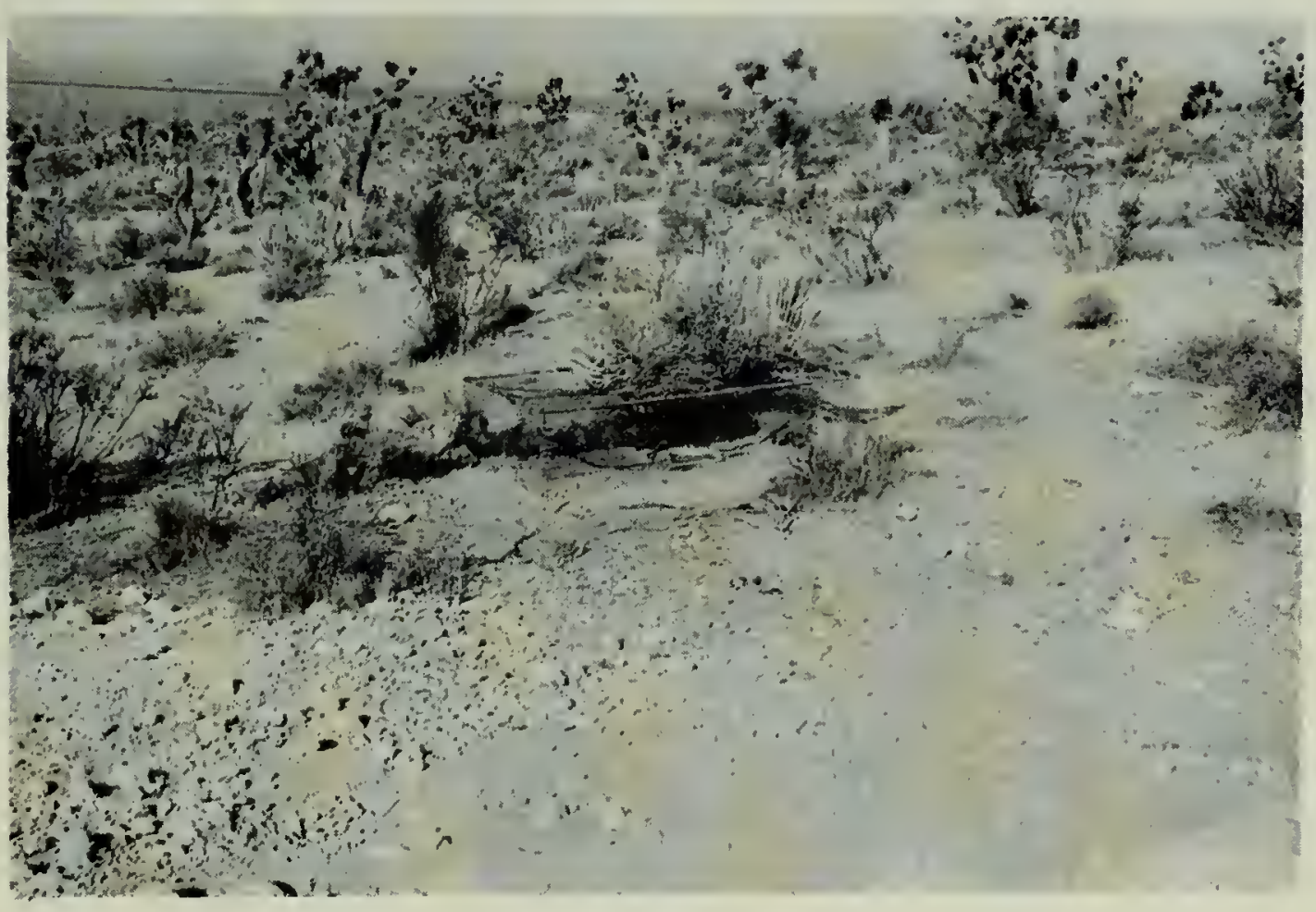

Figure 18. Quail trap showing brush piled on top to provide shade. 



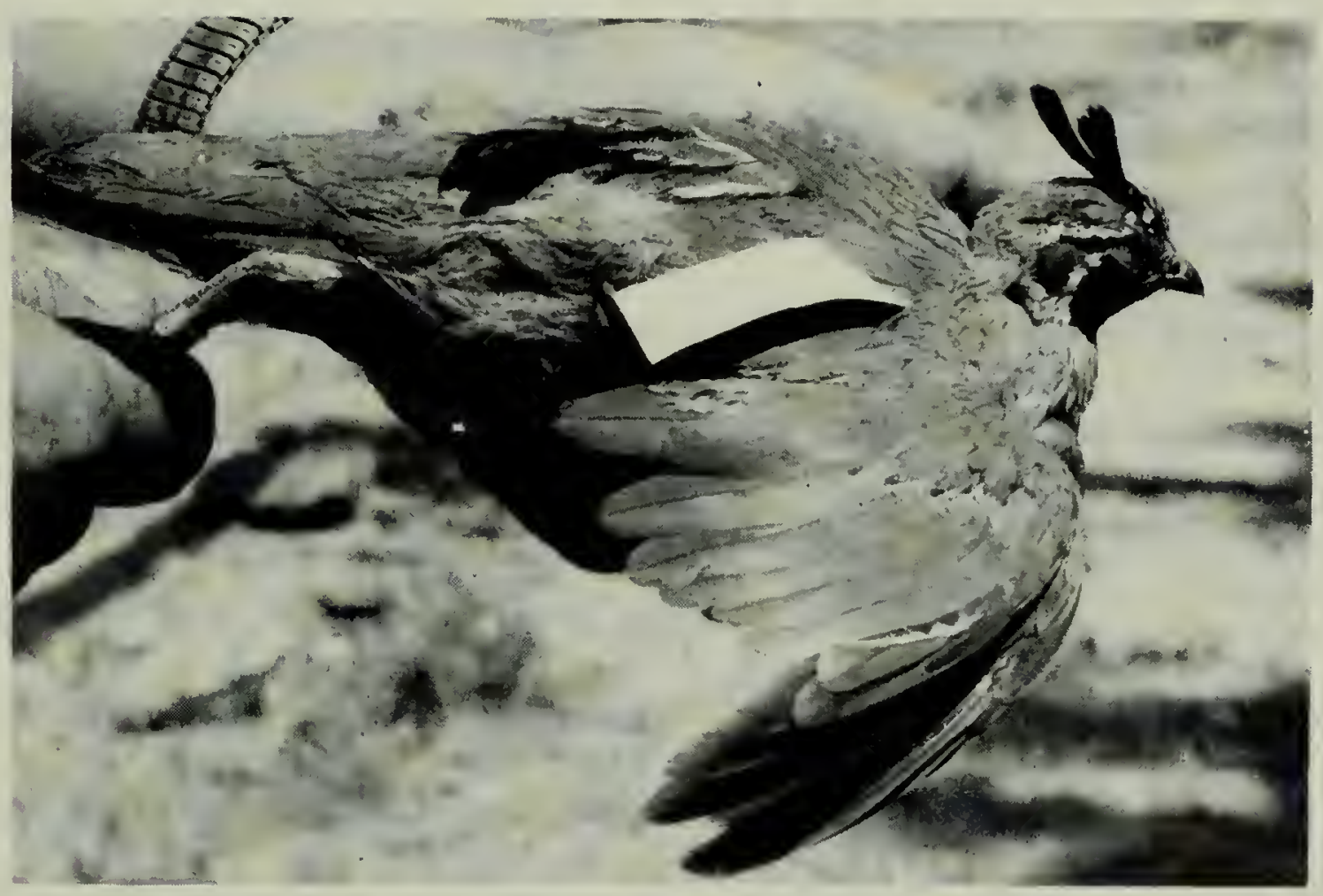

Figure 19. Quail with colored neck tag and band in place. 



\section{Habitat Evaluation}

The purposes of habitat evaluation were to determine the degree of similarity between intensive study areas, to classify vegetation types in the general study area and to correlate these types with quail abundance. Intensive study areas

Two methods of vegetation analysis were used. Line-intercept transects were used primarily for overstory vegetation and rectangular plots for annual and perennial forbs and grasses; however, all vegetation was measured with both methods.

Four line-intercept transects were measured in area $A-1$ and $A-2$. Canopy coverage measurements were made of 100 of every 500 lineal feet of transect. In addition, perpendicular 100-foot measurements were made at two-tenths mile intervals, on alternating sides, along the center-line washes, to assess relative abundance of cover. A total of 5,200 lineal feet of vegetation were measured in these areas.

Five transects were measured in $B-1$ and $B-2$. In all but one of these transects in each area, 100 of every 500 lineal feet were measured. In the other, 100 of every 300 feet were measured. A total of 5,800 lineal feet of vegetation were measured in each area.

Fifty, two by six foot, rectangular plots were measured at 40 pace intervals along a one-mile line perpendicular to the center-line wash at the center of each intensive study area. Percent coverage, density, and frequency were determined for each plant species. A total of 600 square feet were measured in each area.

In addition to vegetation analysis, temperature and precipitation records were maintained for each area from June, 1962 to september, 1963 to detect variations in microclimate which could have a differential effect 
on quail populations. Two weather stations were set up in each area, one at the upper and one at the lower replications in B-I and B-2 and one in each replication of $\mathrm{A}-1$ and $\mathrm{A}-2$. Maximum-minimum registering thermometers and precipitation gauges were used at each station. Thermometers were read and reset. weekly and precipitation measured as it occurred. General study area

To provide a guide to possible future installation of water catchments, the vegetation of the Beaver Dam Mountains was subjectively classified into vegetation types. The value of each type for quail production was assessed by determining relative use of water catchments presently located in each type.

Quail use of catchments was determined each year by long-period counts, estimation based on the abundance of sign, and counts made of quail in the vicinity of catchments during periodic visits.

Food habits of 128 quail were also determined by analysis of crops obtained during the 1962 hunting season. Crop contents were dried, sorted, and a dry volume determined for each item. Percent volume and frequency were determined by the aggregate volume method described by Martin et al. (1946) for each food item. Unknown seeds were identified by comparison to those contained in a reference collection compiled by the state of Nevada Department of Fish and Game.

\section{Life History Information}

No nesting surveys were made, but some effort was expended attempting to find nests each year. The peak of nesting was determined for 1962 by aging juvenile quail using a method described by Raitt (1961).

Sex ratios were obtained from harvest data. 

A comparison of age ratios in cultivated and desert areas was obtained by collection of wings during the fall hunt.

Quail watering habits were determined subjectively from general observations. 



\section{RESULTS}

\section{Quail Population Density}

\section{Line-transect counts}

Line-transect counts proved extremely variable with individual observations (quail observed in a mile of transect) ranging from 0 to 60 quail. Over the study period quail observations became so few that comparison was not possible between transects or replications. The variability of data precluded making a statistical analysis. In spite of this variability, the line-transect counts appeared to show expected population fluctuations and trend throughout the study period (Fig. 20).

$\underline{\text { Areas }} \underline{A-1}$ and $\underline{A-2}$. Preliminary population surveys indicated that study area $\mathrm{A}-1$ was supporting approximately twice as many quail as $\mathrm{A}-2$. Counts in September, 1961 yielded 13.1 and 5.1 quail-per-mile respectively for the two areas. April, 1962 counts resulted in 1.6 and 0.0 quail-per-mile.

After the April counts, the water catchments in area A-I were closed to prohibit quail use. This area was selected for closure because of its higher quail population. After the closure another census was made in June to assess the immediate effects of this closure on population density.

The June census indicated that the population in area A-2 had increased, as would be expected during this period due to reproduction, from 0.0 (April count) to 0.25 quail-per-mile. The index for area $A-1$, rather than increasing as expected, dropped from 1.6 (April count) down to 0.36 quail-per-mile. Thus the relative abundance of quail as indicated by these counts had changed from approximately double in A-l to about even.

During later censuses the relative abundance of quail remained approximately equal, with area $A-I$, the waterless area, usually having more quail, 



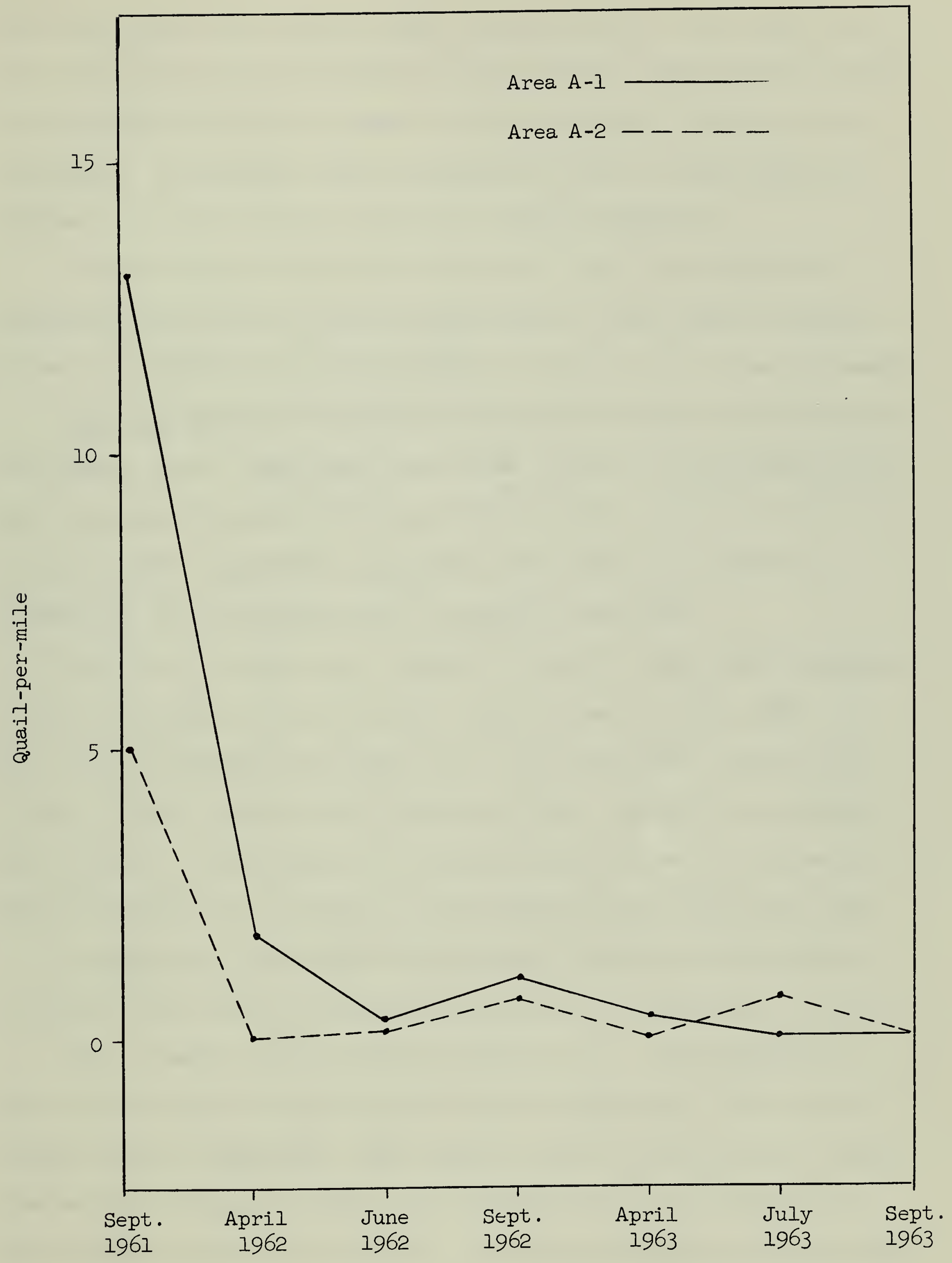

Figure 20. Population trend for areas $A-1$ and $A-2$ during the period from September, 1961 through September, 1963 

until July, 1963 when area A-2 showed a greater index. It is significant that this July census was the only one made during a water-critical period and the greater abundance of quail in A-2 was possibly a result of concentration. By September, 1963 the population level in both areas had dropped to the point where no quail were observed (Table 1 ).

It was uncertain whether the reduction of quail in $A-1$ after the catchment closure was a result of quail moving to other areas in search of water or movement out of the immediate vicinity of the closed catchment.

$\underline{\text { Areas }} \underline{\mathrm{B}-1}$ and $\mathrm{B}-2$. No quail were observed in either area during predevelopment counts. Some quail were known to occur in both areas since 45 had been observed in $B-1$ and 61 in $B-2$ during other routine work prior to transect counts. Apparently population levels were so low that the probability of encountering quail on transects was remote.

The water catchments were installed in area B-2 after pre-development counts in september, 1961. The next census was made in June, 1962. At that time the population was still very low in both areas, but area B-2 showed a slight increase to 0.33 quail-per-mile. Whether this increase was a result of concentration or increased production was not determined. Area B-l yielded only one quail or 0.03 quail-per-mile during this count. In addition to these data, ten quail were observed in B-I and 85 in B-2 during other routine activities between March 22 and August 31, 1962 . Later transect counts yielded no quail in B-I. The population in B-2 varied between 0.0 and 0.36 quail-per-mile (Table 2 ). The last linetransect count in September, 1963 showed no quail in either area. General observations just prior to this count indicated few if any quail in B-I and a probable maximum of 35 in B-2. The long term trend of the population in these areas is depicted in Figure 2l. Little difference in population 
Table 1. Results of line-transect counts in areas A-I and A-2, September, 1961 through September, 1963

\begin{tabular}{lccccc}
\hline $\begin{array}{l}\text { Counting } \\
\text { period }\end{array}$ & $\begin{array}{c}\text { Number of } \\
\text { quail observed }\end{array}$ & $\begin{array}{c}\text { Miles of } \\
\text { transect } \\
\text { per area }\end{array}$ & $\begin{array}{c}\text { Population index } \\
\text { (quail-per-mile) }\end{array}$ \\
\hline September, 1961 & 184 & 72 & 14 & 13.1 & A-I* \\
April, 1962 & 45 & 0 & 28 & 1.6 & 5.1 \\
June, 1962 & 10 & 7 & 28 & 0.36 & 0.0 \\
September, 1962 & 28 & 19 & 28 & 1.0 & 0.68 \\
April, 1963 & 9 & 0 & 28 & 0.32 & 0.0 \\
July, 1963 & 0 & 17 & 28 & 0.0 & 0.61 \\
September, 1963 & 0 & 0 & 28 & 0.0 & 0.0 \\
\hline
\end{tabular}

* The catchments in area $\mathrm{A}-1$ were closed to prevent quail use on May, 1962 . 

Table 2. Results of line-transect counts in areas B-I and B-2, September, 1961 through September, 1963

\begin{tabular}{lccccc}
\hline $\begin{array}{l}\text { Counting } \\
\text { period }\end{array}$ & $\begin{array}{c}\text { Number of } \\
\text { quail observed } \\
\text { B-1 }\end{array}$ & $\begin{array}{c}\text { Miles of } \\
\text { transect } \\
\text { per area }\end{array}$ & $\begin{array}{c}\text { Population index } \\
\text { (quail-per-mile) }\end{array}$ \\
\hline $\begin{array}{l}\text { September, 1961 } \\
\text { June, 1962 }\end{array}$ & 0 & 0 & 24 & 0.0 & 0.0 \\
September, 1962 & 1 & 12 & 36 & 0.03 & 0.33 \\
April, 1963 & 0 & 0 & 36 & 0.0 & 0.0 \\
July, 1963 & 0 & 13 & 36 & 0.0 & 0.36 \\
September, 1963 & 0 & 5 & 36 & 0.0 & 0.14 \\
\hline
\end{tabular}

* Catchments were installed in area B-2 in September, 1961, after the count was completed. 



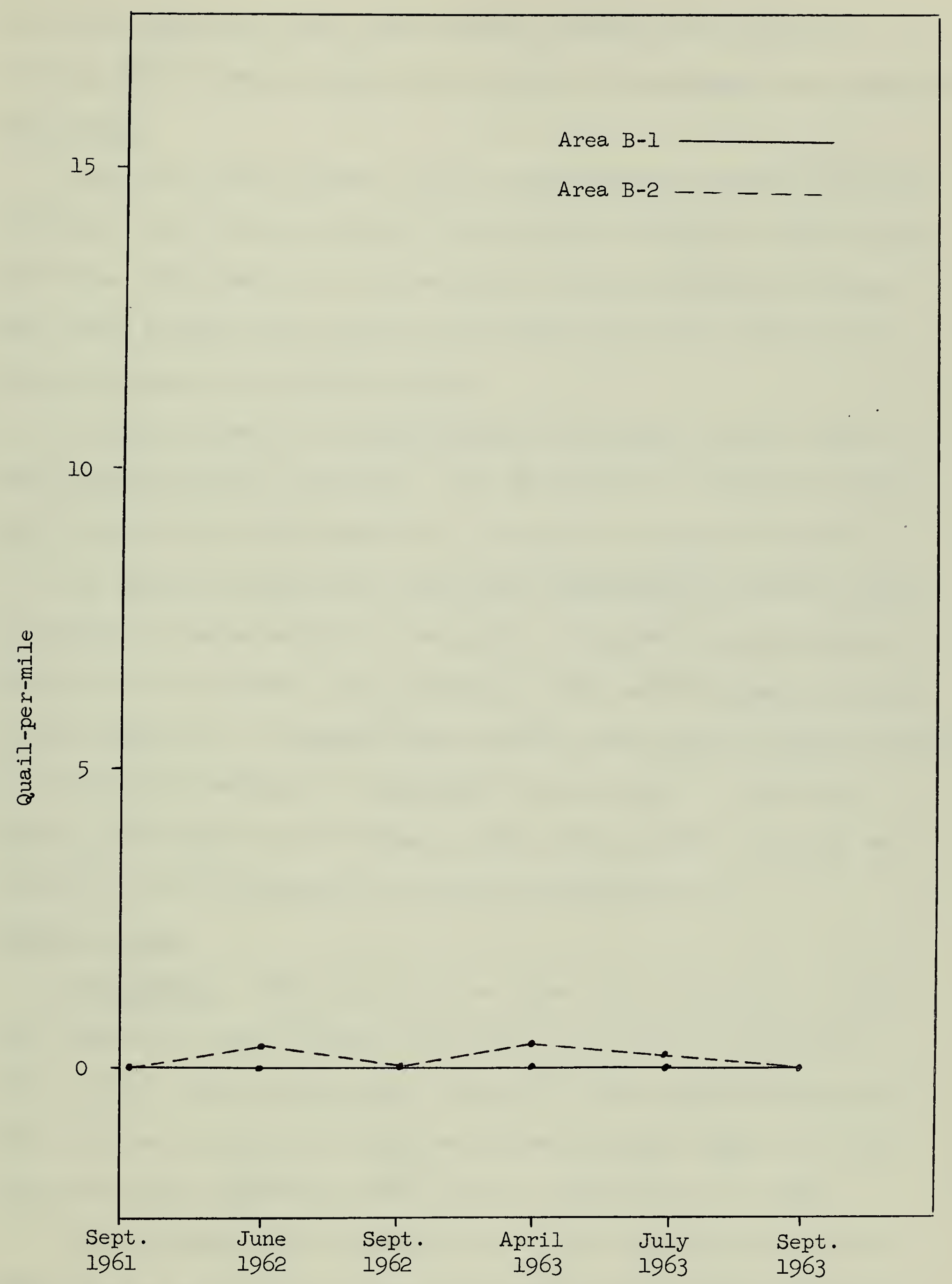

Figure 21. Population trend for areas B-1 and B-2 during the period from September, 1961 through September, 1963. 
level was indicated by this trend; however, general observations indicated that B-2 had more quail than B-l after the catchments were installed. Call counts

Call-count data indicated that the 1963 breeding population was about 60 percent lower than in 1962 and the population in 1964 was 30-60 percent lower than 1963 (Table 3). The variation in percent difference between mean calls and mean quail calling was probably due to the difference in calling frequency of individual males.

In 1962 the peak of calling occurred in late April while in 1963 it was in early May (Fig. 22 and 23). The variability of calling on a daily basis for 1962 and 1963 respectively is depicted in Figures 24 and 25.

The effect of wind on call counts was approximated by pooling counts according to wind velocity into two groups; those made under conditions in excess of an estimated wind velocity of $7 \mathrm{mph}$, and those made at $7 \mathrm{mph}$ or less (Table 4). It appeared that excessive wind velocity reduced calling.

The rate of calling for individual lone males was 3.3 calls per minute or one call each 18 seconds in both 1962 and 1963. The range was from 0.5 to 9.0 in 1962 and 0.5 to 10.0 in 1963 (Table 5). Roadside counts

Pre-breeding. Indexes derived from these counts indicated a 75 percent reduction in quail numbers from 1962 to 1963 and 67 percent from 1963 to 1964. Paired quail counts obtained at this time indicated that about the same proportion of birds were mated each year (Table 6). Five replicate counts were made in 1962, seven in 1963 and four in 1964 .

The occurrence of a high proportion of pairs together in the early morning hours at this time of year (April-May) could indicate failure to breed in a high proportion of pairs rather than possible high breeding 


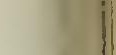


Table 3. Call count indexes determined for the general study area during 1962, 1963 and 1964

\begin{tabular}{|c|c|c|c|c|c|}
\hline Index & 1962 & 1963 & $1964 *$ & \multicolumn{2}{|c|}{$\begin{array}{l}\text { Percent } \\
\text { difference } \\
62-63 \quad 63-64 * *\end{array}$} \\
\hline Mean calls heard per station & $2 \cdot 71$ & $1.05(1.67)^{* *}$ & 0.68 & -61 & -59 \\
\hline Mean quail calling per station & 0.41 & $0.14(0.22)$ & 0.15 & -66 & -32 \\
\hline Mean total calls for route & 41.0 & $16.0(25.0)$ & 10.1 & -61 & -60 \\
\hline Mean total quail calling for route & 7.0 & $2.2(3.3)$ & $2 \cdot 3$ & -68 & -31 \\
\hline
\end{tabular}

* Based on four counts during assumed peak of calling in 1964

* The 1964 means were compared to the means of four counts during the 1963 peak calling period.

Table 4. The effects of wind velocity on calling as indicated by pooling counts according to estimated velocity in 1962

Index

Estimated wind velocity

Over $7 \mathrm{~m} \cdot \mathrm{p} \cdot \mathrm{h}$. $7 \mathrm{~m} \cdot \mathrm{p} \cdot \mathrm{h}$. or less

Mean calls per station

0.59

$3 \cdot 9$

Percent of stations

with quail calling

12

44

Table 5. Frequency of calling of individual male Gambel's quail during 1962 and 1963

$\begin{array}{lll}\text { Year Number of males Total calls Mean calls } & \begin{array}{c}\text { Extremes } \\ \text { per minute (calls per minute) }\end{array}\end{array}$

\begin{tabular}{lllll}
\hline 1962 & 35 & 116 & 3.3 & $0.5-9.0$ \\
1963 & 18 & 59 & 3.3 & $0.5-10.0$ \\
\hline Totals & 53 & 175 & 3.3 & $0.5-9.5$ \\
\hline
\end{tabular}





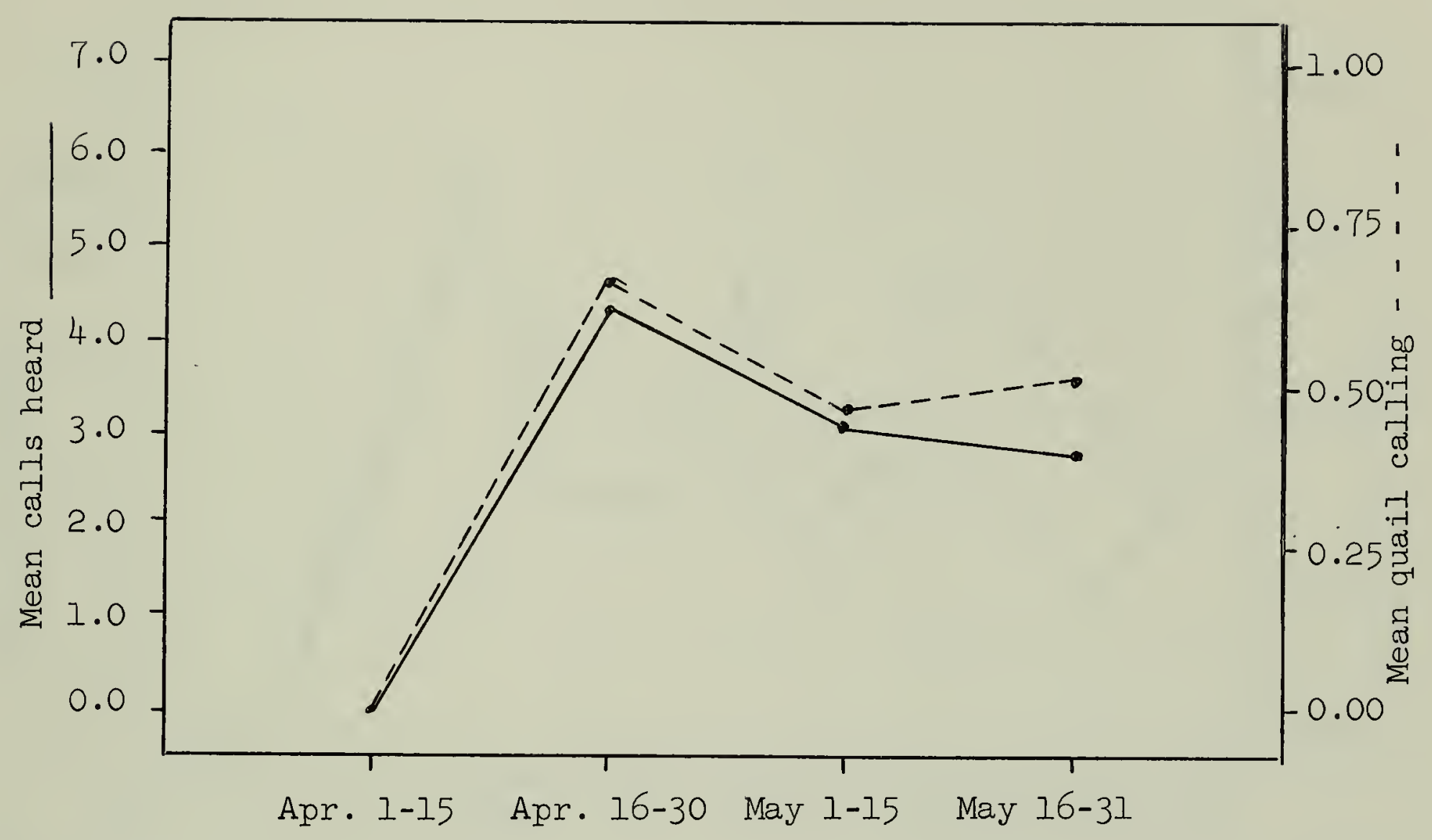

Figure 22. Pooled mean calls heard and quail calling per station showing the trend of calling during April and May, 1962

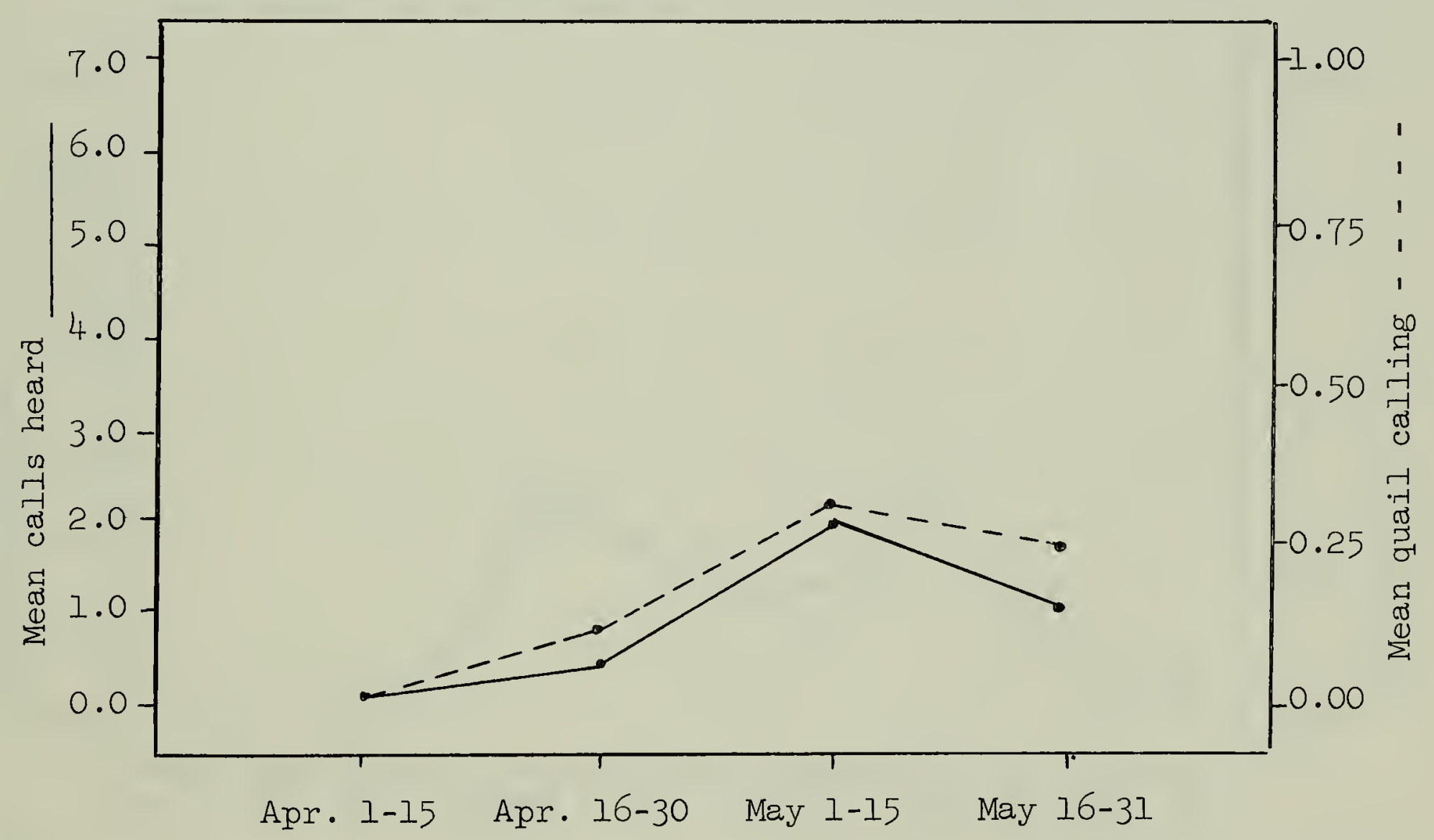

Figure 23. Pooled mean calls heard and quail calling per station showing the trend of calling during April and May, 1963 



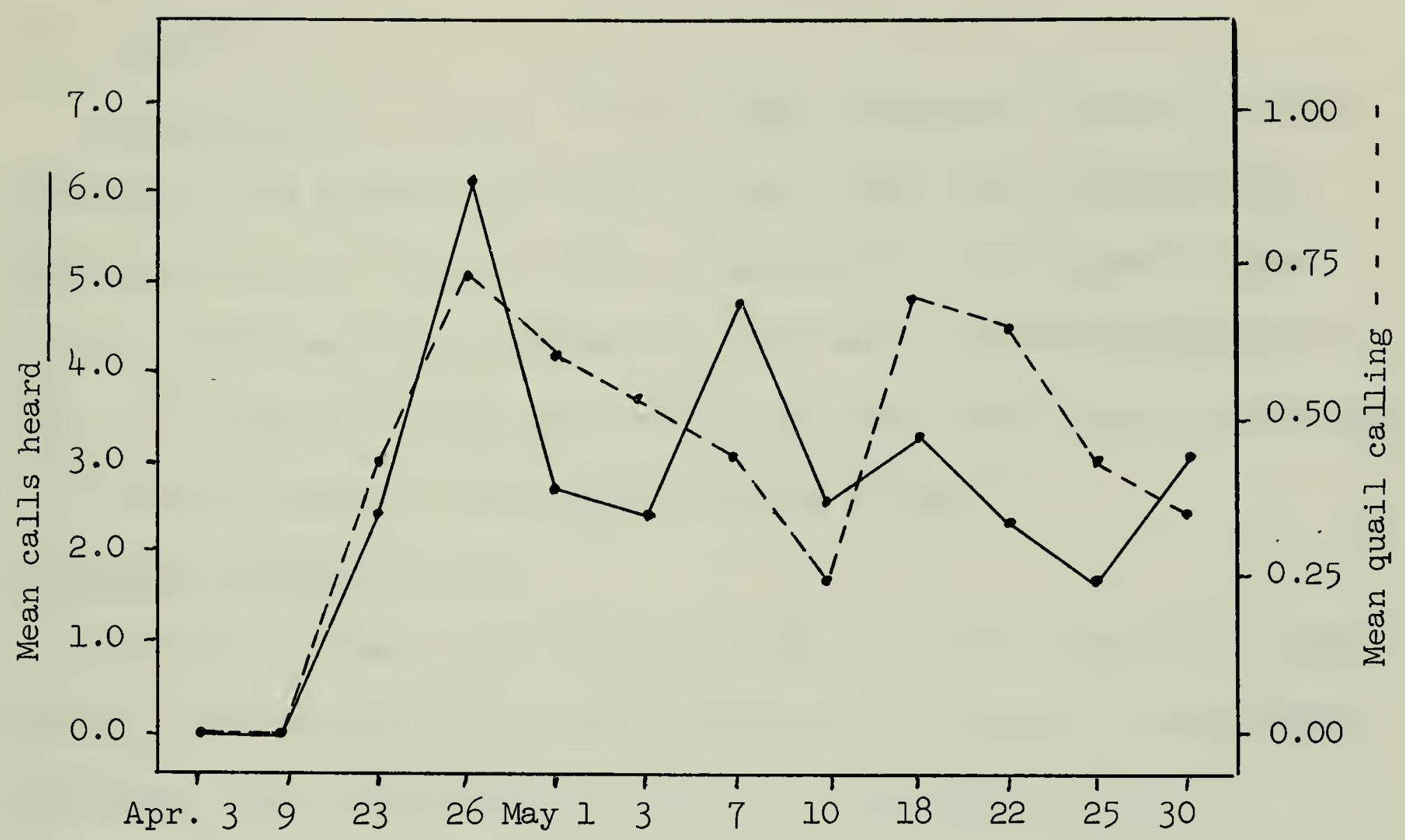

Figure 24. Mean calls heard and quail calling per station for each day's census during April and May, 1962

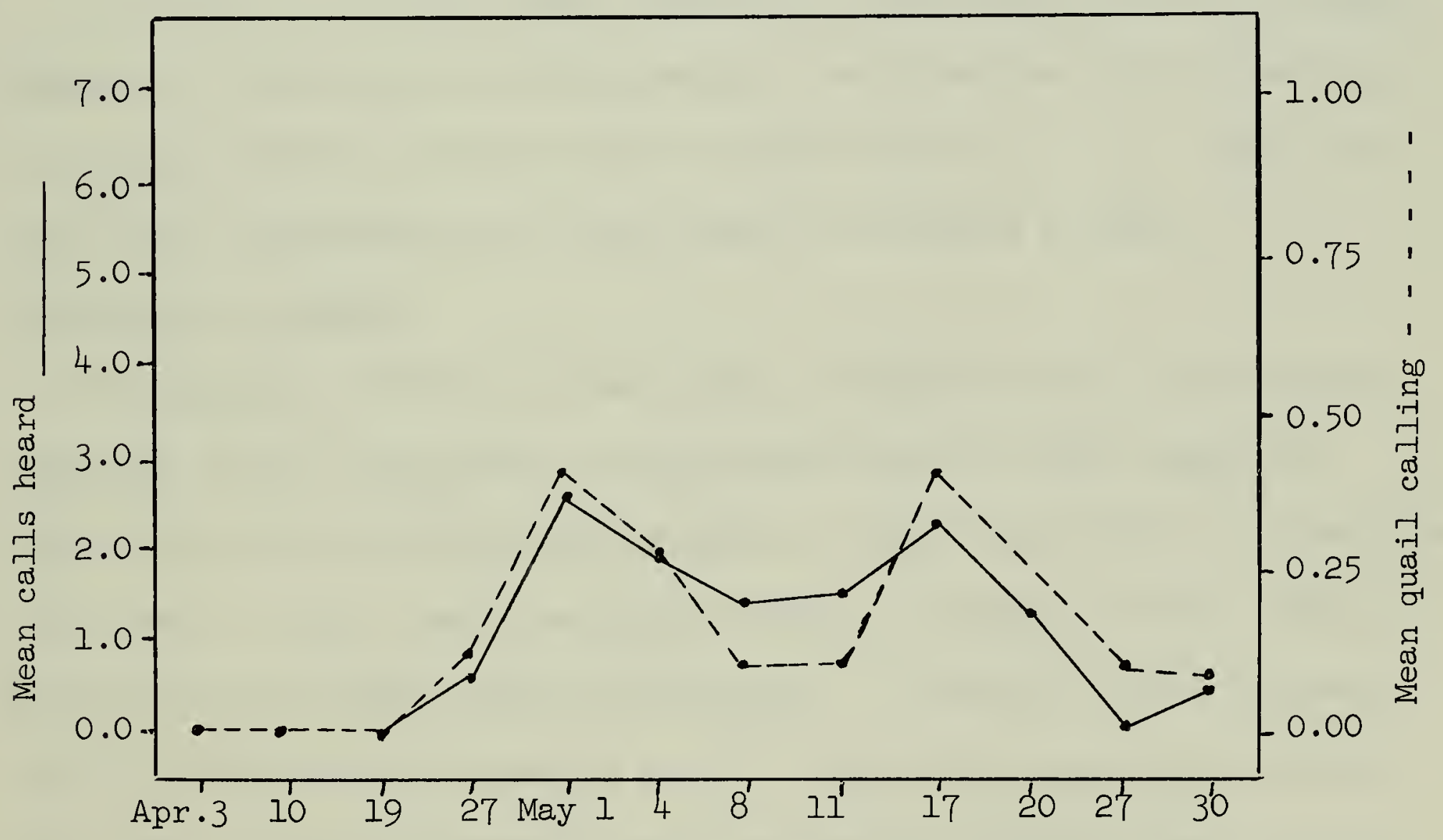

Figure 25. Mean calls heard and quail calling per station for each day's census during April and May, 1963 

activity. The poor reproduction in both years tends to substantiate this supposition.

Post-breeding. The post-breeding index indicated a reduction in the population of 84 percent from 1962 to 1963 . Age ratios indicated much poorer production of young in 1963 as compared to 1962; however, these ratios differ from ratios obtained by other sources and are undoubtedly wrong. The number of birds observed during these counts was not sufficient to accurately determine reproductive success (Table 7). Long-period waterhole counts

In 1962, 245 quail were observed during long-period waterhole counts. Counts in 1963 yielded 101 birds, a reduction of 59 percent. Age ratios from these counts indicated slightly poorer reproduction in 1963 as compared to 1962 (Table 8).

Hunter success

The index to the fall quail population, determined each year as quail bagged per 100 gun hours hunting pressure, revealed the 1963 population to be only 25 percent lower than that of 1962 (Tables 9, 10, 11). This reduction was considerably less than shown by the above methods. Comparison of indexes

The indexes derived from call counts, roadside counts, long-period waterhole counts, and hunter success showed that the quail population declined from 25 to 84 percent from 1962 to 1963 (Table 12). No correlation can be made at this time to determine relative accuracy of these methods because only two years' data are available. It should be noted however, that the reduction as determined by call counts and long-period waterhole counts were in close agreement, while the roadside counts showed a greater decline between the two years. 

Table 6. Results of pre-breeding roadside counts of Gambel's quail for 1962,1963 and 1964

\begin{tabular}{|c|c|c|c|c|c|}
\hline Data & 1962 & 1963 & 1964 & $\begin{array}{r}\text { Percent } \\
62-63\end{array}$ & $\begin{array}{c}\text { difference } \\
63-64\end{array}$ \\
\hline Total quail & 50 & 18 & 2 & & \\
\hline Miles traveled & 70 & 98 & 56 & & \\
\hline Index (quail-per-mile) & 0.71 & 0.18 & 0.04 & -75 & -67 \\
\hline Total pairs & 19 & 7 & 1 & & \\
\hline Percent paired & 76 & 78 & 100 & +2 & +18 \\
\hline
\end{tabular}

Table 7. Results of post-breeding roadside counts of Gambel's quail for 1962 and 1963

\begin{tabular}{|c|c|c|c|}
\hline Data & 1962 & 1963 & Percent difference \\
\hline Adults & 62 & 16 & \\
\hline Juveniles & 23 & 1 & \\
\hline Juveniles: 100 adults & 37 & 6 & \\
\hline Total quail & 85 & 17 & \\
\hline Miles traveled & 56 & 70 & \\
\hline Index (quail-per-mile) & 1.52 & 0.24 & -84 \\
\hline
\end{tabular}



Table 8. Results of long-period waterhole counts for 1962 and 1963

\begin{tabular}{lrcc}
\hline \hline Data & 1962 & 1963 & Percent difference \\
\hline Adults & 154 & 68 & -56 \\
Juveniles & 91 & 33 & -64 \\
Juveniles: 100 adults & 59 & 48 & -19 \\
Index (total quail) & 245 & 101 & -59 \\
\hline
\end{tabular}

Table 9. Quail hunter success in the Beaver Dam Mountain area during 1961

\begin{tabular}{lccccc}
\hline Period & $\begin{array}{c}\text { Total } \\
\text { hunters }\end{array}$ & $\begin{array}{c}\text { Total } \\
\text { quail }\end{array}$ & $\begin{array}{c}\text { Total gun } \\
\text { hours }\end{array}$ & $\begin{array}{c}\text { Quail per } \\
\text { 100 hours }\end{array}$ & $\begin{array}{c}\text { Cripples lost: } \\
\text { 100 quail bagged }\end{array}$ \\
\hline Nov. $4-5$ & 17 & 82 & 70 & 117 & 1 \\
Nov. 25-26 & 28 & 33 & 159 & 21 & 33 \\
Dec. 23-24 & 49 & 67 & 204 & 33 & 10 \\
\hline Totals & 94 & 182 & 433 & 42 & 10 \\
\hline
\end{tabular}

Table 10. Quail hunter success in the Beaver Dam Mountain area during 1962

\begin{tabular}{lccccc}
\hline Period & $\begin{array}{c}\text { Total } \\
\text { hunters }\end{array}$ & $\begin{array}{c}\text { Total } \\
\text { quail }\end{array}$ & $\begin{array}{c}\text { Total gun } \\
\text { hours }\end{array}$ & $\begin{array}{c}\text { Quail per } \\
\text { 100 hours }\end{array}$ & $\begin{array}{c}\text { Cripples lost: } \\
\text { 100 quail bagged }\end{array}$ \\
\hline Oct. 13-14 & 50 & 78 & 207 & 38 & 18 \\
Nov. 24-23 & 7 & 9 & 34 & 27 & 22 \\
Dec. 22-23 & 33 & 46 & 177 & 26 & 37 \\
\hline Totals & 90 & 133 & 418 & 32 & 25 \\
\hline
\end{tabular}



Table 11. Quail hunter success in the Beaver Dam Mountain area during 1963

\begin{tabular}{lccccc}
\hline \hline Period & $\begin{array}{c}\text { Total } \\
\text { hunters }\end{array}$ & $\begin{array}{c}\text { Total } \\
\text { quail }\end{array}$ & $\begin{array}{c}\text { Total hours } \\
\text { pressure }\end{array}$ & $\begin{array}{c}\text { Quail per } \\
100 \text { hours }\end{array}$ & $\begin{array}{c}\text { Cripples lost: } \\
100 \text { quail bagged }\end{array}$ \\
\hline $\begin{array}{l}\text { Nov. 2-24 } \\
\begin{array}{l}\text { Dec. } 21- \\
\text { Jan. } 5\end{array}\end{array}$ & 10 & 18 & 37 & 49 & 28 \\
\hline $\begin{array}{l}\text { Totals } \\
\text { Tats }\end{array}$ & 14 & 32 & 95 & 15 & 29 \\
\hline
\end{tabular}

Table 12. Comparison of estimated population decline as determined by call counts, roadside counts, long-period waterhole counts and hunter success from 1962 to 1963

Index $1962 \quad 1963 \quad \begin{gathered}\text { Percent } \\ \text { difference }\end{gathered}$

Call counts (route basis)

Mean total calls heard

$41 \quad 16 \quad-61$

$\begin{array}{llll}\text { Mean total quail calling } & 7.0 & 2.2 & -68\end{array}$

Roadside counts

$\begin{array}{llll}\text { Pre-breeding (quail-per-mile) } & 0.71 & 0.18 & -78 \\ \text { Post-breeding (quail-per-mile) } & 1.52 & 0.24 & -84\end{array}$

$\begin{array}{llll}\text { Long-period waterhole counts (total quail) } & 245 & 101 & -59\end{array}$

Hunter success (quail:100 gun hours) $\quad 32 \quad 24 \quad-25$ 

The hunter success shown for 1963 was probably atypical from what actually occurred on the west slope of the Beaver Dam Mountains. This could have been a result of bias from the voluntary information recorded by hunters on the questionnaires, but was probably a function of different types of areas being sampled. The various indexes shown in Table 12 were derived from an area which was completely natural. On the other hand, due to the low quail population on the west slope of the Beaver Dam Mountains, most of the few hunters who came to this area in 1963 hunted on two small cultivated ranches along the Beaver Dam Wash. These ranches were known to support greater densities of quail than areas of similar size on the slope. Apparently the populations fluctuated less widely here than where they were dependent solely on natural production of daily requirements. Such a situation was also found by Gullion (1960) in Nevada.

\section{Survival of Young Quail}

\section{Intensive study areas}

The sample size of age-ratio counts in the intensive study areas was poor in 1962 and even worse in 1963. This was a result of low population levels.

There was little indication of better survival in those areas with water (A-2 and B-2). The mediocre sample size does not justify concluding whether water availability did or did not increase survival of young quail in these areas (Tables 30 and 31 ).

The incidence of more quail in the developed areas could have resulted from concentration of quail around available water and resultant ease of observation; however, a great deal of effort was expended attempting to locate quail in the waterless areas ( $A-I$ and $B-I)$. 

General study area

With relation to water. When all broods and age ratios were combined and pooled with relation to distance from water and time, a better indication of the effects of water on survival was obtained, although the sample size still left much to be desired. It appeared from these data, especially in 1962, that water may increase survival of young quail (Fig. 26 and 27). Two possibilities exist which could bias these results: (1) pairs with broods which were occupying areas over one-half mile from water prior to the water-critical period may have moved to water during this period, while those adults without young remained away and (2) adults without young may have ranged farther from water and were more likely to be observed over one-half mile away.

With relation to time. Pooling brood and age ratios on a monthly basis gave an indication of the distribution of juvenile mortality during the summer months (Tables 13 and 14 ). When age ratios were plotted on a semi-logarithmic scale a constant mortality rate was shown (Fig. 28 and 29). Brood size did not decline at a constant rate possibly due to the low sample size.

The incidence of more young per 100 adults in the hunters' bag than in age-ratio counts in both 1962 and 1963 indicated juvenile vulnerability to hunting (Tables 13 and 14). However, chi-square tests of the relative proportions of juveniles bagged during succeeding periods each year proved nonsignificant. (Tables 15 and 16 ).

The relative high proportion of young in the hunters' bag in 1963 was probably due to most of the wings being collected from the cultivated ranches. Here reproduction was better than in natural areas. This may have been the reason for some of the difference in 1962 as well. 



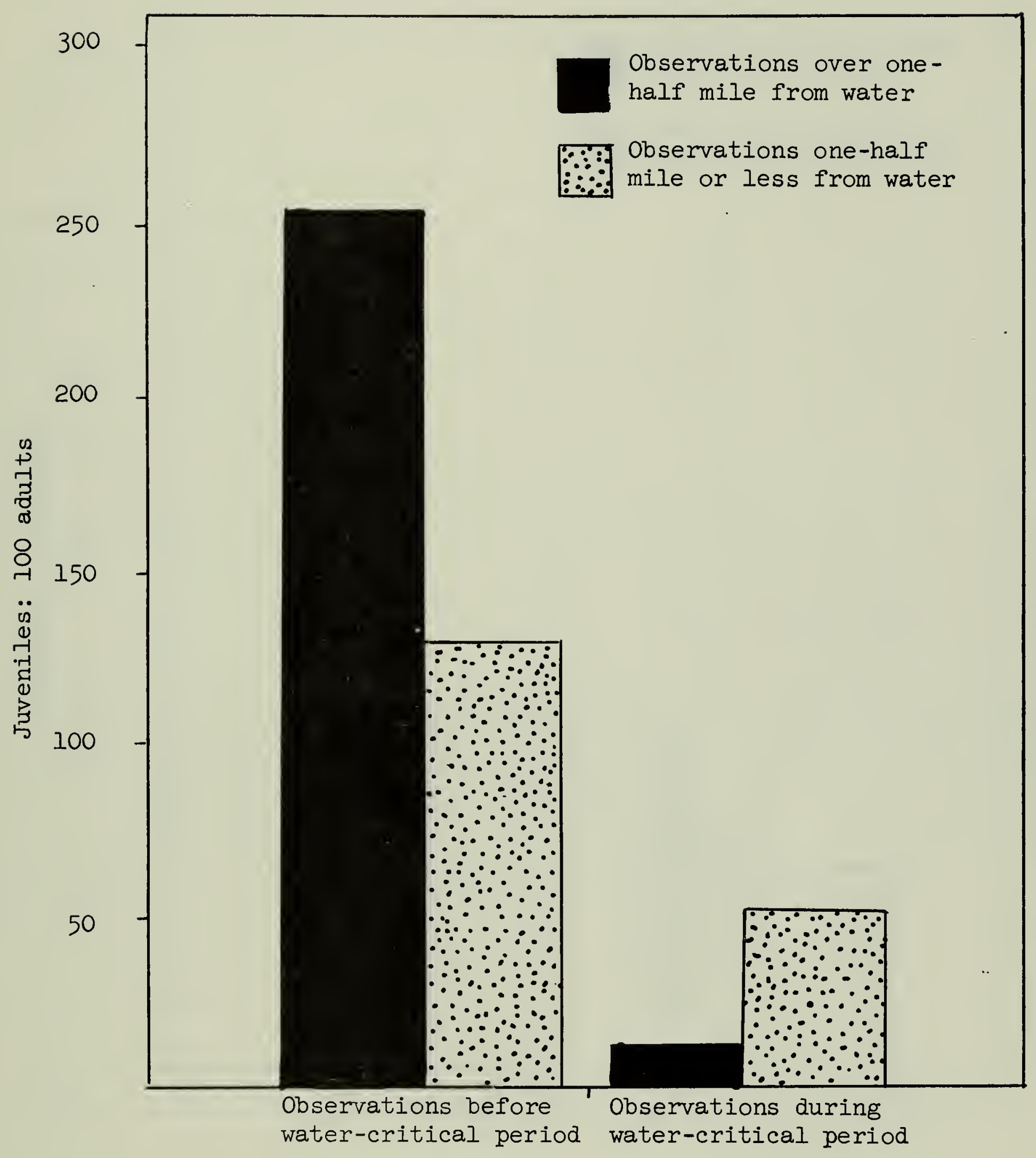

Figure 26. Graph showing the relationship between survival of young quail and distance from available water, 1962 



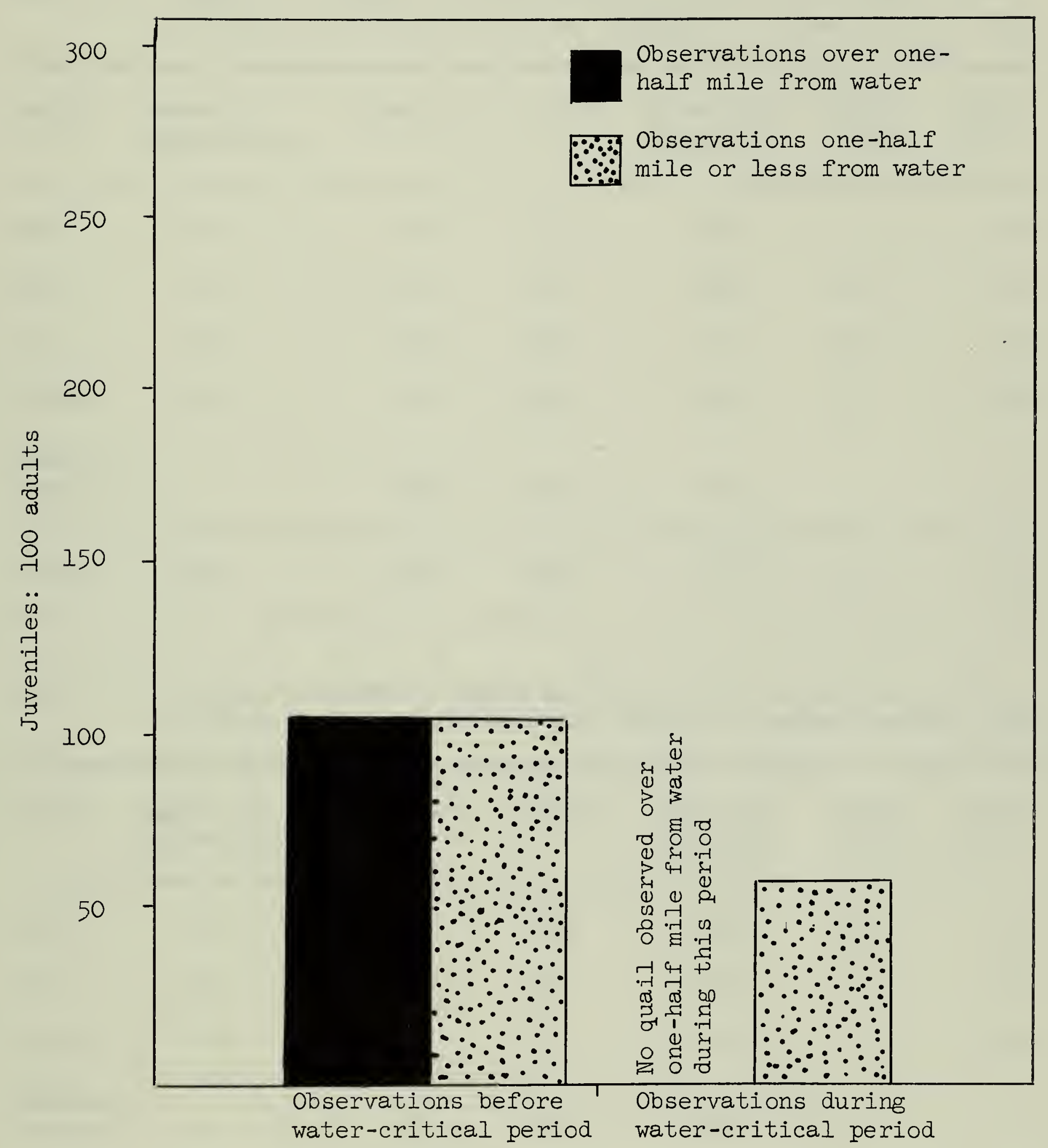

Figure 27. Graph showing the relationship between survival of young quail and distance from available water, 1963 

Table 13. Summary of Gambel's quail monthly brood size and age ratios showing their gradual decline through the summer months, 1962

\begin{tabular}{lcccccc}
\hline \hline Period & $\begin{array}{c}\text { Number of } \\
\text { observations }\end{array}$ & Juveniles & Adults & $\begin{array}{l}\text { Juveniles: } \\
\text { 100 adults }\end{array}$ & $\begin{array}{l}\text { Number } \\
\text { broods }\end{array}$ & $\begin{array}{l}\text { Brood } \\
\text { size }\end{array}$ \\
\hline May & 10 & 85 & 27 & 320 & 5 & 6.6 \\
June & 45 & 167 & 144 & 120 & 18 & 6.2 \\
July & 79 & 147 & 267 & 55 & 26 & 4.0 \\
August & 50 & 84 & 288 & 29 & 14 & 3.5 \\
$\begin{array}{l}\text { Hunting } \\
\text { season }\end{array}$ & -- & 82 & 136 & 60 & -- &.-- \\
\hline \\
Totals
\end{tabular}

Table 14. Summary of Gambel's quail monthly brood size and age ratios showing their gradual decline through the summer months, 1963

\begin{tabular}{|c|c|c|c|c|c|c|}
\hline Period & $\begin{array}{l}\text { Number of } \\
\text { observations }\end{array}$ & Juveniles & Adults & $\begin{array}{l}\text { Juveniles: } \\
100 \text { adults }\end{array}$ & $\begin{array}{l}\text { Number } \\
\text { broods }\end{array}$ & $\begin{array}{l}\text { Brood } \\
\text { size }\end{array}$ \\
\hline June & 27 & 85 & 80 & 106 & 11 & 6.1 \\
\hline July & 26 & 59 & 84 & 70 & 9 & 3.2 \\
\hline August & 19 & 36 & 74 & 49 & 7 & $3 \cdot 7$ \\
\hline $\begin{array}{l}\text { Hunting } \\
\text { season }\end{array}$ & -- & 38 & 28 & 136 & -- & $\ldots$ \\
\hline Totals & 72 & 218 & 266 & 82 & 27 & $4 \cdot 3$ \\
\hline
\end{tabular}





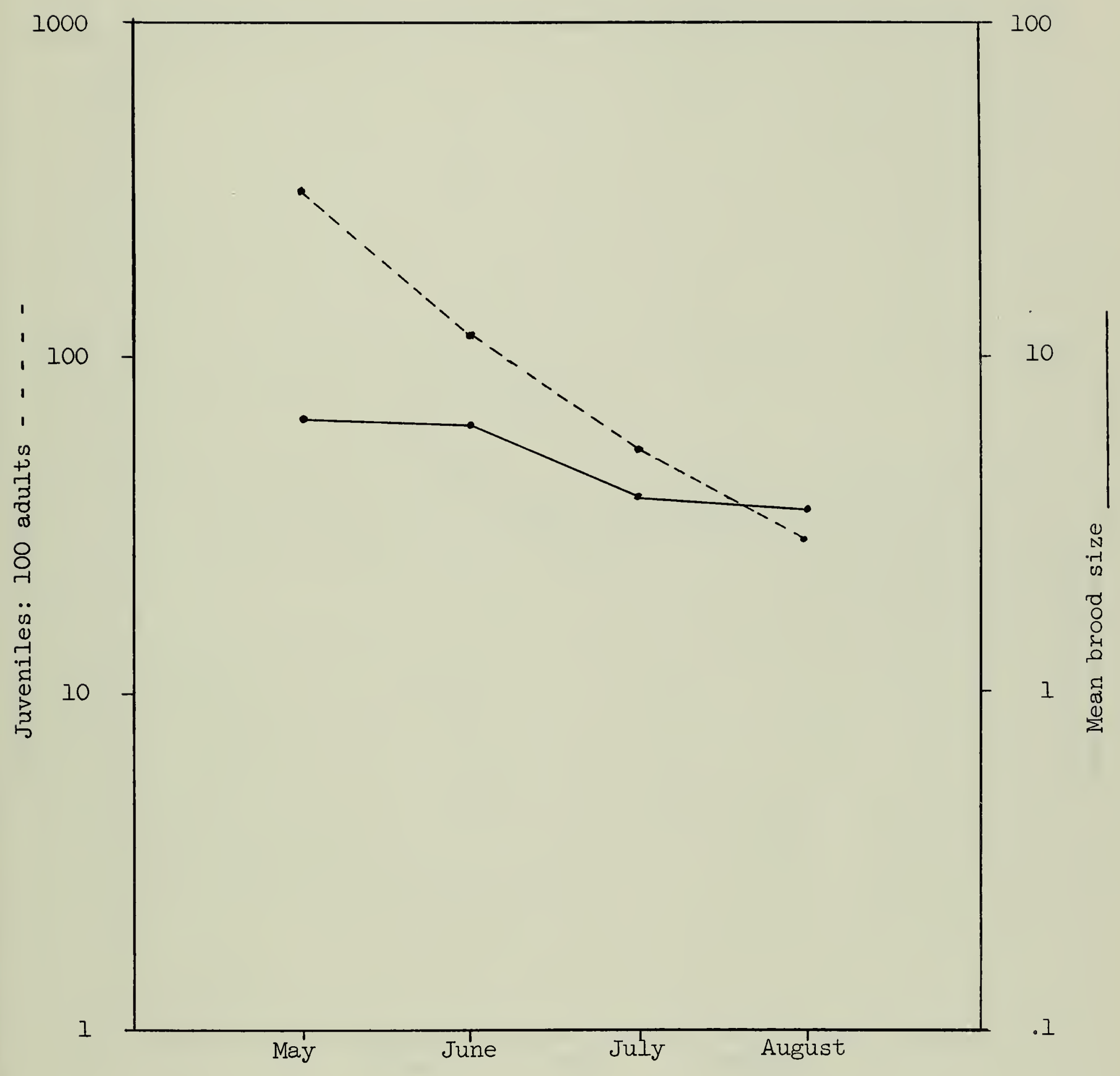

Figure 28. Relationship of mean brood size and age ratios to time, 1962 



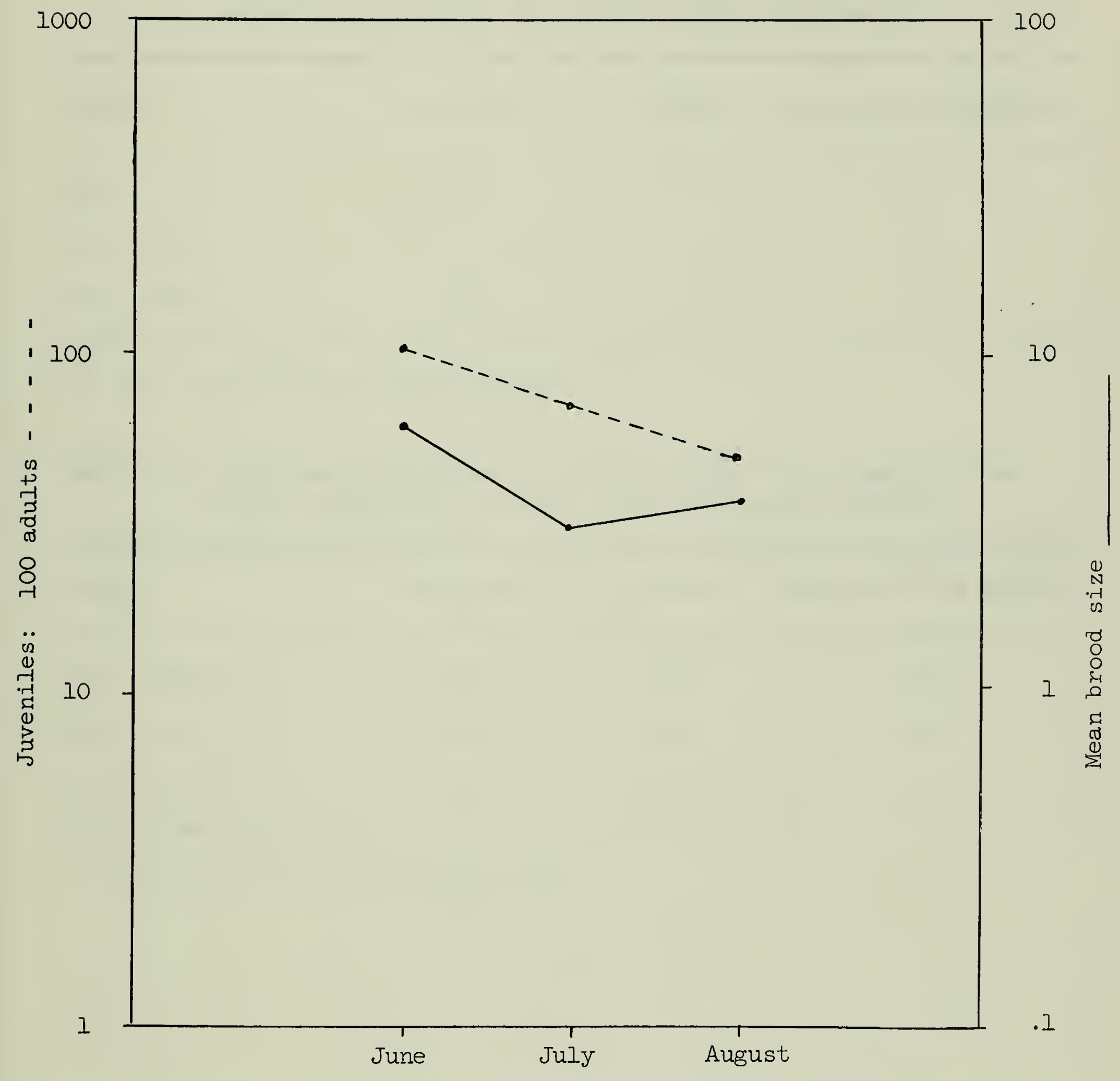

Figure 29. Relationship of mean brood size and age ratios to time, 1963 

Table 15. Relative proportions of juvenile quail in the hunters' bag on succeeding week-ends during the 1961 hunting season

\begin{tabular}{lccc}
\hline \hline Weed-end & Juveniles & Adults & Juveniles: 100 adults \\
\hline Nov. $4-5$ & 24 & 54 & 44 \\
Nov. $25-26$ & 6 & 25 & 24 \\
Dec. $23-24$ & 15 & 57 & 26 \\
\hline
\end{tabular}

$x^{2} .05=2.54(2$ d.f. $)$ nonsignificant

Table 16. Relative proportions of juvenile quail in the hunters' bag during succeeding periods of the 1962 hunting season

\begin{tabular}{lccc}
\hline \hline Period & Juveniles & Adults & Juveniles: 100 adults \\
\hline Oct. $13-16$ & 43 & 58 & 74 \\
Nov. 2-25 & 10 & 22 & 45 \\
Dec. $22-30$ & 29 & 41 & 71 \\
\hline
\end{tabular}

$\mathrm{x}^{2} .05=1.32(2 \mathrm{~d} . \mathrm{f}$.$) nonsignificant$ 



\section{Distribution of Quail}

\section{Intensive study areas}

The distribtuion of quail observed during line-transect counts in the intensive study areas indicated a concentration of quail in the vicinity of water. This concentration was evident even during periods when water was not being utilized. Table 17 lists quail observations relative to water in areas $\mathrm{A}-\mathrm{I}$ and $\mathrm{A}-2$ for all counting periods.

During the September, 1961 counts, a total of 184 quail were observed in area $\mathrm{A}-1$. Of these, 121 ( 66 percent) were one-quarter mile or less from water and 131 (7I percent) were withir three-eighths mile. Area A-2 had 72 total quail during this count of which 68 (94 percent) were within one-quarter and 100 percent within three-eighths mile of available water. No quail were observed in areas B-I and B-2 during pre-development counts .

In April, 1962 a similar pattern was evident. Of 45 total quail in area $A-1,28$ (62 percent) were less than one-quarter mile and 40 (89 percent) less than three-eighths mile from water. No quail were observed in A-2 during this period.

The distribution of quail in area A-I changed entirely after closing the catchments in May, 1962. Instead of concentrating near the water catchments as in the past, the quail observed during the June and September, 1962 counts were all on the edge of the study area over three-eighths mile from water. In fact, many of the observations were on the edge of the area onehalf mile from water. Apparently these quail had stopped orienting their activities around water. During these same counting periods the quail in area A-2 continued to occupy the area within one-quarter mile of the catchments. Of 26 quail observed in June and September, 1962, only three were over this distance and they were within three-eighths mile of water. 



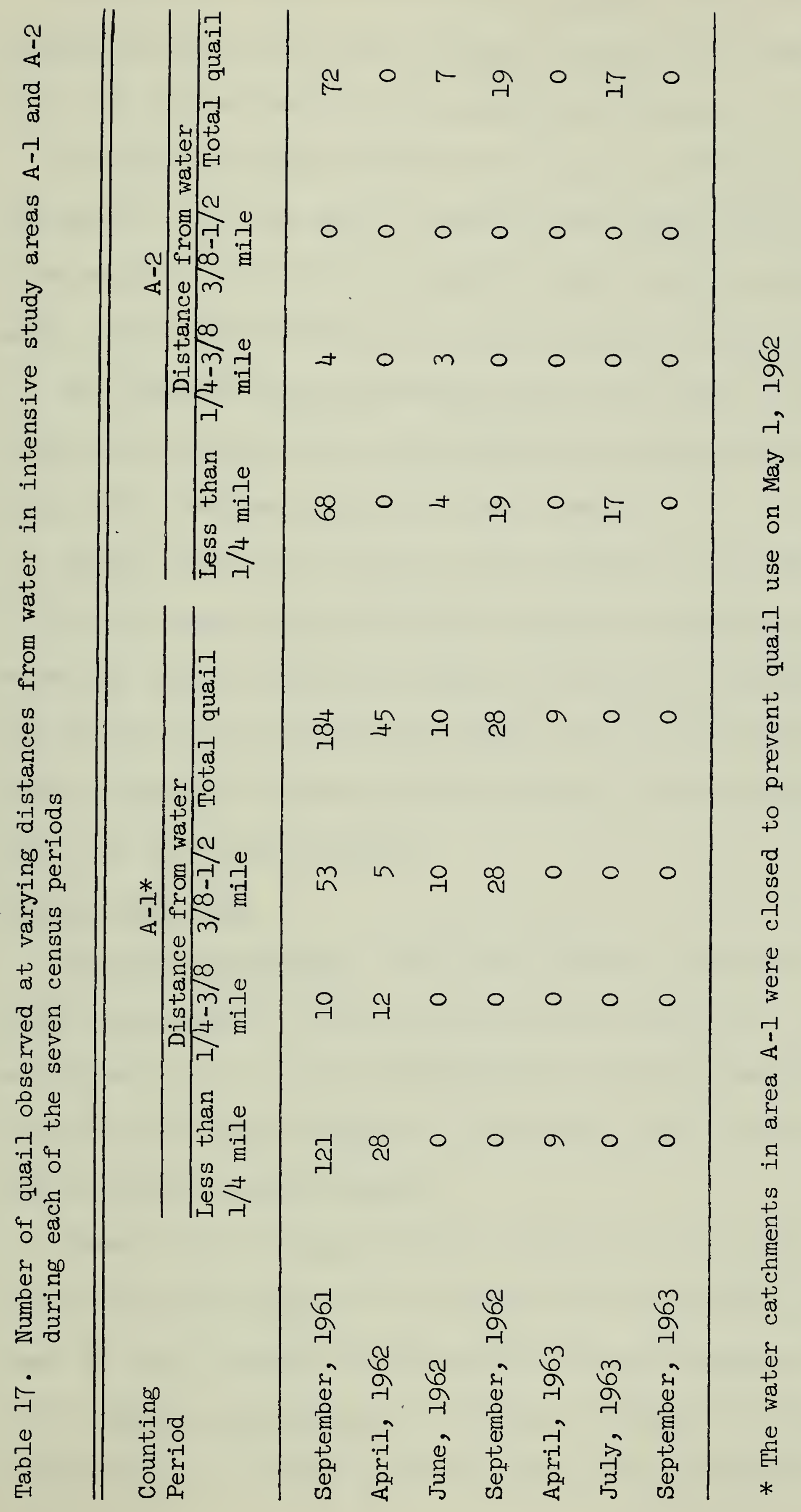



No census was made in B-1 and B-2 in April, 1962. The June and September counts yielded only one quail in area B-1. Area B-2 had 12 quail all of which were in close proximity to water.

The 1963 censuses revealed only 9 quail in area A-l all of which were one-quarter mile from water. Area A-2 had 17 quail which were observed within one-eighth mile of water. Area B-I had no quail as in the past while 18 quail were observed in B-2, all within one-quarter mile of catchments. The population had decreased to such a low level by 1963 in both watered and waterless areas that sampling by any method gave poor results. Those quail obserred were seen close to water.

Though these data show the close orientation of quail around water, it does not negate the possibility of periodic movements away from water especially during the cooler seasons of the year. It was significant that even during the counting periods when quail were not observed to use water, where available, (September and April counts) their pattern of distribution still was one of concentration.

General study area

General observations. Quail were observed throughout the general study area except at elevations above about 5,800 feet. However, they were known to occur above this elevation in other areas and probably do so in the Beaver Dam Mountains. For example, they have been seen at 7,000 feet elevation in Wayne County.

Observations of quail have been made in all vegetation types from the pinyon-juniper down to the creosote-bush--bur-sage. They were usually found in close proximity to dry washes with an abundance of the desertalmond (Prunus fasciculatus), the primary protective cover species. In localized areas at higher elevations this was supplemented or replaced as 

protective cover by squaw-bush (Rhus trilobata), live-oak (Quercus turbinella), or Apache-plume (Fallugia paradoxa). The vegetation types where greatest abundance of quail occurred is discussed in the section concerning habitat evaluation.

When quail covey observations were plotted on a map of the study area, it was found that in 196272 percent of 249 observations recorded were made within one-half mile of water. In 196367 percent of 91 observations were made within one-half mile. Many of the observations in both years over one-half mile from water were only slightly farther away: Observations are included for all seasons of the year (Figures 30 and 31 ). $\underline{\text { Call counts }}$

Call-count data were further analyzed to show the relationship of quail abundance to distribution of water (Table 18) and habitat quality (Table 19). Analysis of variance tests of these data showed that habitat quality had a significant effect on calling intensity while water had an insignificant effect.

\section{Quail Movements}

\section{Trapping success}

A high rate of trapping success was experienced using water as bait, averaging 8, 10 and 10 quail captured per trap day in 1961, 1962 and 1963 respectively. When using wheat as bait the success was three and 0.7 quail per trap day in 1961 and 1962 respectively.

Trap mortality was low with only 11 mortalities occurring among 685 captured quail. Ten of these took place in 1961; three from predation, one of apparent shock, one from scalping and five due to excessive exposure to high temperatures. The latter instance occurred using wheat as bait. 



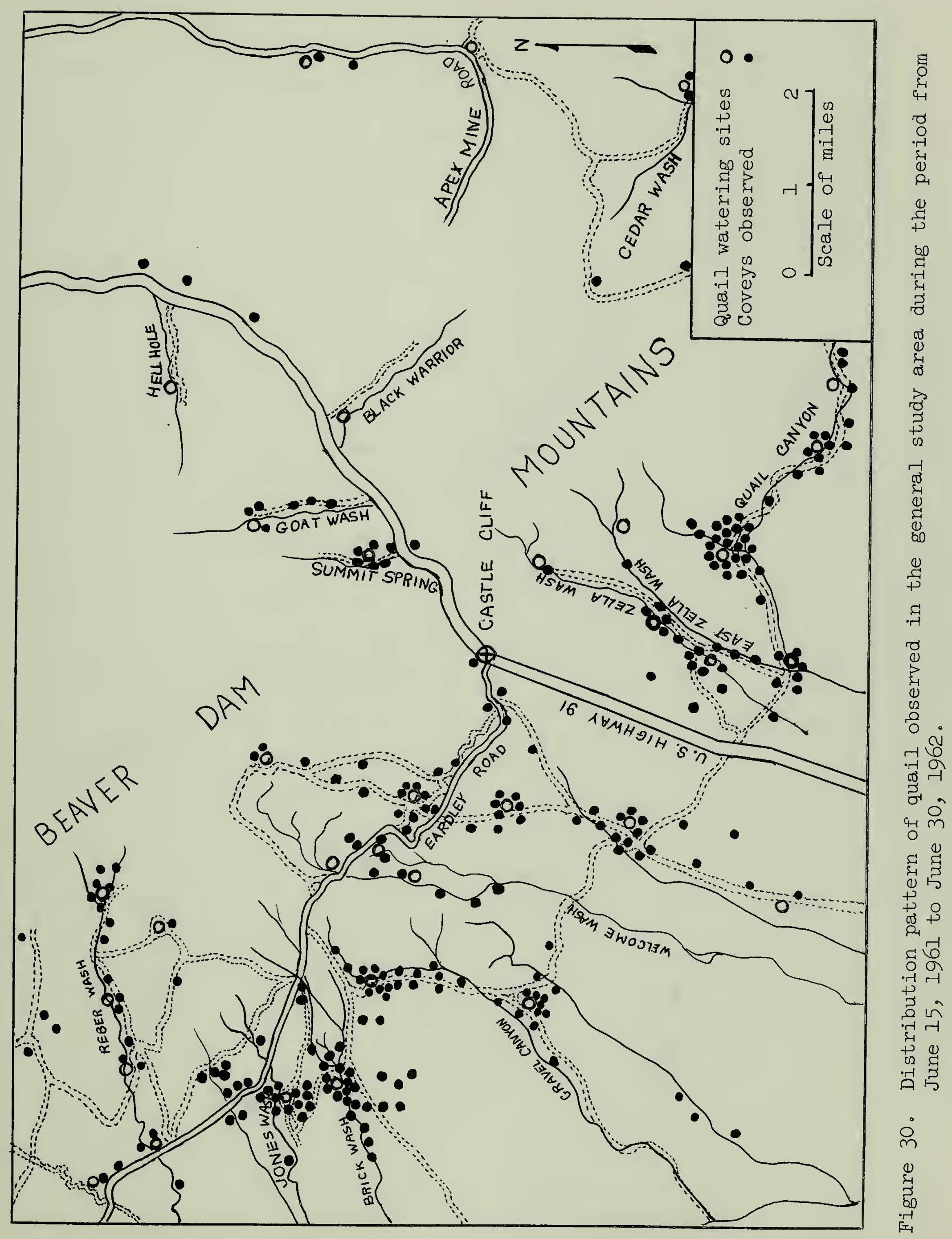





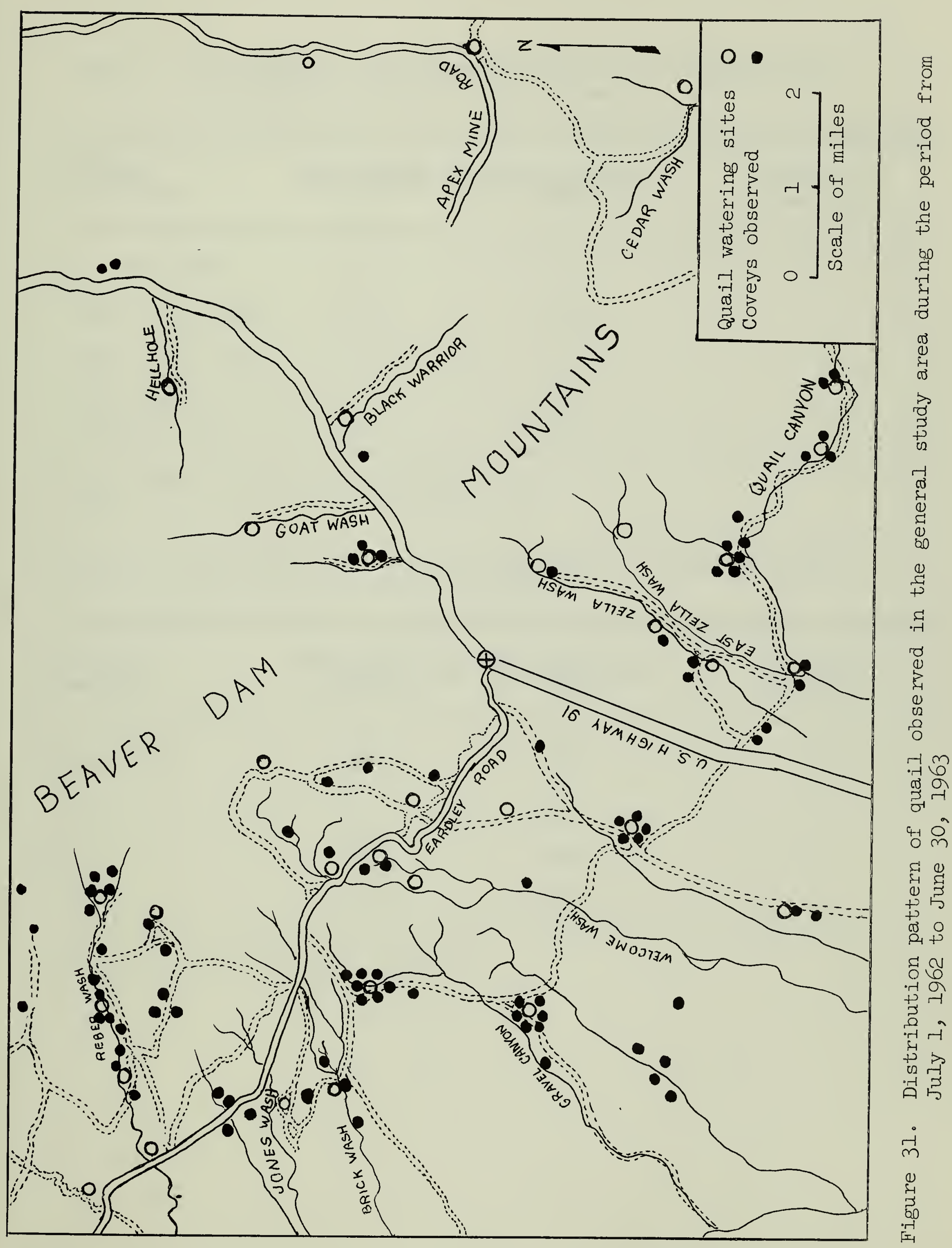



Table 18. Mean number of quail heard calling for stations pooled according to distance from free water

\begin{tabular}{|c|c|c|c|}
\hline $\begin{array}{l}\text { Distance } \\
\text { from water }\end{array}$ & \multicolumn{2}{|c|}{$\frac{\text { Mean number of quail calling }}{1962}$} & $\begin{array}{l}\text { Number of } \\
\text { stations }\end{array}$ \\
\hline $0-0.25$ miles & 0.45 & 0.12 & 5 \\
\hline $0.25-0.50$ miles & 0.50 & 0.14 & 3 \\
\hline $0.50-1.00$ miles & 0.36 & 0.15 & 6 \\
\hline over one mile & 0.33 & 0.25 & 1 \\
\hline \multicolumn{4}{|c|}{$F_{.05}=.1695(3,22$ a.f.) nonsignificant } \\
\hline \multicolumn{4}{|c|}{$\begin{array}{l}\text { Table 19. Mean number of quail heard calling for stations pooled } \\
\text { on the basis of habitat quality }\end{array}$} \\
\hline $\begin{array}{l}\text { Quality } \\
\text { rating }\end{array}$ & $\frac{\text { Mean num }}{1962}$ & $\frac{1 \text { calling }}{1963}$ & $\begin{array}{l}\text { Number of } \\
\text { stations }\end{array}$ \\
\hline Very good & 0.68 & 0.22 & 5 \\
\hline Good & 0.58 & 0.17 & 5 \\
\hline Fair & 0.08 & 0.06 & 4 \\
\hline Poor & 0.08 & 0.00 & 1 \\
\hline
\end{tabular}

$$
\mathrm{F}_{.05}=4.39(3,22 \text { d.f.) significant }
$$


The birds were unavoidably left in a trap exposed to direct sunlight for about five hours. When found, all five birds we re sitting in individual depressions as though seeking the coolness of the ground. There was no sign of violent death. Quail left in traps using water as bait, where the plants used for shade had blown away, apparently were able to avoid harmful effects of high temperature by drinking from the water pan in the trap.

A total of 457 quail were banded over the period of study. Colored neck tags were applied to 284 of those banded.

There was considerable tendency for birds to be recaptured. Many were retrapped each time a particular trap was set after their original date of capture. During the three years 227 recaptures were made (Table 20). $\underline{\text { Band returns }}$

It was anticipated that considerable data would be available from hunter-harvested banded and marked birds. This however, failed to materialize apparently due to such a small portion of the population being harvested. Of the 457 banded and marked quail available for harvest over the three year period, only 16 or three percent were returned by hunters. If only one-fourth of crippled or bagged banded quail were reported, this would indicate that not more than about $12-15$ percent of the population was being harvested by sportsmen.

The average movement of hunter-harvested birds, was one mile (Table 33). There was no difference in mean movements between quail banded in the intensive study areas and at other trap sites. Extreme movements of hunter bagged quail were from zero to two miles from banding sites. Four were harvested near their original trap sites and two at a distance of two miles. Seven of the known distances were one and one-half miles or more. 

Table 20. Summary of trapping success during 1961, 1962 and 1963

\begin{tabular}{lcccc}
\hline \hline Data & 1961 & 1962 & 1963 & Totals \\
\hline Trap days & 47 & 41 & 6 & 94 \\
Quail captured & 397 & 226 & 62 & 685 \\
Quail recaptured & 94 & 97 & 26 & 227 \\
Quail banded & 293 & 128 & 36 & 457 \\
Quail banded and marked & 132 & 116 & 36 & 284 \\
Mortalities & 10 & 1 & 0 & 11 \\
Quail captured per trap-day & 8 & 6 & 10 & 8 \\
\hline
\end{tabular}



Marked quail observations

Marked quail were observed on 27 occasions during this study. A total of 51 marked quail were seen with as many as six marked birds being observed in a single covey.

The average movement of about one-half mile as determined by these observations was only two-thirds that determined from band returns (Table 34). The probable reason for this was the fact that most of these observations were made during the presumably water-critical period whereas hunterbagged birds were taken during a time when water was not being used.

Extreme movements ranged from zero to three miles. Thirteen observations were made at original trap sites and six were one and one-half miles or more away. The two most extreme movements noted were of quail originally marked (August, 196I) at Jones Catchment No. 2 in replication I of area $\mathrm{A}-1$. Both sightings occurred in August of 1962, well after the closure of that catchment. One of the birds had moved three miles eastward to the Reber Spring stock-watering tank and the other moved two miles southeast to Gravel Canyon Catchment No. I in replication I, area A-2. It was unknown if these quail made this move before or after the catchment closure, but the possibility existed that they made their respective movements in search of water.

of 49 birds seen in 26 observations, 10 had apparently changed water catchments. However, included here are the two exchanges after closure of the catchment at their original trapsite. Two others were observed at a new catchment, installed in september, 1961, one mile northwest of their original trap site.

The longest movement in a short time period was that of a juvenile bird banded and marked August 16, 1962 at Quail Canyon Catchment No. 4. 

It was observed early the next morning, one and one-half miles away, feeding in the vicinity of East Zella Wash Catchment No. 2. It did not water at the latter catchment that morning. Whether it returned to Quail Canyon No. 4 was problematical.

\section{Retrapped quail}

of 226 recaptures of previously marked quail only one occurred at a water catchment other than where originally trapped. It was banded at Gravel Canyon Catchment No. 2 in area A-2 on July 30, 1962 and recaptured on August 13, 1962 at Gravel Canyon Catchment No. 1, one and one-half miles away .

\section{Longevity}

The longest time period elapsing between original trapping date and retrapping, observation, or harvest of banded or marked quail was 25 months. This bird was an adult male banded originally at Gravel Canyon Catchment No. 2 in June or July of 1961 and recaptured there in August of 1963. The exact identity of this bird was not known because of one digit in its band being worn beyond recognition. Most of the retrapping occurred within a few days of the original trap date. Eleven of the 26 marked quail observations occurred about one year after marking. The maximum longevity of hunter-harvested banded birds was five months. 



\section{Habitat Evaluation}

Intensive study areas

Areas $\mathrm{A}-1$ and $\mathrm{A}-2$. Vegetation analysis proved these areas to be less similar than was originally assumed. Differences also became apparent with increasing familiarity as a result of routine travel throughout both areas by foot, horseback and vehicle. The distribution pattern of vegetation was found to vary within as well as between areas. This was especially true in area A-2 where topography was most diverse. Variations in plant distribution usually consisted of concentration of particular species on apparently more favorable sites and were not conducive to cover mapping. The general physiognomy of both areas was one of almost complete heterogeneity.

Species composition of overstory vegetation was similar, but the relative abundance of species was quite different. The fact that some species were not encountered in a particular area was probably because of low abundance rather than absence. In fact, it is doubtful if any one species was limited to a single area since no abrupt changes from one type to another occurred in the vegetation belt which these study areas occupied (Table 2l).

Overstory species are listed in order of abundance in each area as follows:

$$
\underline{A-1}
$$

Coleogyne ramosissima Thamnosma montana Larrea divaricata Yucca baccata Krameria parviflora Ephedra nevadensis Acamptopappus spaerocephalus Lycium andersonii Yucca revifolia Opuntia acanthocarpa Prunus fasciculatus

\section{$\underline{A-2}$}

Coleogyne ramosissima

Larrea divaricata

Franseria dumosa

Thamnosma montana

Ephedra nevadensis

Yucca brevifolia

Acamptopappus spaerocephalus

Prunus fasciculatus

Krameria parviflora

Gutierrezia sarothrae

Lycium andersonii 

Table 2l. Relative coverage of shrubs, cacti and yucca in areas A-I and A-2 as determined by line-intercept transect and rectangular plot vegetation analysis in 1962 and 1963

\begin{tabular}{|c|c|c|c|c|}
\hline \multirow[t]{2}{*}{ Species } & \multicolumn{2}{|c|}{ Area $A-1$} & \multicolumn{2}{|c|}{ Area A-2 } \\
\hline & $\begin{array}{l}\text { Percent } \\
\text { ground } \\
\text { coverage }\end{array}$ & $\begin{array}{l}\text { Percent } \\
\text { of veg- } \\
\text { etative } \\
\text { cover }\end{array}$ & $\begin{array}{l}\text { Percent } \\
\text { ground } \\
\text { coverage }\end{array}$ & $\begin{array}{l}\text { Percent } \\
\text { of veg- } \\
\text { etative } \\
\text { cover }\end{array}$ \\
\hline \multicolumn{5}{|l|}{ Shrubs } \\
\hline Coleogyne ramosissima & $3 \cdot 59$ & 20.0 & 7.25 & 39.8 \\
\hline Thamnosma montana & 3.45 & 19.1 & 1.21 & 6.6 \\
\hline Larrea divaricata & 2.72 & 15.1 & 2.49 & $13 \cdot 7$ \\
\hline Krameria parviflora & 1.21 & 6.6 & 0.38 & 2.1 \\
\hline Ephedra nevadensis & 1.10 & 6.1 & 1.17 & 6.4 \\
\hline Acamptopappus spaerocephalus & 0.90 & 4.9 & 0.95 & 5.2 \\
\hline Lycium andersonii & 0.67 & $3 \cdot 7$ & 0.30 & 1.6 \\
\hline Prunus fasciculatus & 0.42 & $2 \cdot 3$ & 0.90 & 4.9 \\
\hline Hymenoclea salsola & 0.30 & 1.7 & -- & -- \\
\hline Franseria dumosa & 0.20 & 1.1 & 1.29 & 7.1 \\
\hline Psilostrophe cooperi & 0.10 & 0.6 & -- & -- \\
\hline Encelia frutescens & 0.09 & 0.5 & 0.06 & 0.3 \\
\hline Gutierrezia sarothrae & 0.04 & 0.2 & 0.34 & 1.9 \\
\hline Salazaria mexicana & 0.04 & 0.2 & 0.04 & 0.2 \\
\hline Dalea fremontii & 0.01 & 0.1 & 0.11 & 0.6 \\
\hline Chrysothamnus paniculatus & - & -- & 0.15 & 0.8 \\
\hline Eriogonum fasciculatum & -- & -- & 0.14 & 0.8 \\
\hline Salvia pilosa & -- & -- & 0.07 & 0.4 \\
\hline Aster abatus & -- & -- & 0.07 & 0.4 \\
\hline Lepidium fremontii & -- & -- & 0.01 & 0.1 \\
\hline Artemisia Iudoviciana & -- & -- & trace & trace \\
\hline \multicolumn{5}{|l|}{ Cacti and yucca } \\
\hline Yucca baccata & 2.14 & 11.9 & 0.18 & 1.0 \\
\hline Yucca brevifolia & 0.62 & 3.4 & 1.07 & 5.9 \\
\hline Opuntia acanthocarpa & 0.46 & 2.5 & 0.04 & 0.2 \\
\hline Opuntia basilaris & trace & trace & trace & trace \\
\hline
\end{tabular}



Hymenoclea salsola

Franseria dumosa
Yucca baccata

Chrysothamnus paniculatus

The most conspicuous differences between these areas were the greater abundance of black-brush (Coleogyne ramosissima) and bur-sage (Franseria dumosa) in area $\mathrm{A}-2$ and the preponderance of turpentine-broom (Thamnosma montana), banana yucca (Yucca baccata), ratany (Krameria parviflora) and wolfberry (Lycium andersonii) in area $A-1$. Also the aspect of area $A-1$ was more heterogeneous in that no one species was as abundant as black-brush in $\mathrm{A}-2$.

When " $t$ ".05 tests were made of the difference between the means of black-brush and turpentine-broom in each area, it was found that these differences were highly significant. Inspection of data in Table 21 indicated that the abundance of Krameria parviflora, Lycium andersonii, Franseria dumosa, Yucca baccata, Yucca brevifolia, and Opuntia acanthocarpa was at least significantly different.

With respect to protective cover along the center-line wash, area A-2 had about twice as much desert-almond as A-I; however, this species was relatively abundant in the latter area. Also rabbit-brush was more abundant along the wash in area $\mathrm{A}-2$ (Table 2l).

Virtually all of the herbaceous understory vegetation consisted of annual forbs and grasses. Scattered clumps of perennial bunch grasses persisted only where protected from grazing livestock, such as under the cover of shrubs. The annuals occurred only after growth inducing rains in fall and spring. During the dry months (July and August) of each year no succulent annual vegetation was present.

The first plants to appear following periods of precipitation were filaree (Erodium cicutarium) and spurge (Euphorbia albomarginata). These 

were observed to grow whenever moisture was sufficient. Most other annual forbs were observed only in spring.

The distribution and abundance of the various annual plants varied within and between study areas as well as from one year to the next. As in the case of overstory vegetation, few if any species occurred in only one area. The difference in abundance of species with relation to both space and time was largely a function of variation in amounts of precipitation. The most prominent species of annual forbs in order of abundance in each area for each year of study were:

1962

\section{$\underline{A-1}$}

Erodium cicutarium Astragalus nuttallianus Gilia leptomeria Lepidium lasiocarpum Pectocarya setosa Descurainia sophia Eriogonum inflatum

1963

\section{$\underline{A-1}$}

Erodium cicutarium Astragalus nuttallianus Eriophyllum wallacei Eriogonum maculatum Plantago purshii Baileya multiradiata

$\underline{A-1}$

Erodium cicutarium Astragalus nuttallianus Gilia leptomeria Plantago purshii Lepidium lasiocarpum Descurainia sophia Lesquerella gordoni
$\underline{A-2}$

Erodium cicutarium Gilia leptomeria Eriophyllum wallacei Astragalus nuttallianus Lepidium lasiocarpum Descurainia sophia Eriogonum inflatum 

Table 22 shows all forbs and grasses found in areas A-1 and A-2. Filaree was by far the most abundant species present each year. In 1962 and 1963 it was most dense in area A-2, but in 1964 it was most abundant in A-1. The dwarf milk-vetch (Astragalus nuttallianus) density was greatest in area A-1 in 1962 and 1964 and in A-2 during 1963. Of the other common annuals, sand pepper-grass (Lepidium lasiocarpum), comb-bur (Pectocarya setosa), tansy-mustard (Desurainia sophia), bladder-stem (Eriogonum inflatum), woolly-daisy (Eriophyllum wallacei), and bladder-pod (Lesquerella gordoni) showed a similar pattern of shifting greatest density from one area to the other; however, their changes vere not consistent with abundance of moisture. With these less abundant species the number of plots measured may have been insufficient to accurately depict their true relative abundance.

The difference in the means of filaree were highly significant all three years, while those of dwarf milk-vetch were highly significant in 1962 and 1964, but were not significant in 1963 at the "t".05 confidence level.

The relative ability of these areas to produce annual plants may have been shown during the spring of 1963. Precipitation during the preceeding winter had been approximately equal in amount ( 3.21 inches in $\mathrm{A}-1 ; 3.01$ inches in $\mathrm{A}-2$ ) and occurred at the same times in both areas. During the vegetation surveys in May, area A-2 yielded 15 species of annual forbs compared to 9 in $\mathrm{A}-1$. Of the seven species common to both areas, three were most abundant in $\mathrm{A}-1$, three in $\mathrm{A}-2$ and one was of equal abundance. Eight species were encountered in $A-2$ that were not found in $A-1$, while two were seen in $\mathrm{A}-1$ that were not observed in A-2. Of the annual grasses, red brome (Bromus rubens) was of greater abundance in A-1 than in A-2 while 

Table 22. Relative density (plants per square foot) of forbs and grasses in areas $\mathrm{A}-1$ and $\mathrm{A}-2$ as determined by rectangular plot vegetation analysis in 1962, 1963 and 1964.

Species

$$
\frac{1962}{\mathrm{~A}-1 \mathrm{~A}-2} \frac{1963}{\mathrm{~A}-1 \mathrm{~A}-2} \frac{1964}{\mathrm{~A}-1 \mathrm{~A}-2}
$$

Forbs

Erodium cicutarium

Astragalus nuttallianus

Gilia leptomeria

Lepidium lasiocarpum

Pectocarya setosa

Descurainia sophia

Eriogonum inflatum

Phacelia fremontii

Cryptantha nevadensis

Eriophyllum wallacei

Amsinckia tessellata

Lesquerella gordoni

Baileya multiradiata

Eriogonum maculatum

Plantago purshii

Gilia polycladon

Plantago insularis

Sphaeralcea grossulariaefolia Chorizanthe brevicornu

Chorizanthe rigida
2.80

0.12

0.08

0.04

0.03

0.01

0.01

0.008

0.008

0.005

0.003

0.003

0.002

--

$--$

$-$

$-$

$-$

$-$

$-$
4.60

0.05

0.10

0.02

0.003

0.02

0.02

0.28

0.46

1.02

0.46

0.025

0.042

0.38

0.045

-- 0.004

--

0.007

0.04

0.017

0.013

0.025

$-$

0.002

0.003

0.02

$--$

0.002

0.012

0.005

$--$

0.029

0.002

$--$

--

0.06

$--$

--

$--$

-.

0.007

0.004

0.005

-.

$--$

0.002

--

0.012

$--$

0.012

0.002

0.002

0.002

0.005

0.002

--

0.002

0.017

$--$

0.004

0.002

0.002

0.002

0.06

0.002

0.002

0.002

--

$0 .-002$

0.002

$-$

\section{Grasses}

Bromus rubens

Schismus barbatus

Tridens pulchella

Hilaria jamesii

$\begin{array}{ccccc}9.03 & 4.00 & 2.12 & 0.78 & \text { Not } \\ 0.01 & 0.30 & -- & 0.03 & \text { measured in } \\ -- & -- & 0.01 & 0.02 & 1964 \\ -- & -- & 0.002 & 0.002 & \end{array}$



the reverse was true of Mediterranean grass ( grass (Tridens pulchella). The greater abundance of red brome in A-I may have been detrimental to the production of annual forbs, and thus accounted for the greater densities of filaree and dwarf milk-vetch in area A-2 during this period.

There were only slight differences between areas $A-1$ and $A-2$ with regard to maximum and minimum temperatures. It was found that variations within each area were as great as between them. On most occasions differences amounted to only one to three degrees. The widest variation within an area occurred in May of 1963 when the maximum in replication I of area A-I was eight degrees higher than in replication II. The widest variation between areas was seven degrees in replication II during October, 1963 with A-2 being the hottest. No set pattern of variation was apparent except perhaps that area $\mathrm{A}-\mathrm{I}$ tended to have the highest maximums during June and July, the hottest months.

Precipitation varied considerably within and between areas. It was not uncommon for rain showers to cover a strip one mile or less in width, especially in early fall. The winter rains were usually more widespread but still the distribution of precipitation was uneven over the area. During the 15-month measuring period the total precipitation at the four stations in areas $A-1$ and $A-2$ varied from 2.93 to 4.51 inches. Replication I in area $A-2$ received the most rainfall ( 4.51 inches). This was possibly due to its location at the base of a high rocky ridge which extended about 500-1000 feet above the area. The amount of rainfall in the other three replications was more equal (Table 35).

$\underline{\text { Areas }} \underline{B-1}$ and $\underline{B-2}$. Overstory vegetation in these areas proved to be quite similar. The order of abundance of the most common shrubs, cacti and yucca in each area was as follows: 



\section{$\underline{B-1}$}

Coleogyne ramosissima

Thamnosma montana

Prunus fasciculatus

Purshia glandulosa

Yucca baccata

Ephedra nevadensis

Gutierrezia sarothrae

Yucca brevifolia

Eriogonum fasciculatum

Dalea fremontii

Larrea divaricata

Salazaria mexicana
$\underline{B-2}$

Coleogyne ramosissima

Thamnosma montana

Larrea divaricata

Gutierrezia sarothrae

Yucca brevifolia

Yucca baccata

Prunus fasciculatus

Ephedra nevadensis

Hymenoclea salsola

Salazaria mexicana

Eriogonum fasciculatum

Artemisia tridentata

Black-brush was the most abundant shrub in both areas. In area B-I it constituted 17.7 percent of the total ground cover and 64.5 percent of the total canopy cover, while in B-2 these percentages were 16.9 and 63.2 respectively. Using a " $t$ ".05 test of the difference between the means of the two areas, it was found that no significant difference existed between the abundance of black-brush or turpentine-broom in the two areas. Those species in which a significant difference probably existed included:

desert-almond (Prunus fasciculatus), bitter-brush (Purshia glandulosa), snake-week (Gutierrezia sarothrae), indigo-bush (Dalea fremontii), creosotebush (Larrea divaricata), burro-brush (Hymenoclea salsola) and Joshua-tree (Yucca brevifolia). The high incidence of snake-weed in B-2 was a result of one transect line having passed through a burned area in the southeast corner of this study area which was dominated by that species (Table 23). Though the relative abundance of several species proved to be significantly different, their coverage, five percent or less of the vegetative ground cover, was such that their influence on quail was probably negligible.

In general, the physiognomy of these areas, with the exception of the burned area in B-2, was similar. There was some concentration of blackbrush into relatively pure stands, especially in the north half of both areas. The most conspicuous difference was in the greater abundance of 

Table 23. Relative coverage of shrubs, cacti and yucca in areas B-I and B-2 as determined by line-intercept transect and rectangular plot vegetation analysis in 1962 and 1963

\begin{tabular}{|c|c|c|c|c|}
\hline \multirow[t]{2}{*}{ Species } & \multicolumn{2}{|c|}{ Area B-1 } & \multicolumn{2}{|c|}{ Area B-2 } \\
\hline & $\begin{array}{l}\text { Percent } \\
\text { ground } \\
\text { coverage }\end{array}$ & $\begin{array}{l}\text { Percent } \\
\text { of veg- } \\
\text { etative } \\
\text { cover }\end{array}$ & $\begin{array}{l}\text { Percent } \\
\text { ground } \\
\text { coverage }\end{array}$ & $\begin{array}{l}\text { Percent } \\
\text { of veg- } \\
\text { etative } \\
\text { cover }\end{array}$ \\
\hline \multicolumn{5}{|l|}{ Shrubs } \\
\hline Coleogyne ramosissima & $17 \cdot 70$ & 64.5 & 16.90 & $63 \cdot 2$ \\
\hline Thamnosma montana & 2.60 & 9.5 & 2.00 & $7 \cdot 5$ \\
\hline Prunus fasciculatus & $1 \cdot 58$ & 5.8 & 0.50 & 1.9 \\
\hline Purshia glandulosa & 1.40 & 5.1 & 0.05 & 0.2 \\
\hline Ephedra nevadensis & 0.60 & 2.2 & 0.50 & 1.9 \\
\hline Gutierrezia sarothrae & 0.46 & 1.7 & 1.24 & 4.6 \\
\hline Eriogonum fasciculatum & 0.39 & 1.4 & 0.22 & 0.8 \\
\hline Dalea fremontii & 0.38 & 1.4 & trace & trace \\
\hline Larrea divaricata & 0.36 & $1 \cdot 3$ & 1.56 & 5.8 \\
\hline Salazaria mexicana & 0.35 & 1.3 & 0.34 & 1.3 \\
\hline$\overline{\text { Lycium andersonii }}$ & trace & trace & 0.10 & 0.4 \\
\hline Hymenoclea salsola & -- & -- & 0.50 & 1.9 \\
\hline Artemisia tridentata & -- & -- & 0.22 & 0.8 \\
\hline Acamptopappus spaerocephalus & -- & -- & 0.20 & 0.7 \\
\hline Krameria parviflora & -- & -- & 0.10 & 0.4 \\
\hline \multicolumn{5}{|l|}{ Cacti and Yucca } \\
\hline Yucca baccata & 1.06 & $3 \cdot 9$ & 1.15 & $4 \cdot 3$ \\
\hline Yucca brevifolia & 0.46 & 1.7 & 1.18 & 4.4 \\
\hline Echinocereus engelmannii & 0.10 & 0.4 & -- & -- \\
\hline Opuntia acanthocarpa & 0.01 & 0.1 & trace & trace \\
\hline Opuntia basilaris & trace & trace & -- & -- \\
\hline Mammillaria chlorantha & trace & trace & -- & -- \\
\hline
\end{tabular}



bitter-brush in B-1. Both areas were much more homogeneous in appearance than were areas $A-1$ and $A-2$.

The greatest difference between areas $B-1$ and $B-2$ was in the abundance of annual forbs. In 1962 only three species were found in B-I and ten in B-2. In 1963 and 1964 five and six, and 12 and 15 species were found respectively in each area. The order of abundance of the most common species in each area for each year of study was:

1962

$\underline{B-1}$

Erodium cicutarium

Eriastrum sparsiflorum

Astragalus nuttallianus

$\underline{B-1}$

Erodium cicutarium

$\underline{B-I}$

Erodium cicutarium

Astragalus nuttallianus

Cryptantha circumcissa

Eriophyllum wallacei

Lesquerella gordoni
$\underline{B-2}$

Erodium cicutarium Gilia leptomeria Euphorbia albomarginata Cryptantha nevadensis

1963

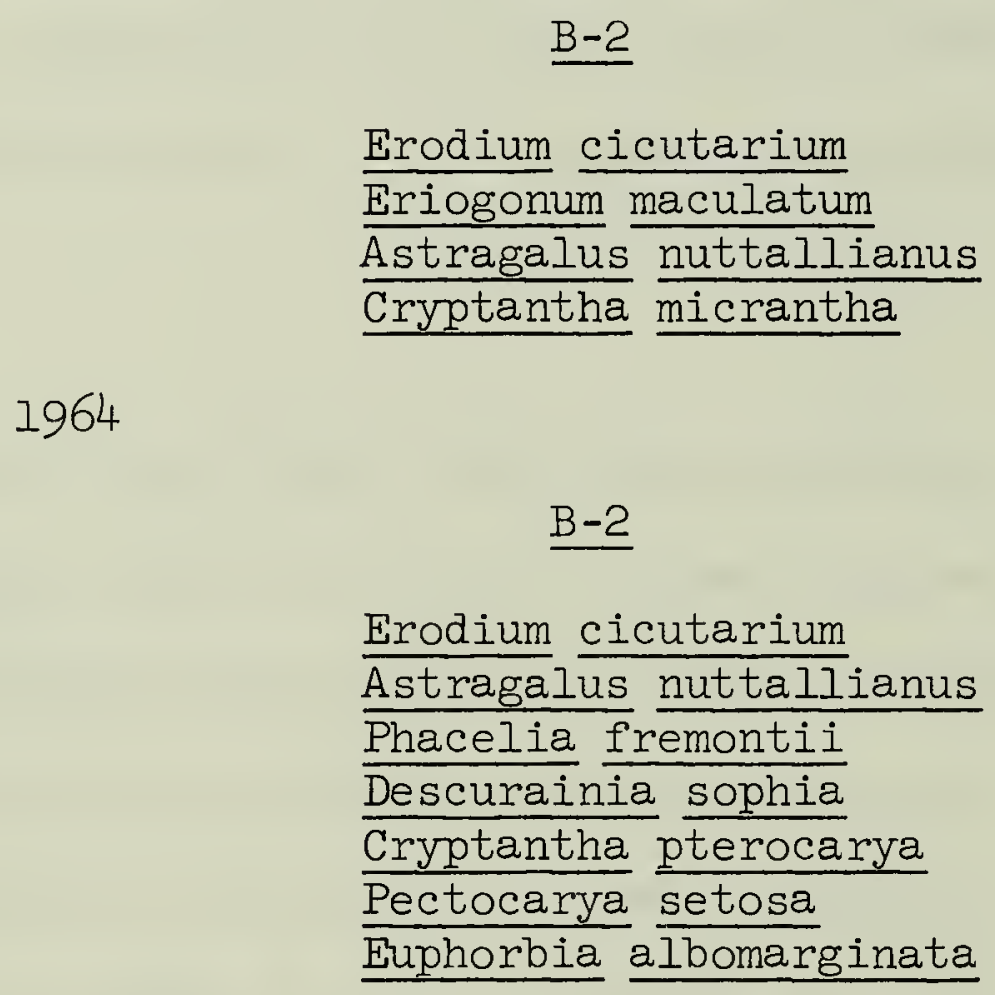

Erodium cicutarium Eriogonum maculatum Astragalus nuttallianus Cryptantha micrantha

Erodium cicutarium Astragalus nuttallianus Phacelia fremontii Descurainia sophia Cryptantha pterocarya Euphorbia albomarginata

The most prominent differences in annual forbs between the two areas was in the greater abundance of filaree and dwarf milk-vetch in B-2 during all three years. The same pattern of abundance was also evident with regard to most of the less common species. These differences were largely a result of rainfall; however, it seemed evident that even with equal 

amounts of rainfall, area B-2 would have produced considerably greater quantities of annual forbs than B-I (Table 24). The differences in the abundance of filaree and dwarf milk-vetch in the two areas proved to be highly significant in all three years when "t".05 tests were made of the difference between their respective means.

The abundance of grasses in these areas was similar with respect to the annuals, but perennial bunch grasses were more abundant in area B-I, possibly because of less grazing pressure.

The maximum temperature in area $\mathrm{B}-2$, replication $I$ was consistentIy an average of five degrees higher than the same replication in $B-1$. Replication III in B-2 was usually hotter than its corresponding location in B-1. As a rule minimum temperatures were also higher in area B-2. Precipitation was 0.44 inches higher in replication I of B-I than in its counterpart in $B-2$, while replication III in $B-2$ had 1.28 inches more rainfall than the corresponding station in B-I during the 15-month measuring period (Table 36).

General study area

The vegetation of the general study area varied with increasing elevation. In addition, the plant cover on the east and west slopes of the Beaver Dam Mountains was different below about 4,000 feet elevation. The vegetation of the western bajada was largely ecotonal between the creosote-bush--bur-sage association at low elevations and the pinyonjuniper and black-brush at higher levels and was characterized by the presence of the Joshua-tree. On the east slope, the vegetation was mostly a creosote-bush--bur-sage or black-brush type with the Joshua-tree entirely lacking.

On a general vegetative basis, this area has been classified by a number of authors. Tidestrom (1925) described it as part of the Lower 

Table 24. Relative density (plants per square foot) of forbs and grasses in areas $\mathrm{B}-1$ and $\mathrm{B}-2$ as determined by rectangular plot vegetation analysis in 1962, 1963 and 1964.

Species

$\frac{1962}{\mathrm{~B}-1 \mathrm{~B}-2} \frac{1963}{\mathrm{~B}-1 \mathrm{~B}-2} \frac{1964}{\mathrm{~B}-1 \mathrm{~B}-2}$

Forbs

Erodium cicutarium

Eriastrum sparsiflorum

Astragalus nuttallianus

Gilia leptomeria

Euphorbia albomarginata

Cryptantha nevadensis

Eriophyllum wallacei

Cryptantha micrantha

Descurainia sophia

Cryptantha circumcissa

Langloisia setosissima

Eriogonum maculatum

Lepidium lasiocarpum

Pectocarya setosa

Lesquerella gordoni

Chorizanthe sp.

Phacelia fremontii

Plantago purshii

Cryptantha pterocarya

Gilia sp.

Plagiobothrys arizonicus Lupinus sparsiflorus

$$
\begin{array}{llcccc}
0.12 & 0.92 & 0.03 & 0.59 & 0.19 & 0.82 \\
0.005 & 0.007 & -- & -- & -- & -- \\
0.002 & 0.007 & -- & 0.004 & 0.048 & 0.15 \\
-- & 0.02 & -- & -- & 0.002 & 0.003 \\
-- & 0.02 & -- & -- & -- & 0.01 \\
-- & 0.01 & 0.002 & -- & -- & -- \\
-- & 0.008 & -- & -- & 0.01 & 0.002 \\
-- & 0.007 & 0.002 & 0.004 & -- & -- \\
-- & 0.005 & -- & -- & 0.002 & 0.022 \\
-- & 0.003 & 0.002 & -- & 0.045 & 0.005 \\
-- & -- & 0.002 & -- & -- & -- \\
-- & -- & -- & 0.01 & -- & -- \\
-- & -- & -- & 0.002 & 0.002 & 0.008 \\
-- & -- & -- & 0.002 & 0.005 & 0.012 \\
-- & -- & -- & -- & 0.008 & 0.002 \\
-- & -- & -- & -- & 0.002 & -- \\
-- & -- & -- & -- & 0.002 & 0.025 \\
-- & -- & -- & -- & 0.002 & -- \\
-- & -- & -- & -- & -- & 0.017 \\
-- & -- & -- & -- & -- & 0.002 \\
-- & -- & -- & -- & -- & 0.005 \\
-- & -- & -- & -- & -- & 0.002
\end{array}
$$

\section{Grasses}

Bromus rubens

Bromus tectorum

Stipa sp.

Sitanion hystrix

Schismus barbatus

Hilaria rigida

$\begin{array}{ccccc}7.3 & 10.3 & 1.62 & 1.52 & \text { Not } \\ -- & 0.05 & -- & -- & \text { Measured in } \\ \text { trace } & -- & -- & -- & 1964 \\ 0.002 & -- & 0.002 & 0.002 & \\ 0.06 & 0.003 & -- & -- & \\ 0.002 & -- & -- & -- & \end{array}$



Sonoran Life Zone, a classification based on minimum winter and maximum summer temperatures. Dice (1939) classified it as belonging to the Sonoran Biotic Province; however, in a later publication (Dice, 1943) he referred to it as a part of the Mohavian Biotic Province. Clements (1920) included this area in his Western Desert Shrub Association while Shantz (1925) referred to it as part of the Southern Desert Shrub Formation. Hardy (1945) subdivided the vegetation of this area into several associations. They were the Larrea-Franseria, Larrea, Yucca-Larrea, Prunus, and Coleogyne. Christian (1962) described the area as consisting of the creosote-bush, Joshua-tree, black-brush, biack-brush--juniper, pinyonjuniper, and ponderosa pine vegetation belts from the lowest to highest elevations. Both Behle (1943) and Billings (1949) referred to the vegetation of the west slope of the Beaver Dam Mountains as being transitional between the southern and northern desert shrub associations.

During this study it became evident that objective classification of the vegetation of the western bajada was extremely difficult. Two distinct types were clearly apparent; the creosote-bush--bur-sage and the blackbrush. Between these types was a gradual transitional area which did not lend itself to classification readily because of the absence of distinct type boundaries. At any one point between these types the relative composition and abundance of species was different. This vegetation corresponded to the Yucca-Larrea type of Hardy (1945) and the Joshua-tree type of Christian (1962). Neither of these names accurately described this vegetation because the species for which they were named were, though conspicuous, of relatively low abundance. For the purposes of this study this was described as the mixed-shrub type of vegetation. Following is a description of vegetation types in the general study area: 

Creosote-bush--bur-sage type. This occurred at elevations below approximately 2,500 feet elevation. Creosote-bush and bur-sage dominated the scene in this type. At its upper limits ratany, and wolf-berry were common shrubs and cacti of the genera Opuntia, Echinocereus and Mammillaria occurred. This type produced a relative abundance of filaree when moisture was suitable. Other prominent annuals included the dwarf milk-vetch and red brome. The desert washes at this elevation were numerous and shallow and consequently produced very little of the primary protective cover species, desert-almond (Fig. 32).

Mixed-shrub type. This type occupied much of the area between 2,500 and 4,500 feet elevation on the western bajada. Plants found here were a composite of species found in other types. Relative species composition varied from the lower to upper limits of the type, but the following overstory species predominated: black-brush, turpentine-broom, creosote-bush, ratany, Brigham tea (Ephedra nevadensis), golden-head (Acamptopappus spaerocephalus) wolf-berry, burro-brush and bur-sage (Fig. 33). These and other species of lesser abundance which commonly occurred in this type are shown in Table 21. From the standpoint of annual forbs, this type produced the greatest diversity and abundance. Filaree and dwarf milk-vetch were by far most abundant. Red brome was most abundant of the annual grasses with fluff grass and Mediterranean grass being common. Very few perennial species persisted due to excessive grazing. It was in this type that intensive study areas A-I and A-2 were located. The larger washes in this type were usually welllined with desert-almond which provided excellent protective cover (Fig. 34). 



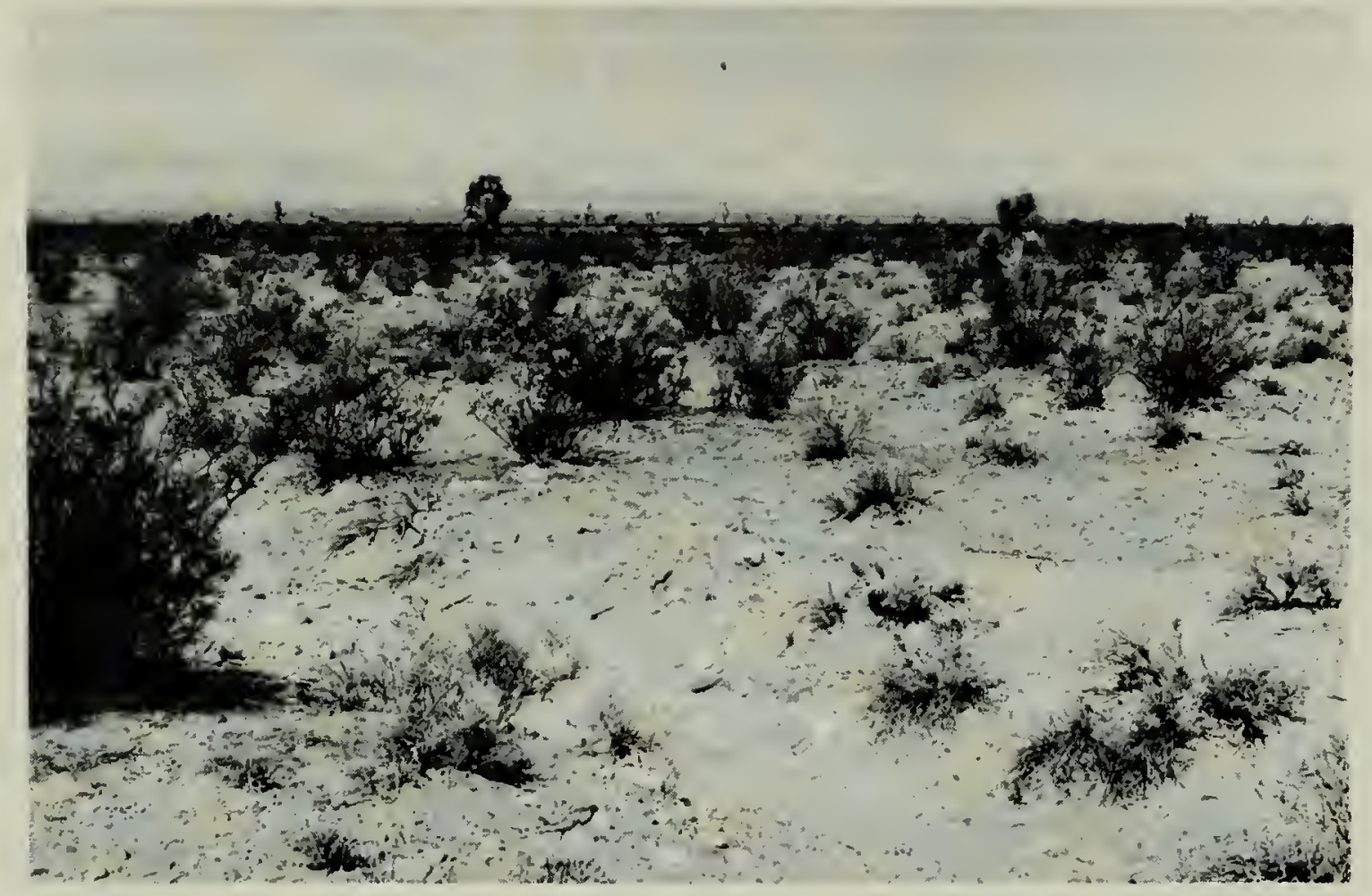

Figure 32. The creosote-bush--bur-sage vegetation type.

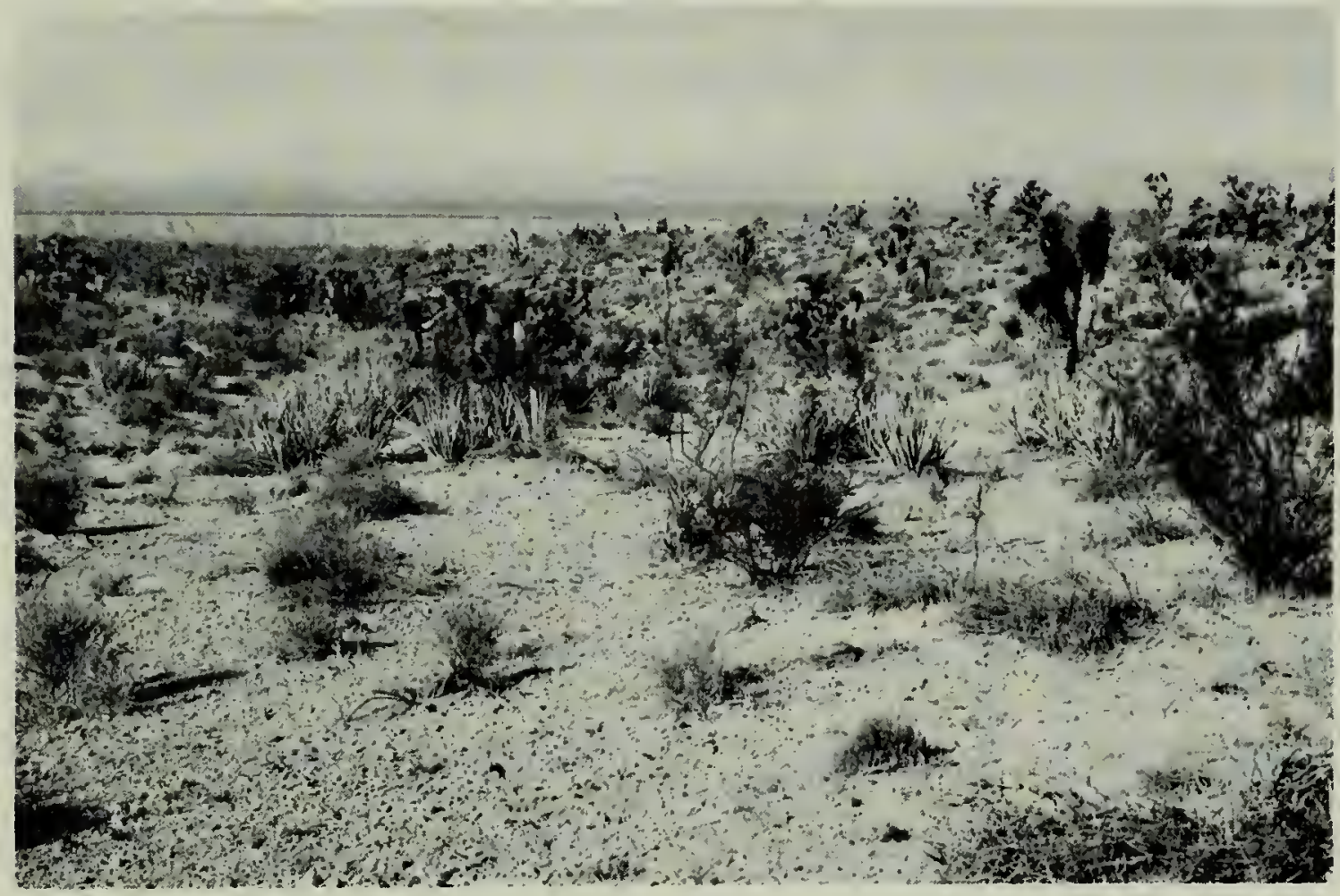

Figure 33. The mixed-shrub vegetation type. 

Black-brush type. The elevation of this type ranged from 4,0005,000 feet. It consisted of homogeneous stands of black-brush with little else interspersed. Many of the aforementioned shrubby species occurred in this type but their coverage was low. Intensive study areas B-I and B-2 were borderline between this and the mixed-shrub types. Both had over 60 percent of the vegetative ground cover composed of black-brush. The Joshua-tree and creosote-bush were noticeable here but individuals were generally widely scattered. Dry washes usually had considerable desert-almond and other mixed-shrub species present (Fig. 35).

Mountain-shrub type. This occurred above about 4,000 feet on the east and 5,000 feet elevation on the west slope of the mountains. Many of the same species which occupied the mixed-shrub type occurred here. Black-brush was very common but was usually interspersed with many other species including juniper (Juniperus osteosperma), Brigham tea (two species), buckwheat (Eriogonum sp.), big sagebrush (Artemisia tridentata), pinyon-pine (Pinus monophylla), cholla (ㅇuntia sp.), mountain-balm (Eriodictyon angustifolium), live-oak (Quercus turbinella), indigo-bush, banana yucca, Fremont barberry (Berberis fremontii), snake-weed, buckbrush (Ceanothus greggii) cliff-rose (Cowania stansburiana), and squaw-bush (Rhus trilobata). Annual forbs included those mentioned for the mixed-shrub type plus spurge (Euphorbia albomarginata), deserttobacco (Nicotiana trigonophylla), beardtongue (Penstemon palmeri), yellow bee-plant (Cleome lutea), lambs-quarters (Chenopodium album), Russian thistle (Salsola $\underline{\mathrm{kali}}$ ) and globe-mallow (Shaeralcea grossulariaefolia). The latter was very abundant in a large burned area (About 11,000 acres) along the east slope of the mountains from U. S. Highway 91 



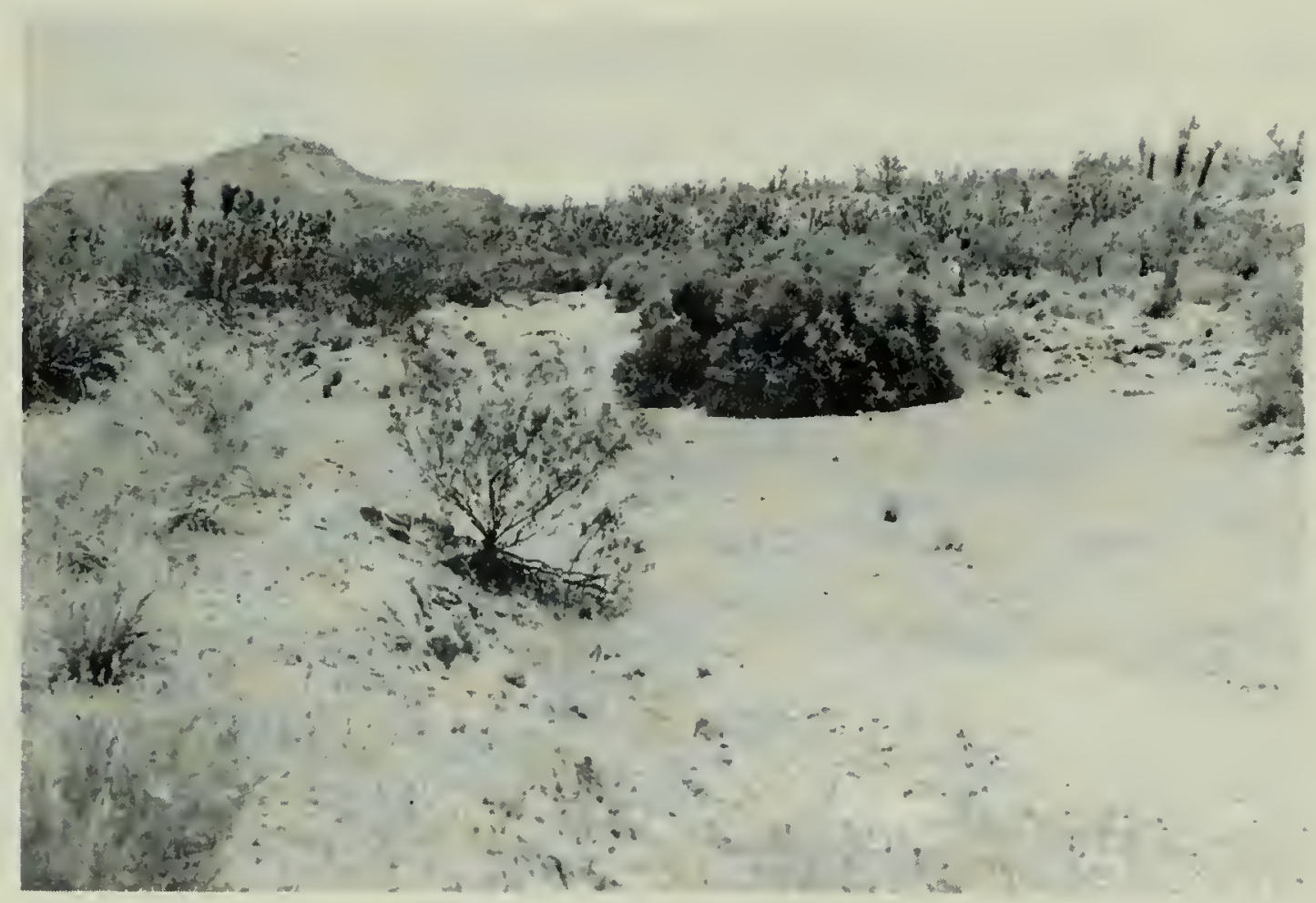

Figure 34. Typical clumps of desert-almond

(Prunus fasciculatus) lining the margin of a large dry wash on the west slope of the Beaver Dam Mountains.

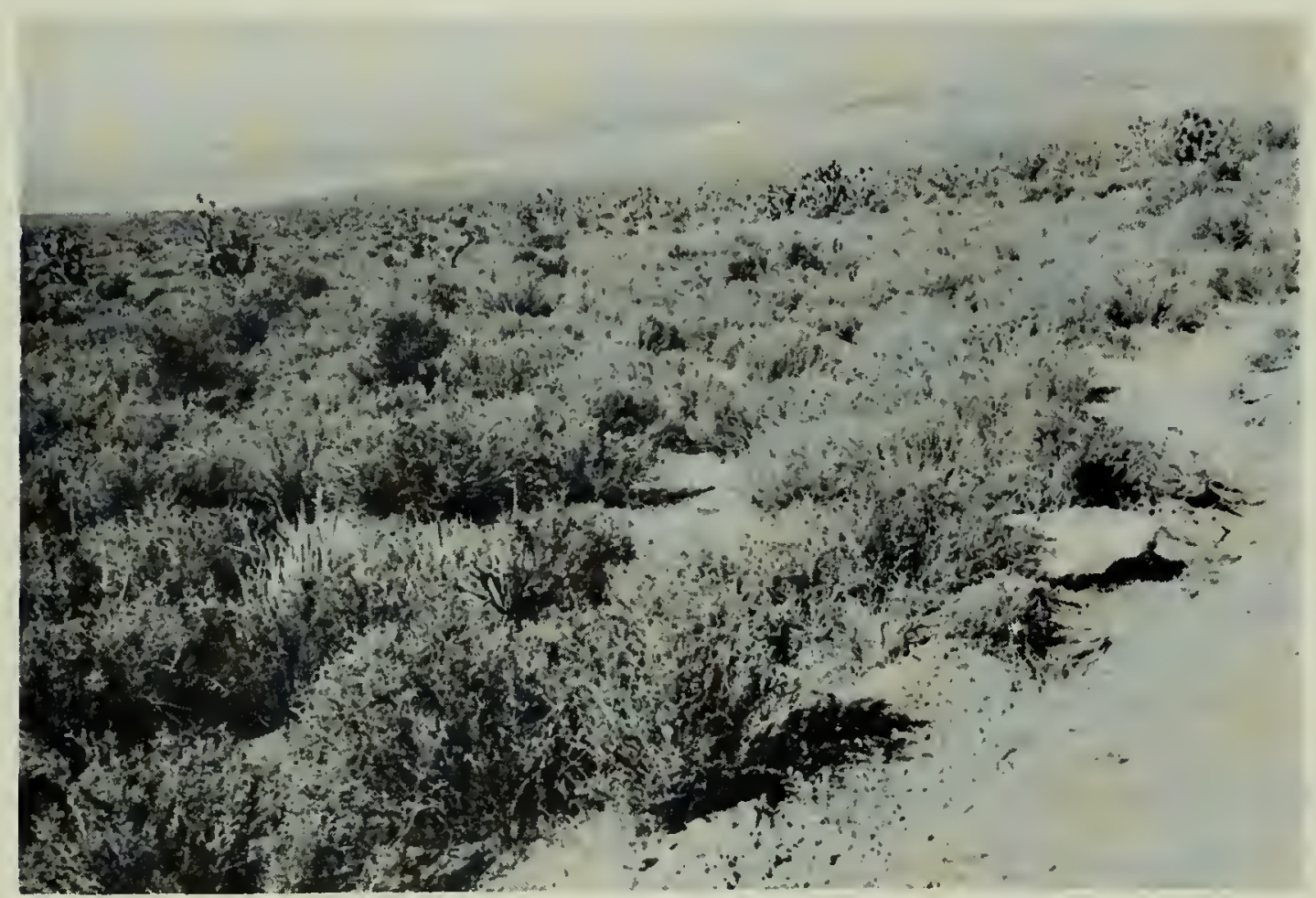

Figure 35. The black-brush vegetation type. 

southward. Also abundant in this burn were beardtongue and cheatgrass (Bromus tectorum). Many other species which were common in this type which are not noted here were listed by Christian (1962). Desert-almond was found on the slopes of this type in addition to the dry wash margins. It was supplemented as protective cover by live-oak, squaw-bush, and Apache-plume (Fallugia paradoxa) (Fig. 36).

Pinyon-juniper type. This type was found primarily on the north end of the mountains and in localized areas along both sides. Both juniper and pinyon-pine were common in the mountain-shrub, but only in this type were they abundant enough to exclude other species. The total area occupied by this type was relatively small. Plant species named for the mountain-shrub type were usually associated with this type but were less abundant. Desert-almond was also found along washes in this type (Fig. 37)

Habitat quality

Determination of quail use of watering sites in the various vegetation types indicated that the mixed-shrub was most conducive to quail abundance. It was also apparent that no vegetation type produced quail except in the vicinity of adequate protective cover usually located along the larger dry washes. Cover was usually more abundant along washes in the mixed-shrub and mountain-shrub types (Table 25).

Even with good wash cover nearby, large homogeneous stands of black-brush did not produce an abundance of quail. The watering sites in black-brush which had quail use always had a large wash nearby with adequate cover. These washes usually contained many of the species found in the mixed-shrub type, often in abundance. 



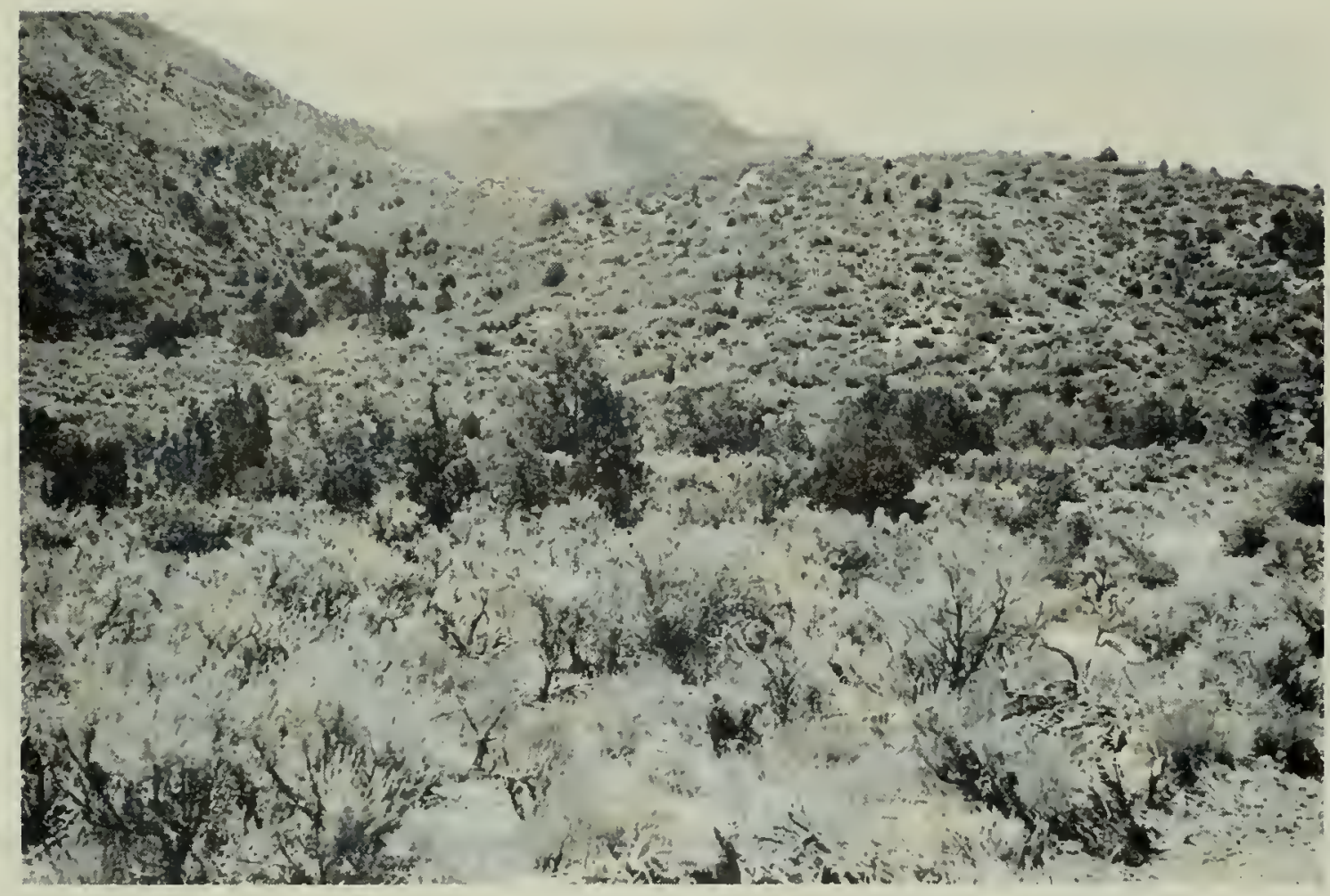

Figure 36. The mountain-shrub vegetation type.

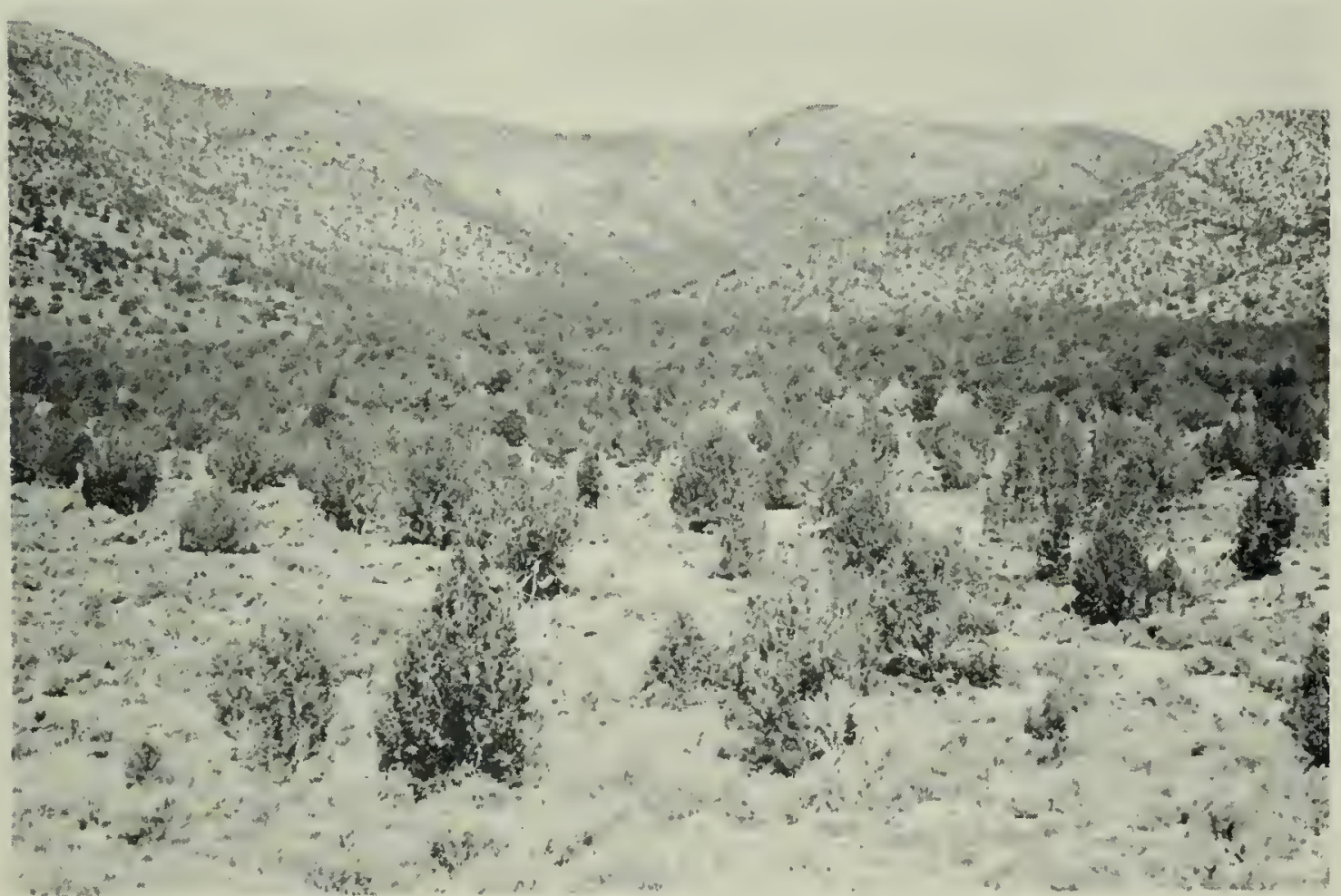

Figure 37. The pinyon-juniper vegetation type. 

Table 25. Relative quail use of watering devices in the various vegetation types in the Beaver Dam Mountain area during 1962 and 1963

\begin{tabular}{lccc}
\hline $\begin{array}{l}\text { Habitat } \\
\text { type }\end{array}$ & $\begin{array}{c}\text { Number of } \\
\text { watering sites }\end{array}$ & $\frac{\text { Mean quail use per site }}{1962}$ & 1963 \\
\hline Pinyon-juniper & 2 & 0 & 0 \\
Mountain-shrub & 4 & 25 & 8 \\
Black-brush & 12 & 18 & 5 \\
Mixed-shrub & 15 & 32 & 15 \\
Creosote-bush--bur-sage & 2 & 8 & 4 \\
\hline
\end{tabular}



The mountain-shrub type had many areas of good shrubby plant cover consisting of desert-almond, live-oak or both. Where these areas were close to watering devices, relatively high quail use resulted.

The creosote-bush--bur-sage type usually lacked cover along the shallow washes, consequently few quail were found in this type. Where large washes with good cover were available in this type, quail were also present.

No quail were ever observed in the dense pinyon-juniper areas. This was a result of poor cover and food conditions. Quail have been observed in association with these two plant species where they were found sparsely scattered in the mountain-shrub type.

Food habits

Quail crops were collected from various places in the general study area and from two small cultivated ranches along the Beaver Dam Wash. The food habits were different in the two types of areas.

Cultivated areas. The diet of 44 quail in these areas consisted of 68.95 percent seeds, 24.37 percent greens, and 6.68 percent animal foods. Only an unmeasurable trace of grit was observed in these crops.

Seeds of the desert-willow (Chilopsis linearis) made up 51.88 percent of the crops analyzed. Panicum sp. seeds were next in order of abundance consisting of 5.62 percent volume; however, it was found in only 15.9 percent of the crops. Filaree seeds occurred in 61.4 percent of the crops, but only made up 3.04 percent of the food eaten. Twenty-one other dry food items were identified, at least to the genus, but no one of them composed more than one percent of the diet. Those of greatest importance were two species of pig-weed (Amaranthus sp.) dwarf milk-vetch, red brome, creosote-bush, cat-claw (cacia greggii), Johnson grass (Sorghum halpense), mallow (Malva sp.) and goose foot (Chenopodium sp.). 

The leaves of alfalfa or clover (Medicago sp.) were most abundant of succulent foods comprising 9.90 percent of total foods eaten. It occurred in 20.5 percent of the crops. Filaree made up 7.20 percent volume and was eaten by 54.5 percent of the quail. The only other significant succulent food was the fruit (pome) of the apple (Malus sp.). It comprised 6.43 percent volume but was only found in 11.4 percent of the crops.

Animal foods eaten were primarily insects from the orders Lepidoptera (tent caterpillars), Hymenoptera (ants), Coleoptera (beetles) and Diptera (true flies). The droppings of small rodents were also commonly found (Table 26).

General study area. The proportion of the types of food eaten here were different from that found in cultivated areas. Succulent foods made up 53.30 percent of the total volume of 84 crops analyzed while seeds and animal foods represented 40.12 and 5.71 percent volume respectively.

The seeds of the dwarf milk-vetch made up 19.96 percent of the total volume of foods eaten and occurred in 66.7 percent of the crops. Filaree constituted a lesser volume ( 9.29 percent) but occurred in more crops (89.3 percent) than did the former species. Spurge (Euphorbia albomarginata) comprised 5.8 percent volume and was in 50.0 percent of crops examined. Turpentine-broom made up 3.85 percent volume and had a frequency of 42.9 percent. Of twelve other species red-brome, desert-willow and Aster sp. were most prominent but were still relatively insignificant.

The succulent leaves of filaree were the most important green food constituting 28.58 percent of the total volume of food eaten and occurring in 73.8 percent of the crops. The leaves of what appeared to be an annual Cryptantha (no positive identification) comprised 16.56 percent volume and were eaten by 70.2 percent of the quail from which crops were 

Table 26. Food items found in 44 quail crops collected from cultivated areas along the Beaver Dam Wash during the fall of 1962

Food items

Percent

volume

6.15

0.45

0.08

trace

trace

51.88

5.62

3.04

0.90

0.80

0.76

0.61

0.59

0.57

0.45

0.45

0.39

0.37

0.35

0.33

0.33

0.16

0.16

0.12

0.12

0.08

0.07

trace

trace

trace

trace

trace

trace

0.81

$9 \cdot 90$

7.20

6.43

0.16
Percent

frequency
$13 \cdot 6$

$22 \cdot 7$

13.6

2.3

$2 \cdot 3$

61.4

15.9

61.4

15.9

18.2

27.1

2.3

18.2

2.3

9.1

6.8

25.0

9.1

9.1

2.3

6.8

4.5

2.3

4.5

2.3

6.8

9.1

4.5

4.5

4.5

4.5

$2 \cdot 3$

4.5

--

20.5

54.5

11.4 

obtained. Other species providing green food were desert-almond, dwarf milk-vetch and spurge.

Six orders of insects and one acrinid were represented in the animal diet of quail. None comprised more than one percent of the total volume of food eaten. Rodent droppings made up 3.59 percent of the total volume and was found in 47.6 percent of the crops. Bone fragments of either a small bird or mammal were found in three of the 84 specimens analyzed. Grit was observed in 25 percent of the crops but only made up 0.50 percent of the total volume of crop contents (Table 27).

Areas $A-1$ and $A-2$. Twenty-four and nine crops were collected from intensive study areas $A-I$ and $A-2$ respectively. The disparity of sample size very likely was responsible for a greater number of food items found in area $A-I$, but the relative abundance of the major foods was probably indicative of availability in the two areas.

Area A-2 had slightly more filaree and dwarf milk-vetch seeds than did A-I. In both areas the latter comprised the greatest volume of seeds eaten. The greatest difference was in the high incidence of spurge in A-I and complete absence of this species in A-2. Turpentine-broom was also commonly eaten in $\mathrm{A}-1$ and lacking in $\mathrm{A}-2$. Other species found were all in insignificant amounts.

There was considerable difference in the relative abundance of green foods in the two areas, probably due to availability. Presumed Cryptantha leaves were the most abundant succulent food in A-I while filaree was predominant in A-2. Other species utilized as green food were desertalmond, dwarf milk-vetch and spurge. Green foods constituted a greater portion of the diet in A-2 (55.64 percent) than in A-1 (45.43 percent). Considering the sample size, the food availability in the two areas was 

Table 27. Food items found in 84 quail crops collected on the west slope of the Beaver Dam Mountains during the fall of 1962

\begin{tabular}{|c|c|c|}
\hline Food items & $\begin{array}{l}\text { Percent } \\
\text { volume }\end{array}$ & $\begin{array}{l}\text { Percent } \\
\text { frequency }\end{array}$ \\
\hline $\begin{array}{l}\text { Animal } \\
\text { Rodent droppings } \\
\text { Lepidoptera (tent caterpillars) } \\
\text { Hymenoptera (ants) } \\
\text { Bone fragments } \\
\text { Acrina (ticks) } \\
\text { Coleoptera (beetles) } \\
\text { Homoptera } \\
\text { Orthoptera (grasshopper) } \\
\text { Hemiptera } \\
\text { Unidentified insect fragements }\end{array}$ & $\begin{array}{l}3.59 \\
0.88 \\
0.60 \\
0.23 \\
0.14 \\
0.03 \\
0.03 \\
0.03 \\
\text { trace } \\
0.17\end{array}$ & $\begin{array}{r}47.6 \\
26.2 \\
27.4 \\
3.6 \\
4.8 \\
4.8 \\
3.6 \\
1.2 \\
4.8 \\
2.4\end{array}$ \\
\hline $\begin{array}{l}\text { Plant (seeds) } \\
\text { Astragalus nuttallianus } \\
\text { Erodium cicutarium } \\
\frac{\text { Euphorbia albomarginata }}{\text { Aster sp. }} \\
\text { Chilopsis linearis } \\
\text { Compositae } \\
\text { Bromus rubens } \\
\text { Eriogonum sp. } \\
\text { Larrea divaricata } \\
\text { Sphaeralcea grossulariaefolia } \\
\text { Plantago sp. }\end{array}$ & $\begin{array}{l}19.96 \\
9.29 \\
5.80 \\
0.57 \\
0.40 \\
0.34 \\
0.17 \\
0.01 \\
\text { trace } \\
\text { trace } \\
\text { trace }\end{array}$ & $\begin{array}{l}66.7 \\
89.3 \\
50.0 \\
3.6 \\
1.2 \\
2.4 \\
9.5 \\
2.4 \\
6.0 \\
1.2 \\
7.1\end{array}$ \\
\hline $\begin{array}{l}\text { Plant (vegetative parts) } \\
\text { Erodium cicutarium } \\
\frac{\text { Cryptantha sp.* }}{\text { Prunus fasciculatus }} \\
\frac{\text { Astragalus nuttallianus }}{\text { Euphorbia }} \\
\frac{\text { Purshia glbomarginata }}{\text { Unidentified plant fragments }}\end{array}$ & $\begin{array}{l}28.58 \\
16.56 \\
1.45 \\
1.15 \\
0.29 \\
\text { trace } \\
5.29\end{array}$ & $\begin{array}{r}73.8 \\
70.2 \\
46.4 \\
4.8 \\
3.6 \\
1.2 \\
--\end{array}$ \\
\hline Grit & 0.50 & 25.0 \\
\hline
\end{tabular}

* Not positively identified 

probably similar with the exception of Cryptantha. Spurge seeds were most abundant in crops from $\mathrm{A}-1$ but the reverse was true with regard to succulent vegetative parts eaten (Table 28).

Food preferences. Turpentine-broom, desert-willow, creosote-bush, black-brush and indigo-bush were the only woody plants represented in the quail diet. Of these only turpentine-broom occurred in over six percent of the crops analyzed or constituted more than 0.50 percent of the total volume of food measured. The most abundant shrubs such as black-brush, creosote-bush, ratany, Brigham tea, golden-head, wolf-berry, bur-sage, burro-brush, snake-weed, and buck-wheat contributed little or nothing to the diet of quail. Also, seeds of the various cacti and yucca which are common in the area were not found in the crops.

Red brome was the most abundant annual plant found in the areas where vegetation analysis was completed, but contributed only trace amounts to the diet of quail. Next in order of abundance were filaree and the dwarf milk-vetch, both of which were extremely important foods. Of these filaree was always much more abundant in vegetation samples, but from a volume standpoint dwarf milk-vetch seeds were eaten in considerably greater quantities. Filaree occurred in a greater percentage of the crops analyzed probably due to its greater availability. Spurge was another important food that was seldom encountered in vegetation analysis. Desert-willow seemed to be a preferred food where available, but its limited distribution in areas other than along the Beaver Dam Wash greatly reduced its importance. Seeds of the many other common annuals such as gilia, sand pepper-grass, tansy-mustard, buckwheat, plantain and various borages were not utilized by quail. 

Table 28. Relative utilization of plant foods by quail collected from intensive study areas $A-1$ and $A-2$ during the fall of 1962

Food items

$\underline{\text { Percent volume }}$

$\frac{\text { Percent frequency }}{A-1}$

Seeds

Astragalus nuttallianus

22.84

$24 \cdot 34$

$95.80 \quad 100.0$

Euphorbia sp.

$13 \cdot 17$

$--$

$83 \cdot 30$

Erodium cicutarium

7.88

9.49

100.00

100.0

Thamnosma montana

$5 \cdot 50$

$-$

50.00

Aster sp.

trace

4.17

trace

4.17

trace

12.50

trace

8.33

trace

4.17

Bromus rubens

- $\quad$ trace

11.1

Eriogonum sp.

-- trace

11.1

Vegetative parts

Cryptantha sp.

38.66

5.71

100.00

55.6

Erodium cicutarium

6.04

48.37

75.00

100.0

Prunus fasciculatus

0.57

1.55

29.17

44.4

Astragalus nuttallianus

0.16

$--$

4.17

Euphorbia albomarginata

trace

0.31

8.33

11.1

Listed in order of abundance in the control area $\mathrm{A}-1$

Sample size was 24 crops in $A-1$ and 9 in $A-2$. 


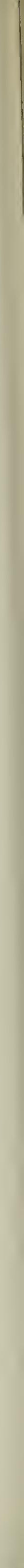


Filaree was important for its succulent leaves as well as for its seeds. From the standpoint of relative availability the presumed Cryptantha leaves were probably preferred even to filaree which was many times as abundant. The relatively abundant desert-almond leaves were utilized only to a small degree. Perhaps during periods of drought when annual forbs are not available this species becomes more important. Future research should include a study of food habits during the water-critical period.

\section{Life History Information}

\section{Nesting}

It was assumed at the outset of the study that some quail nests would be encountered during routine work, but this did not prove to be true. Only one nest was found during the entire study period, despite some searching. The single nest observed contained 14 eggs, all of which hatched. During 1961, nesting occurred much earlier than in 1962 and 1963. On May 20, 1961 a number of broods were observed in the study area some of which appeared to be at least one month old. It was likely that during 1961 hatching began in early April at least.

The peak of nesting (nest starting) as determined by the age distribution of hunter-harvested juvenile quail was about April 18-28 in 1962, with the peak of hatching following during the period from May 27-June 6 . The first brood observed that year was on May 18 .

The peak of nesting in 1962 coincided with the peak of calling which occurred during the period from April 16-30th. If this was always true then the peak of nesting in 1963 occurred during the period from May 115th, with the peak of hatching about June 10-25th. The first brood was observed on May 27, 1963. 
Age ratios

Age ratios for the general study area have been discussed in a previous section. It is of interest to note the difference in reproductive success between the desert area of the west and the cultivated areas of the east portions of Washington County.

During 1962 the cultivated areas experienced excellent quail reproduction. A sample of 96 wings collected from hunters indicated the presence of 380 juveniles per 100 adults. At the same time hunters in the general study area harvested 60 juveniles per 100 adults as determined from a sample of 218 quail wings.

In 1963, reproduction in the cultivated areas, as determined from a sample of 42 wings, was poorer than 1962 (220 juveniles: 100 adults), but was still better than indicated by the 66 wings from the general study area (136 juveniles: 100 adults).

\section{Sex ratios}

The sex ratios of quail in the hunters' bag in 1961 and 1962 were 136 and 118 males per 100 females each year respectively. The greater preponderance of males in 1961 probably reflected poor hen survival during the summer of 1960 when reproduction in the general study area was apparently very good and the population reached a peak. The poor reproduction during 1961 and 1962 resulted in low hen mortality and consequently a closer ratio between hens and cocks in the fall of 1962 .

\section{$\underline{\text { Harvest }}$}

Hunting pressure was low in the general study area. Ninety-four, 90 and 22 hunters were checked in 1961, 1962 and 1963 respectively. In 1961 and 1962 a checking station was manned on three different week-ends and in 1963 two voluntary hunter checking stations were used in addition 

to field bag checks. The low hunting pressure in the latter year reflected the low quail population level in the area. Hunters did not consider it worth while to visit the area and those who came hunted the two small ranches in the Beaver Dam Wash.

In 1961 the quail hunt opened on the same day as the pheasant season. Consequently only 17 hunters visited the general study area in two days. The 1962 quail season was opened earlier than the pheasant hunt in order to induce more hunters into the area but even then only 50 hunters were checked the first week-end.

Hunter success was 42 quail per 100 gun hours pressure in 1961 and aropped off in succeeding years to 32 and 24 quail per 100 hours. Success was always better on the first week-end of the hunt. After that the birds became much more wild and difficult to bag.

The effects of hunting on the population were slight. During the three years only 16 of 457 ( 3 percent) banded and marked quail were returned by hunters. It is doubtful if over $12-15$ percent of the population succumbed to hunting.

Crippling loss as reported by hunters varied from year to year. In 1961, ten birds were lost for each 100 bagged. The loss was 25 and 28 per 100 quail bagged in 1962 and 1963 respectively. The presence of the spiny cacti and yucca plants influenced most hunters to leave their dogs at home and probably resulted in a higher crippling loss (Tables 9, 10, 11). Quail weights

During trapping operations in July of 1961, 17 adult male and 16 adult female quail were weighed. Males averaged 168.0 grams with a range of from 153.2 and 180.9 grams. Female weights ranged from 150.8 to 174.8 grams and averaged 164.4 . 


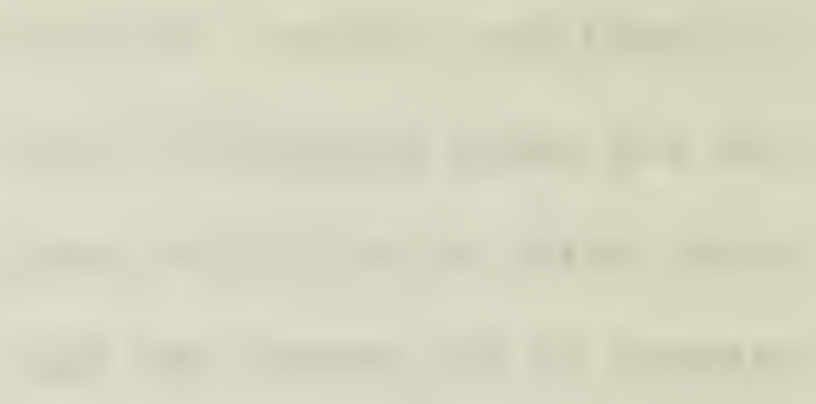

(1) 


\section{Quail watering habits}

Quail were observed to drink water only during the summer months. Date of initial use varied from year to year depending on availability of succulent green feed and probably temperature. In 1961 quail were drinking water in May while in 1962 and 1963 use of water did not start until late June. Termination of use each year coincided with the first fall rainstorm, usually in late August or early September.

During the period when water was apparently critical quail visited catchments regularly. Records of retrapped quail indicated that many probably made trips to water each morning. Very few were observed watering during the afternoon and evening.

of 81 covey observations during 1962 and 1963 long-period waterhole counts, 78 percent of the quail counted arrived at water between 7:00 and 9:00 a.m. Only one observation was made prior to 6:00 a.m. and four after 10:00 a.m. during both years combined (Fig. 38).

No records were kept of the proportion of birds actually watering but it appeared that most of them drank from the catchments.

The few non-watering birds noticed were usually adults with young. In such cases the young would go to the catchment to drink while the adult male perched nearby. The female usually drank with the young or loafed or searched for food.

After watering the birds often loafed in the shade of nearby vegetation. Coveys seldom loitered in the area more than one-half hour. 



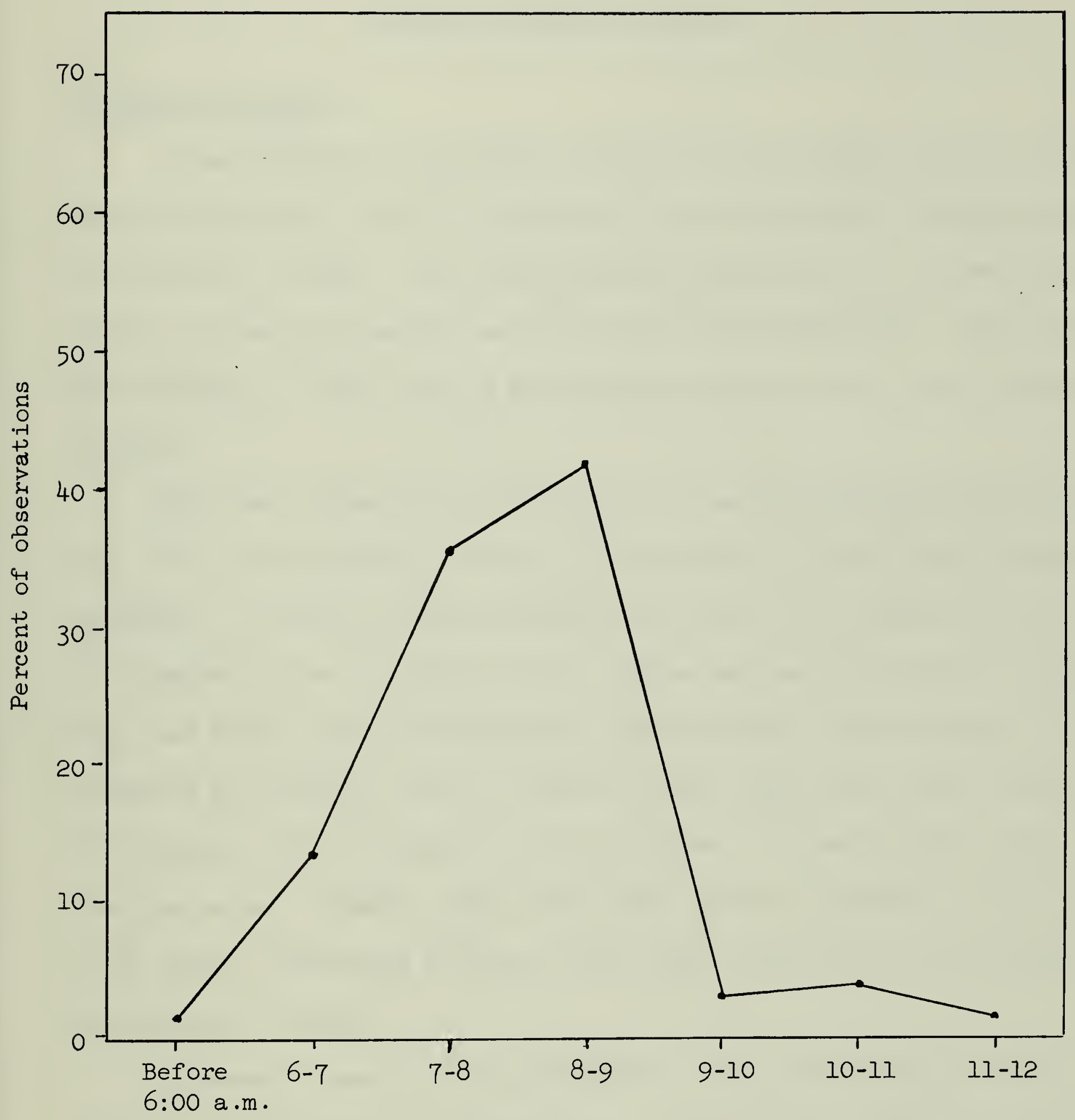

Figure 38. Distribution of 81 quail coveys arriving at water during the morning hours of July and August, 1962 and 1963 



\section{DISCUSSION AND CONCLUSIONS}

\section{Effects of Water on Quail}

\section{Population density}

It was apparent from indexes derived from the various trend techniques that drinking water was not the factor which limited quail abundance during this period of study. The quail population declined to an extremely. low level in areas with as well as without free water available. This decline was primarily a result of low precipitation and resultant poor food availability •

There was evidence that the presence of water influenced quail density, but this could have been a result of concentration rather than increased abundance. During the pre-development surveys in the areas with water $(A-1$ and $A-2)$ area $A-1$ had more than double the quail population of $A-2$. This was true in both the September, 1961 and April, 1962 surveys, indicating that area $\mathrm{A}-1$ was, at least at that time, better quail habitat. The closure of the catchments in A-I resulted in a lower index in the succeeding census. However, this area still, with the exception of the July, 1963 census, maintained as many or more quail than did area A-2 despite the absence of water.

In areas $B-1$ and $B-2$ pre-development counts indicated that the population in both areas was extremely low. Later surveys after water catchments were installed in B-2 showed a slight quail increase in that area.

The extreme difference in quail numbers between areas $\mathrm{A}-1$ and $\mathrm{A}-2$ (13.I and 5.1 quail-per-mile) and $B-1$ and $B-2(0.0$ quail-per-mile in both areas) during the September, 1961 census indicated that water (which was 

present in the former areas) may have substantially increased quail in those areas. However, later vegetation analysis and habitat evaluation showed areas $A-1$ and $A-2$ to be better quail habitat and this was probably responsible for much of the difference. The possibility existed that the greater abundance of quail in $A-1$ and $A-2$ was at least partly due to the presence of water.

Poor reproduction each year of study caused the population to steadily decline and the presence of water in the developed areas did not counteract this shrinkage though it may have retarded it.

Survival of young quail

There were some indications that those quail using the available drinking water experienced better survival than those persisting without it. Age ratios of quail over one-half mile from water prior to the presumed water-critical period in 1962 and 1963 showed as great or greater proportion of young than those of quail observed less than that distance from free water. Age ratios during the period when water was assumed critical, because of intensive use by quail, showed more juveniles in the areas close to water in 1962, and in 1963 no quail were found over onehalf mile from available drinking water despite considerable searching. Even with the mediocre sample size involved, these data indicated that drinking water may have increased the survival of young quail during the drouth periods, thus maintaining the population at a level higher than would otherwise have been present. How much higher was problematical.

Pooling brood and age-ratio information with relation to time showed that the juvenile mortality rate was constant each year. Distribution

Quail showed a definite tendency to concentrate in the vicinity of available water, even during periods when they were not observed to drink. 

Birds observed during line-transect counts were usually seen one-quarter mile or less from the water in the developed areas. The closure of the catchments in area $A-I$ had a pronounced effect on the distribution of quail. In fact, the low population index in that area during June of 1962 was a result of a change in the quail distribution pattern from one of concentration to a more or less random dispersal which very likely resulted in some quail leaving the study area.

Of the quail observed in general observations more than two-thirds were within one-half mile of water. These included observations made at all seasons of the year.

In view of these findings it seemed probable that quail could be lured into presumed suitable areas apparently not occupied by quail during this study. Several areas existed which appeared to have suitable cover and food, but relatively few if any quail. Also better utilization of presently occupied areas could conceivably be accomplished by proper distribution of water catchments as has been described by Gullion (1958) for Nevada.

\section{Movements}

It became apparent that the birds oriented their activities around water and to this extent their movements were influenced by it. During the water-critical period when succulent green annual forbs were no longer present and maximum temperatures usually exceeded $100^{\circ} \mathrm{F}$, frequent, possibly daily, trips were made to water.

Two significant instances of movement were noted after the closure of the catchments in intensive study area $A-I$. One quail banded and marked in replication I of that area in 1961, prior to closure, was observed three miles eastward at Reber spring in August, 1962. Another banded and 

marked at the same time moved two miles to the catchment in replication I of area A-2 and was observed there in August, 1962. There was a possibility that both movements occurred during the winter of 1961-62 prior to the closure, but they were not observed until after. It was possible that both birds moved in search of water during the summer of 1962. No quail were ever observed to move from area $A-2$ to $A-I$.

The one-mile mean movement of hunter-harvested banded quail and twothirds mile mean movement of marked quail observed were somewhat greater than the one-half mile or less mean movements found by Gullion (1954a) in Nevada and Greenwalt (1955) in Arizona. Extreme movements varied from zero to three miles. These data indicated that quail in this area may occasionally travel up to one and one-half miles daily, but probably remain in the same general area and in this respect are quite sedentary. They appeared to be somewhat "nomadic" in that they were seldom observed consistently in the same place. Instead, they tended to be always on the move.

Less than one percent of the retrapped quail were taken at a catchment other than where originally captured. On the other hand, one-fifth of the marked quail observed had apparently changed catchments.

\section{Habitat Evaluation}

The vegetative differences in the two sets of study areas complicated the interpretation of the effects of water on relative abundance of quail. Though the species composition of plants was similar in the two areas, relative abundance varied widely especially with regard to annual plants. Differences occurred not only between areas but also from one year to the next depending on rainfall. The only plausible solution to resolving these 

differences would be to compare the areas through a peak population pe riod as presently developed and then switch the design and make the presently developed areas waterless and supply water in the now waterless areas. After this is done, the population trends should be followed through another period of high quail abundance.

It was doubtful that the slight temperature variation between intensive study areas affected quail abundance. On the other hand precipitation could have had considerable influence. For this reason any future comparisons of intensive areas must involve relative abundance of annual plants.

The total rainfall for the 15 -month measuring period (5.41 inches maximum) was below the six-inch level described by Gullion (1954b) as producing light or no populations of Gambel's quail in Nevada.

During this study it was obvious that, though different vegetatively, areas $A-1$ and $A-2$ both represented good quail habitat while B-I and B-2 were somewhat less desirable. The incidence of greater numbers of quail in A-I during pre-development surveys indicated that the relative abundance and composition of vegetation was more favorable for quail than in $\mathrm{A}-2$. It appeared that B-2 may be more desirable for quail than B-I due to greater abundance of annual forbs. The greater abundance of black-brush in the latter areas especially and in A-2 to some extent, tended to make them less desirable for quail than area $A-1$.

The abundance of turpentine-broom proved to be a good indicator of favorable quail habitat. Gullion (1960) made similar conclusions in Nevada.

Pooling of call-count data on an extensive basis indicated that habitat quality was more important in determining quail distribution than was the presence of water.

Five vegetation types were described in the general study area. The mixed-shrub constituted most of the favorable quail habitat, followed by 
the mountain-shrub, black-brush, creosote-bush--bur-sage and pinyon-juniper. None of the types mentioned produced quail without the presence of considerable protective cover, usually desert-almond, along the larger dry washes.

\section{Food Habits}

The diet of quail was distinctly different between cultivated and natural or desert areas. Relative use of foods was largely a function of availability in both types of areas, although some preferences were shown.

Of over 40 different plant food items found in cultivated areas only desert-willow seeds, filaree seeds and leaves, apple fruit and alfalfa or clover leaves constituted over one percent total volume in the diet. Desert-willow was by far most abundant constituting 51.98 percent of the total volume of food eaten. Seeds of species associated with cultivation commonly eaten included the genera Salsola, Medicago, Helianthus, Amaranthus, Malva, Panicum, Setaria, Sorghum, and Chenopodium. Native species included, in addition to filaree and desert-willow, the genera. Thamnosma, Astragalus, Larrea, Sphaeralcea, Bromus, Phoradendron, Euphorbia, Cucurbita and Acacia. Animal food consisted of representatives of the orders Lepidoptera, Hymenoptera, Diptera and Coleoptera. Rodent droppings were occasionally found. Dry seeds composed 68.95 percent of the total diet while succulent vegetation and animal food made up 24.37 and 6.68 pe reent respectively. Grit was found only in trace quantities.

Quail on the slope used succulent green foods to a greater extent than those in the cultivated areas. In this natural area green food constituted 53.3 percent of the total volume. Seeds and animal foods made up 40.12 and 5.71 percent respectively. Filaree leaves made up the 

greatest portion of food eaten, followed by the seeds of dwarf milk-vetch, leaves of what appeared to be a species of Cryptantha, filaree seeds and the seeds of turpentine-broom and spurge. Rodent droppings constituted 3.59 percent volume and occurred in 47.6 percent of the crops analyzed. This relatively great use of droppings indicated more than accidental occurrence. With regard to this Hungerford (1962) reported that droppings contained vitamin $B_{12}$ and concluded that they had nutritive value for quail. The relative abundance of food items in crops from areas $A-1$ and $A-2$ showed the major food items, filaree and dwarf milk-vetch, to be in near equal volumes in each area. The most distinct difference was the greater use of turpentine-broom and spurge seeds in A-1. Succulent vegetation in A-l consisted mainly of Cryptantha leaves while in A-2 filaree was most important. Several more genera were represented in A-I crops, but this was likely a result of unequal sample size.

When the intensive areas $A-1$ and $A-2$ were evaluated on the basis of food habits and vegetation analysis combined it appeared that $\mathrm{A}-2$ contained as much or more of the primary foods (filaree and dwarf milk-vetch) as A-l. The latter had a greater abundance of plant species, both shrubs and forbs, used to a lesser degree and as a result offered a greater variety of foods. This seemed to be the reason for the greater quail abundance in $\mathrm{A}-1$ during the fall of 1961 .

Gullion (1954c) concluded that the incidence of red brome and creosotebush seeds in quail crops in Nevada indicated poor food availability. Their occurrence in this study may have been indicative of a similar food shortage.

\section{Value of Water Development}

In order for water developments to be of practical value in quail management, they must provide an increased return to the hunters' bag. 
Such an increase has not been apparent during the past three years. Quail numbers declined in spite of water availability and consequently hunting was poor, especially in 1962 and 1963.

Whether or not the presence of water maintained a higher population level where it was available was neither proven or disproven during this study. There were indications that it did, but the problem of discerning between concentration of quail and increased abundance prohibited making accurate conclusions in this regard. The fact that area A-I maintained as many or more quail than $A-2$ after water was no longer available indicated that quail can persist in favorable habitat without water. Conversely, the fact that the relative abundance of quail changed from more than double in $\mathrm{A}-\mathrm{I}$ to about even after the catchment closure indicated that $A-I$ was possibly capable of maintaining higher population levels with water than without it.

The fact that quail tended to concentrate around water even during months of non-use could have increased hunter success. No data were available to prove this, but it was logical that if hunters concentrated their efforts in the vicinity of water, which they have done to a large degree, then their success was probably greater than if they had spread their efforts over a larger area. From this aspect water development may have value.

The results of this study do not warrant the conclusion that water development has no value in quail management. Its effects on distribution, even with a limited sample size, were evident. Also increased survival of young and greater quail densities in developed areas were indicated. Nevertheless, since this study showed that these effects were relatively insignificant insofar as maintaining good hunting was concerned, it is 

recommended that no further development work for Gambel's quail be done, at least until research reveals the value of water to be greater tlian shown during this study.

If the benefits of water provision are only realized "in favorable years" as stated by MacGregor (1953) then it is questionable whether it has value at all.

\section{Evaluation of Trend Techniques}

With only two years data it was not possible to correlate any of the trend techniques used with hunter success to determine the relative accuracy of the methods. This will only be possible after several years of study. A number of problems arose however, which should be considered before continuing work on this phase of study.

Since most, if not all, of the collection of management data has been, and will probably continue to be done by local Conservation Officers, it is imperative that a method of detecting trends be adopted which provides a maximum of information in a minimum of time.

The work done during this study indicated that though the late summer roadside count may have shown the trend of the population, it provided very little information on brood size and age ratios due to the small number of birds observed. This could only be overcome by replicating the counts many more times each year, which would overload the already rushed schedule of most Conservation Officers. Call counts probably showed the population trend, but did not show the reproductive success which, to a large degree, determines the fall population level. The same applied to the pre-breeding roadside census. Only the long-period waterhole counts provided information concerning both population trend and productivity. 

During these counts relatively large numbers of quail can be observed thus providing good information on productivity. The main shortcoming of this method was that these counts can only be conducted in July and August which was rather late in the year for setting hunting seasons. In past years these data have not been required prior to this time, but if it becomes necessary to set seasons and bag limits earlier in future years this method would lose its value in that respect.

It was found during 1963 that indiscriminate sampling of hunters on the west slope of the Beaver Dam Mountains did not give a true picture of hunter success in the natural areas. Data obtained indicated success on the small ranches and not in the area where census methods were being used. There, hunter success was probably much lower. The various trend techniques are to be correlated to hunter success thus requiring its accurate measurement. The few hunters who visited the area in 1963 hunte $\ddot{d}$ on the two small ranches where the population was relatively higher than on the slope, resulting in a misleading hunter-success index. In future years a checking station must be manned and an attempt made to distinguish between hunter success in natural and cultivated areas.

\section{Life History Information}

The limited data obtained regarding life history of the Gambel's quail substantiated the findings of previous workers.

The peak of nesting occurred in March of 1961, late April in 1962 , and early May of 1963. In 1962 the age distribution of juvenile quail during the fall hunt indicated that the peak of nesting coincided with the peak of calling. Similar results were reported by Senteney (1957) for Arizona. 

The hatching peak occurred in April of 1961, late May or early June of 1962 and mid-June in 1963.

Age ratios indicated much wider fluctuations of populations in desert as compared to agricultural areas as found by Gullion (1960). In desert areas precipitation was the primary factor influencing production. In agricultural areas this was probably also true, although in 1962 production in this area was excellent with what was probably less than average precipitation. Therefore, other factors must also be important.

Sex ratios favored males each year, but in the fall of 1961 they were more extreme in favor of males than in 1962. This was probably a reflection of greater hen mortality during 1960 when reproduction was relatively high. Such a situation was reported for Arizona by Sowls (1960). He concluded that hen mortality was greater in years of good reproduction and less when production was poor due to decreased stress on non-nesting hens.

The hunter harvest of quail had little effect on the population. Only three percent of the banded and marked quail were reported killed by hunters. Judging from this it seemed unlikely that more than $12-15$ percent of the population succumbed to hunting. Hunting pressure was low in 1961 and 1962 and almost lacking 1963.

Crippling loss varied from 10 to 28 quail lost per 100 bagged, slightly less than reported for Nevada by Gullion (1954d). There it ranged from 29 to 45 quail lost per 100 bagged.

Live adult male quail were found to weigh an average of four grams more than females during the summer of 1961. 



\section{RECOMMENDATIONS}

1. The water evaluation phase of the project should be continued through a. period of high population. The increased sample size resulting from greater quail densities would prove more conclusive than that derived during this period of study. Also it would show the effects of water on an expanding population.

After following the effects of water through a peak period using the present design, water availability should be reversed and the results determined for another period of years. This would enable distinguishing between the influence of water and of habitat quality since the intensive study areas were somewhat different.

The minimum information required to provide continuity of data in the intensive study areas includes: (I) relative abundance of annual forbs as determined by rectangular plot studies during April and May each year, (2) information on survival of young by monthly brood and age-ratio counts, (3) line-transect counts at least once each year until the population increases and then during spring, summer and fall and (4) continued information on distribution and movements. Additional work on the latter need not be done until the population begins to increase. Prior to switching the design, as much marking of quail as possible should be done to facilitate detection of inter-area movement after water availability has been reversed.

2. Work on comparing the various trend techniques should be continued for several years until an adequate test of correlation between hunter success and each technique is possible. In addition an effort must 

be made in the future to distinguish between success of hunters utilizing the two ranches and those hunting in natural areas. Unless this is accomplished, the differential hunter success will affect the validity of any correlation tests in the future.

3. In future work a study of comparative food habits of quail utilizating water and those living independent of water during the summer water-critical period would be of value to more fully depict the influence of water on quail.

4. During the spring of 1963 the United States Bureau of Land Management developed a number of springs on the west slope of the Beaver Dam Mountains and piped them into stock-watering tanks. One tank was placed in the south half of replication $I$ area $B-I$, a waterless control area. If this project is continued in the future as recommended, this area will have to be abandoned or relocated elsewhere. 



\section{SUMMARY}

Research was conducted in Washington County, Utah concerning the effects of water on Gambel's quail with regard to population density, survival of young and distribution and movements. Work was also done on habitat evaluation, testing various trend techniques and recording life history information.

The effects of water were determined by comparison of intensive study areas with and without drinking water available. Relative abundance was determined in quail-per-mile by horseback line-transect counts. Survival of young quail was assessed by monthly brood and age-ratio counts. Distribution was determined relative to water from line-transect data and by recording and plotting all quail observations. Movements were detected by trapping and marking quail. Habitat evaluation was done in the intensive study areas for comparison purposes, by the line-intercept and rectangular plot methods of vegetation analysis and extensively by subjectively classifying vegetation into types. Habitat quality was determined by comparing water catchment use by quail in different habitat types. Trend techniques being tested were call counts, roadside counts (spring and summer) and long-period waterhole counts. Call counts and roadside counts were made over the same 14-mile route. Waterhole counts were made at six different catchments during the July and August water-critical period. Hunter success was determined using a hunter checking station. Life history information was recorded incidental to other work.

Poor reproduction each year of study resulted in a declining quail population. As a result the sample size of population data was limited. 
It was concluded that water had a distinct influence on quail. It was shown that quail tended to concentrate around water where available. This was true even during the period from september to June when it was not being utilized. There was evidence, though not conclusive, that quail utilizing water experienced better survival than those persisting without it. Quail in areas with water appeared more dense, but the problem of distinguishing between concentration and increased abundance masked the actual effects of water in this regard.

Movements were affected to the extent that during the water-critical period from June to September quail made frequent, possibly daily, trips to water and the birds oriented their movements accordingly. Extreme movements of two and three miles were noted following catchment closures. Twenty percent of marked quail observed had apparently changed catchments . Mean movements of hunter-harvested and marked quail were 1.0 and 0.63 miles respectively. Only one quail was known to move from one intensive study area to another.

Habitat evaluation proved the intensive study areas to be somewhat dissimilar. Area $\mathrm{A}-1$ appeared to be better quail habitat than A-2, and B-2 better than B-I. This disparity necessitates switching the design after a period of years in order to distinguish between the effects of water and habitat quaility.

Five vegetation types were described but the ecotonal nature of the area obscured boundary lines between types. They included the creosotebush--bur-sage, mixed-shrub, black-brush, mountain-shrub and pinyonjuniper types.

Protective cover for quail was usually provided by desert-almond. This shrub occurred along the margins of the larger dry washes and influenced quail abundance and distribution to a greater extent than water. 

The mixed-shrub type proved to be the most suitable habitat for quail, but large washes in other types produced relatively good populations. The diet of quail was largely a function of food availability. Seeds constituted the greatest volume in cultivated areas while succulent green vegetation was eaten most in natural areas. Only a small percentage of the diet in either type consisted of animal foods. The two most important plant foods utilized were filaree and dwarf milk-vetch. The rest of the diet consisted of many different items most of which constituted less than one percent of the total volume of food measured.

Even though water was found to influence quail, its practical value for improving hunting was questioned. During this study drinking water was not limiting population increase. Quail numbers declined each year despite the presence of water. As a result, hunting was poor and few people were attracted to the area. The possibility exists that during years of high population the concentrating and possibly increasing effect of water may substantially improve hunter success. Only additional research will determine this satisfactorily. It was recommended that no further water development be done unless future research reveals greater benefits than found during this study.

No conclusions were made concerning the relative accuracy of the trend techniques for measuring population fluctuations because of only two years data being available. It did appear however, that the long-period waterhole counts provided the most information on reproductive success in addition to indicating trend of the population. This phase of the project should be continued by the Fish and Game Department.

Life history data confirmed the findings of other workers and added no new knowledge concerning this species.

Recommendations outlining future research needs were also presented. 



\section{LITERATURE CITED}

Arnberger, L. P. 1954. Flowers of the Southwest mountains. Southwestern Monuments Assoc. Popular Ser. No. 7, Globe, Arizona. $112 \mathrm{p}$.

1 Bartholomew, G. A. and R. E. MacMillen. 1961. Water economy of the California quail and its use of sea water. Auk 78: 505-514.

Behle, W. H. 1943. Birds of the pine Valley Mountain region, southern Utah. Univ. Utah Bull. Vol. 34 (2), Biol. Ser. Vol. VII (5). 85 p.

Billings, W. D. 1949. The shadscale zone of Nevada and eastern California in relation to climate and soil. The Am. Midland Naturalist 42: 87-109

2 Campbell, H. 1960. An evaluation of Gallinaceous guzzlers for quail in New Mexico. J. Wildl. Mgmt. 24: 2l-26.

Christian, R. W. 1962. Plant geography of the Beaver Dam Mountains. Unpub. M. S. thesis, Univ. Utah. $159 \mathrm{p}$.

Clements, F. E. 1920. Plant indicators; the relation of plant communities to process and practice. Carnegie Inst. Wash. Publ. No. 290. 388 p.

Dice, I. R. 1939. The Sonoran biotic province. Ecol. 20: 118-129.

Dice, I. R. 1943. The biotic provinces of North America. Univ. Michigan Press, Ann Arbor. $78 \mathrm{p}$.

Dodge, N. N. 1958. Flowers of the Southwest deserts. Southwestern Monuments Assoc. Popular Ser. No. 4, Globe, Arizona. 112 p.

3 Elder, J. B. 1956. Watering patterns of some desert game animals. J. Wildl. Mgmt. 20: 368-78.

4 Gallizioli, S. and R. Smith. 1959. Gambel quail and cottontail rabbit population trend techniques. Job Completion Report, Fed. Aid Proj. W-78-R-4, Work Plan 1, Jobs 2 and 3, Arizona Game and Fish Dept. Phoenix, Arizona. $10 \mathrm{p}$.

5 Glading, B. 1947. Game watering devices for the arid Southwest. Trans. l2th N. Am. Wildl. and Nat. Resources Conf. 286-292.

6 Gorsuch, D. M. 1934. Life history of the Gambel quail in Arizona. Univ. Arizona Bull. Vol. 5(4), Biol. Sci. Bull. No.2. 89 p.

7 Greenwalt, L. A. 1955. Mobility of Gambel quail in a desert grasslandoak woodland area in southeastern Arizona. Unpub. M. S. thesis, Univ. Arizona, Tucson. $37 \mathrm{p}$. 

8 Grinnell, J. 1927. A critical factor in the existence of southwestern game birds. Science 65: 528-29.

Gullion, G. W. 1954a. Gambel's quail range in southern Nevada. Job Completion Report, Fed. Aid Proj. W-8-R, Work Plan 2, Job No. I, Nevada Fish and Game Comm. Reno. Il p. (Mimeographed)

10 Gullion, G. W. 1954b. Recommendations for Gambel's quail management. Job Completion Report, Fed. Aid Proj. W-8-R, Work Plan 6, Job No. 1, Nevada Fish and Game Comm. Reno $7 \mathrm{p}$. (Mimeographed)

// Gullion, G.W. 1954c. Food study. Job Completion Report, Fed. Aid Proj. W-8-R, Work Plan 3, Job No. 2, Nevada Fish and Game Comm. Reno. 6 p. (Mimeographed)

Gullion, G. W. 1954d. Inimical factors. Job Completion Report, Fed. Aid Proj. W-8-R, Work Plan 4, Job No. 1, Nevada Fish and Game Comm. Reno. $28 \mathrm{p}$. (Mimeographed)

12 Gullion, G.W. 1958. The proximity effect of water distribution upon desert small game populations. Proc. 38th Ann. Conf. W. Assoc. of State Game and Fish Comm. 187-89.

13 Gullion, G.W. 1960. The ecology of Gambel's quail in Nevada and the arid Southwest. Ecology 41: 518-36.

Hardy, R. 1945. The influence of types of soil upon the local distribution of some mammals in southwestern Utah. Ecol. Monographs 15: 71-108.

14 Hungerford, C. R. 1960. Water requirement of Gambel's quail. Trans. 25th N. Am. Wildl. Conf. 231-40.

Hungerford, C. R. 1962. Adaptions shown in selection of food by Gambel quail. Condor 64: 213-19.

Jaeger, E.C. 1944. Desert wildflowers. Stanford Univ. Press, Revised. Ed. $322 \mathrm{p}$.

Kearney, T. H. and R. H. Peebles. 1960. Arizona flora. Univ. California Press, Berkeley and Los Angeles. 1081 p.

Lowe, C.H. Jr. 1955. Gambel quail and water supply on Tiburon Island, Sonora, Mexico. Condor 57: 244 .

1. MacGregor, W. 1953. An evaluation of California quail management. Proc. 33rd Ann. Conf. W. Assoc. of State Game and Fish Comm. 157-160.

Martin, A. C., R. H. Gensch and C. P. Brown. 1946. Alternative methods in upland gamebird food analysis. J. Wildl. Mgmt. 10:8-12.

Mclean, D. D. 1930. The quail of California. California State Dept. Nat. Resources, Div. of Fish and Game, Bull. No. 2. $47 \mathrm{p}$. 
. 
Nelson, I. K. 1955. A pheasant neck tag. J. Wildl. Mgmt. 19: 414-15.

Patraw, P. M. 1959. Flowers of the Southwest mesas. Southwestern Monuments Assoc. Popular Ser. No. 5, Globe, Arizona. 112 p.

Raitt, R. J. Jr. 1961. Plumage development and molts of California quail. Condor 63: $294-303$.

Ross, F. 1951. California's quail development program. Proc. 3lst Ann. Conf. W. Assoc. of State Game and Fish Comm. 124-130.

Schemnitz, S. D. 1961. Ecology of the scaled quail in the Oklahoma panhandle. Wildlife Monographs No. $847 \mathrm{p}$.

17 Senteny, P. F. 1957. Factors affecting the nesting of Gambel quail in southern Arizona. Unpub. M. S. thesis, Univ. Arizona, Tucson. $42 \mathrm{p}$.

Schantz, H. I. 1925. Plant communities in Utah and Nevada. In I.Tidestrom, Flora of Utah and Nevada, Contr. U. S. Natl. Herb. 25: 15-23.

(8 Sowls, L. K. 1960. Results of a banding study of Gambel's quail in southern Arizona. J. Wildl. Mgmt. 24: 185-90.

Tidestrom, I. 1925. Flora of Utah and Nevada. Contr. U. S. NatI. Herb. 25: $1-665$.

(9) Vorhies, C. T. 1928. Do southwestern quail require water? Am. Naturalist 62: 446-52.

Wallmo, 0. C. 1956. Ecology of the scaled quail in west Texas. Texas Game and Fish Comm. $134 \mathrm{p}$.

Wright, J.T. and E. L. Webb. 1956. The evaluation of water development in wildlife habitat improvement. Project Report for Proj. W-62-R-5 Arizona Dept. of Game and Fish, Phoenix. $25 \mathrm{p}$. 


\section{APPENDIX}


Table 29. Locations of intensive study areas $A-1, A-2, B-1$ and $B-2$ as determined by examination of sectionalized aerial photographs

Area

Location

$A-1$

South $\frac{1}{2}$ section 28 , southwest $\frac{1}{4}$ section 27 , west $\frac{1}{2}$ section 34 , section 33 , Township 42 south,.

Range 19 west; north $\frac{1}{2}$ section 4 , northwest $\frac{1}{4}$ section 3, Township 43 south, Range 19 west.

$A-2$

Southeast $\frac{1}{4}$ section 34 , southwest $\frac{1}{4}$ section 35 , Township 42 south, Range 19 west; east $\frac{1}{2}$ section 3 , west $\frac{1}{2}$ section 2 , section 10 , west $\frac{1}{2}$ section 11, north $\frac{1}{2}$ section 15, Township 43 south, Range 19 west.

$B-1$ South $\frac{1}{2}$ section 10 , south $3 / 4$ section 11 , north $\frac{1}{2}$ section 15 , north $\frac{1}{2}$ section 14 , east $\frac{1}{2}$ section 16, southeast $\frac{1}{4}$ section 9 , Township 42 south Range 19 west.

$\mathrm{B}-2$ South $\frac{1}{2}$ section 15 , south $\frac{1}{2}$ section 14 , section 21 , section 22 , west $\frac{1}{2}$ section 23 , east $\frac{1}{2}$ section 20, Township 42 south, Range 19 west. 

Table 30. Survival of young quail as indicated by pooled monthly age ratios in areas $A-1$ and $A-2,1962$ and 1963

Period

$$
\frac{\text { Area A-l (waterless) }}{\text { Juv. Adults Juv.:100 ad. Juv. Adults Juv.:100 ad. }}
$$

1962

$\begin{array}{lrrrrrr}\text { May 18-June 30* } & 3 & 7 & 43 & 8 & 23 & 35 \\ \text { July } & 0 & 0 & 0 & 15 & 62 & 24 \\ \text { August } & 0 & 12 & 0 & 0 & 0 & 0\end{array}$

1963

\begin{tabular}{lrrrrrr} 
June & 9 & 2 & 450 & 0 & 0 & 0 \\
July & 0 & 0 & 0 & 8 & 7 & 110 \\
August & 0 & 0 & 0 & 55 & 66 & 83 \\
\hline Totals & 12 & 21 & 57 & 86 & 158 & 54
\end{tabular}

* Quail were first observed using water in A-2 about June 30th both years.

Table 31. Survival of young quail as indicated by pooled monthly age ratios in areas B-I and B-2, 1962 and 1963

Period

$$
\frac{\text { Area B-1 (waterless) }}{\text { Juv. Adults Juv.:100 ad. Juv. Adults Juv.:100 ad. }}
$$

1962

$\begin{array}{llllrrr}\text { May 18-June 30* } & 0 & 1 & 0 & 19 & 8 & 240 \\ \text { July } & 0 & 0 & 0 & 0 & 8 & 0 \\ \text { August } & 0 & 0 & 0 & 2 & 12 & 17\end{array}$

1963

$\begin{array}{lrlllrr}\text { June } & 0 & 0 & 0 & 3 & 10 & 33 \\ \text { July } & 0 & 0 & 0 & 0 & 6 & 0 \\ \text { August } & 0 & 1 & 0 & 8 & 11 & 73\end{array}$

$\begin{array}{lllllll}\text { Totals } & 0 & 2 & 0 & 32 & 55 & 58\end{array}$

* Quail were first observed using water in B-2 about June 30th both years. 


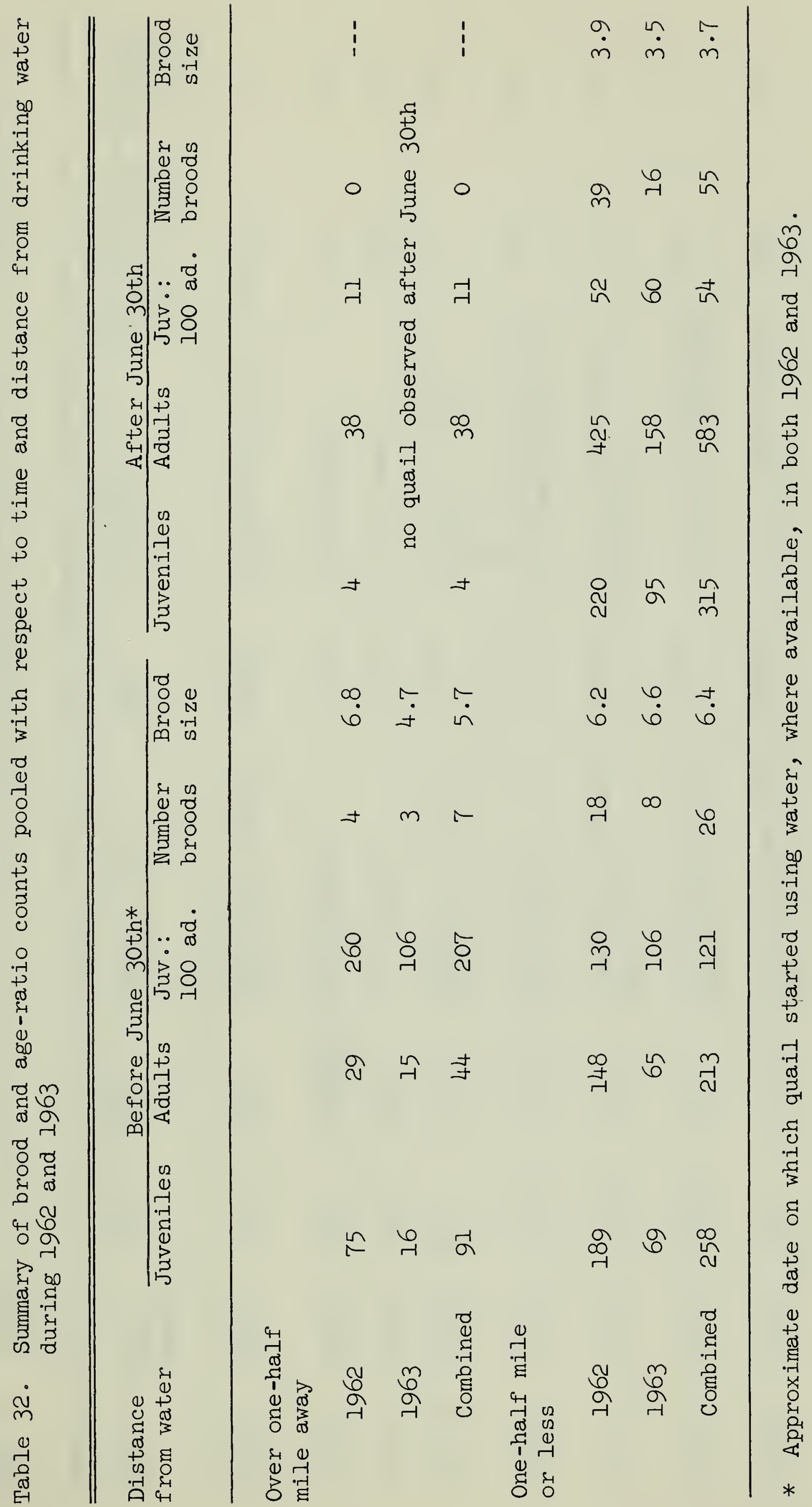





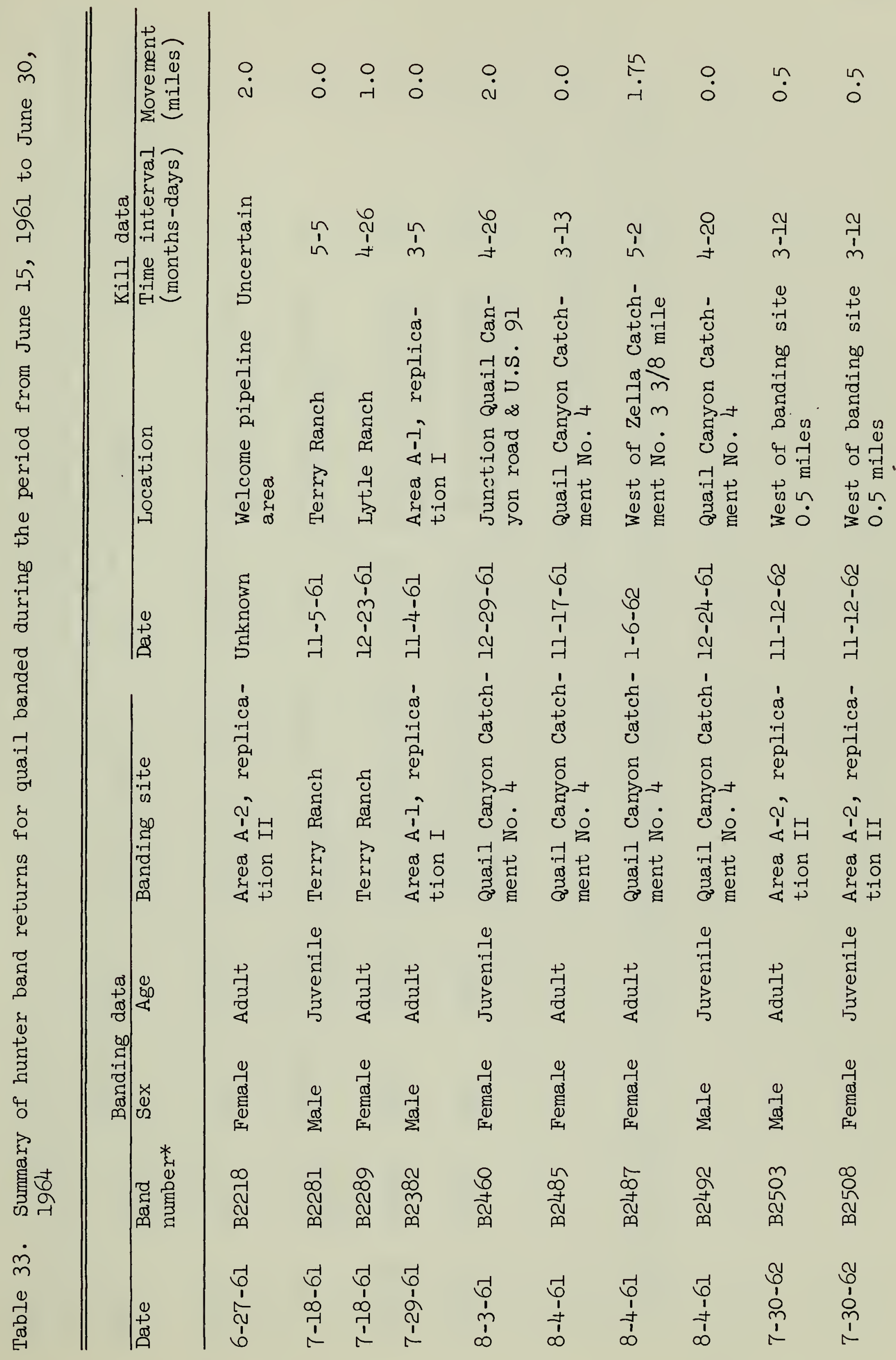





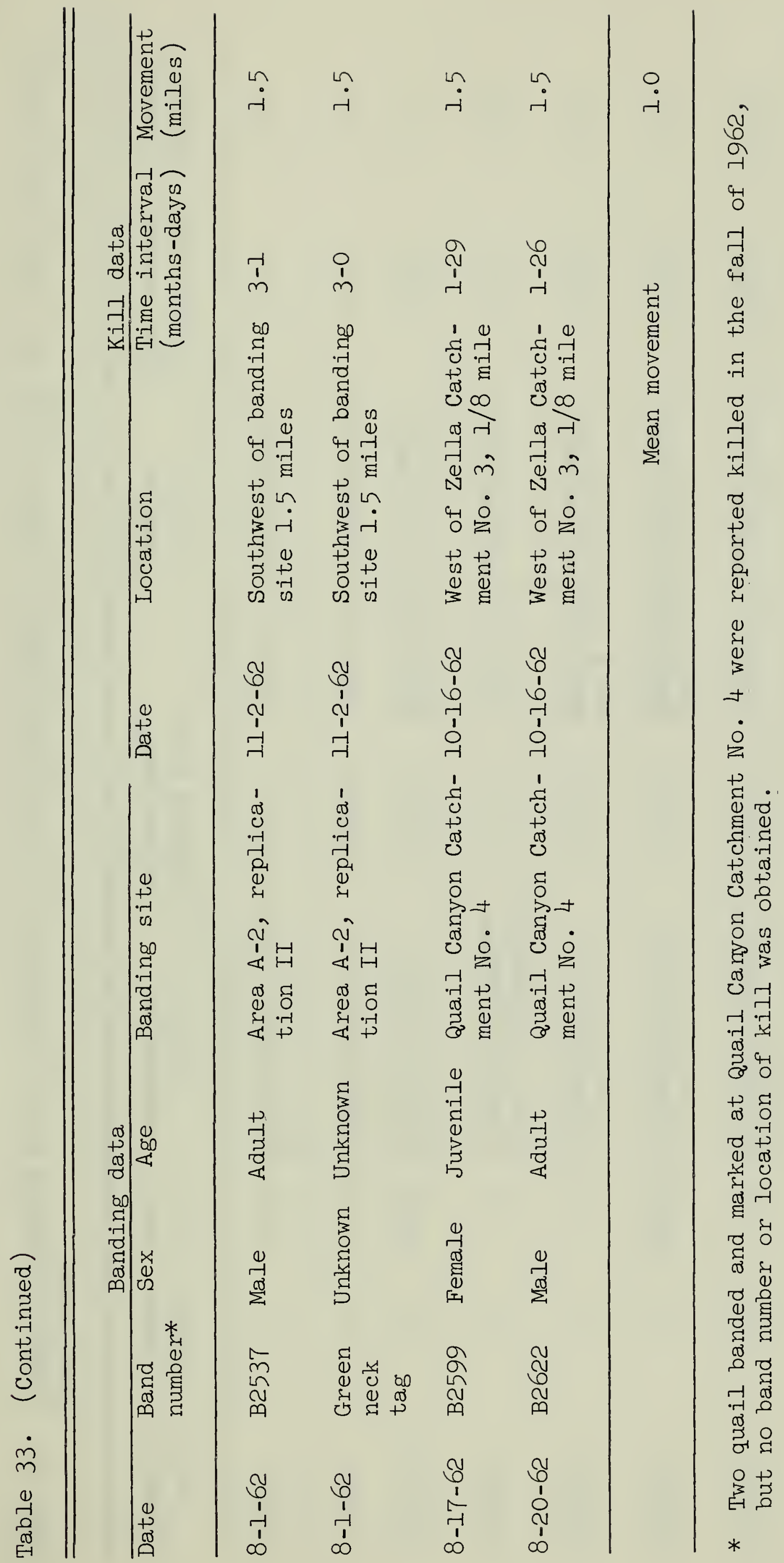





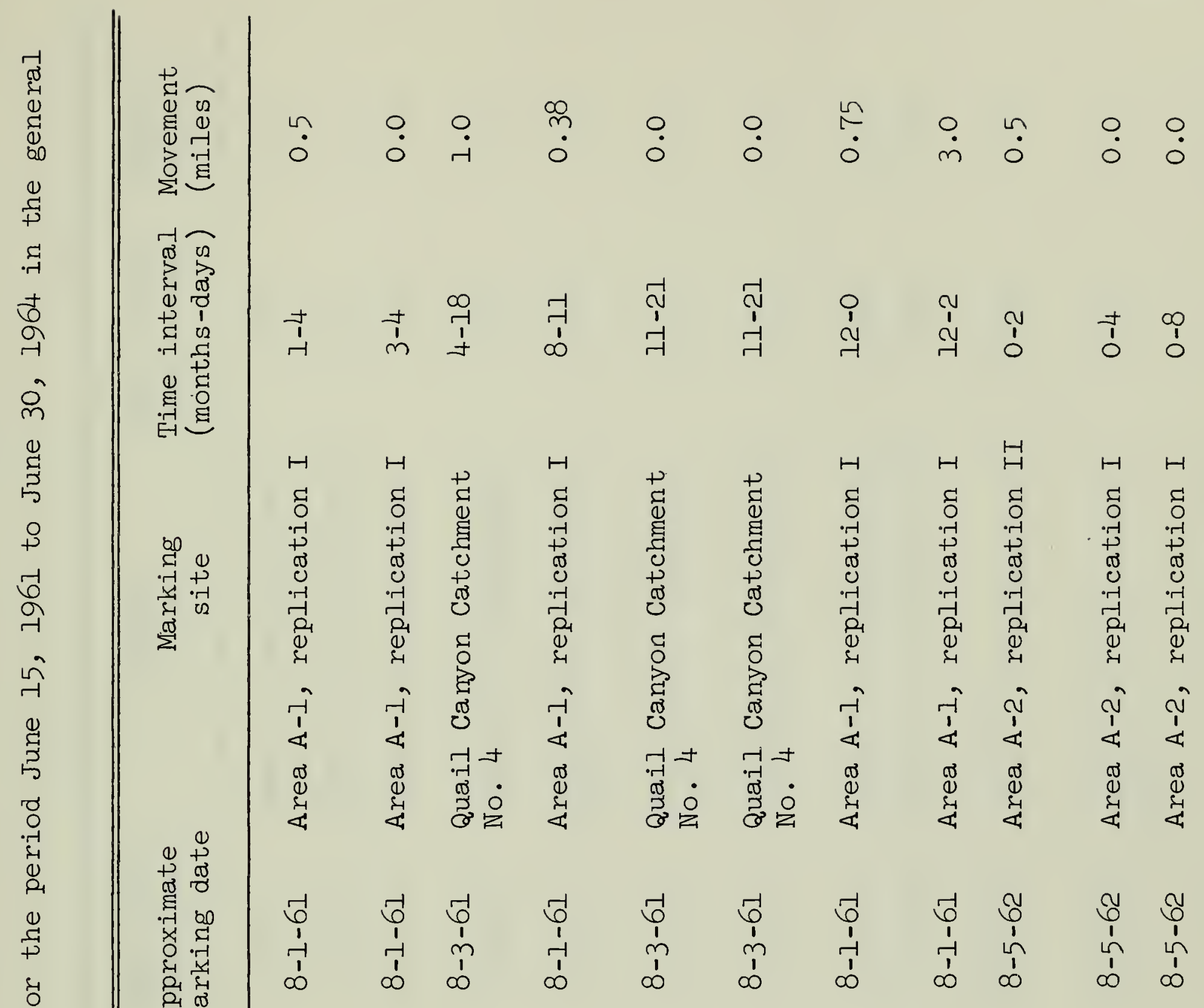

02
01
0
-1
+3
0
0
3
0
0
0
0
0
0

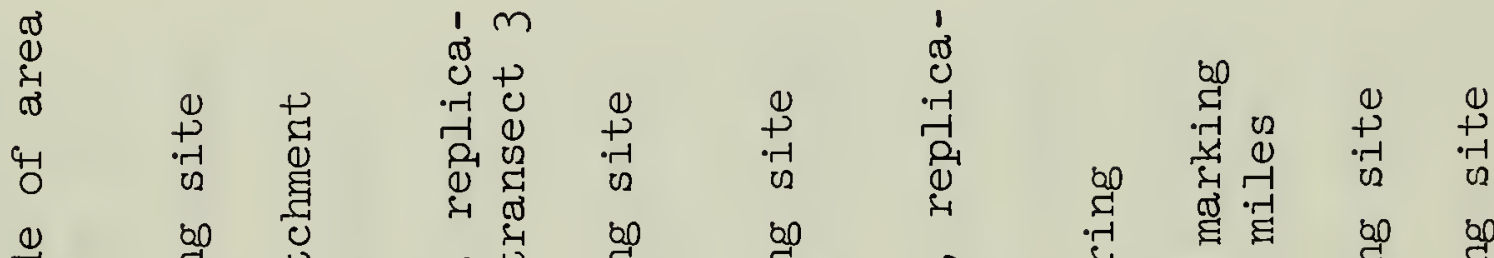

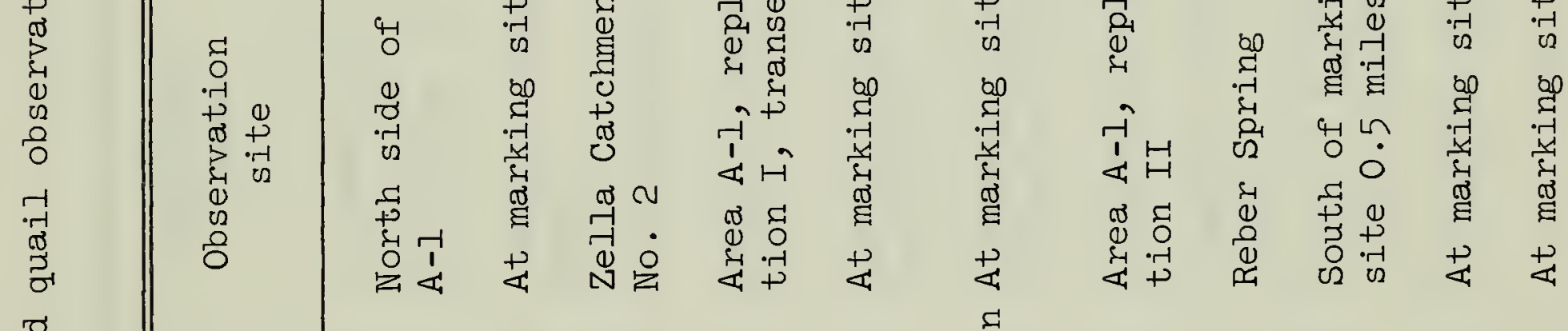

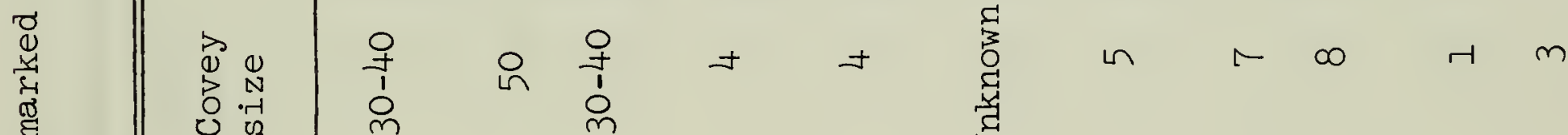
घ 0 o

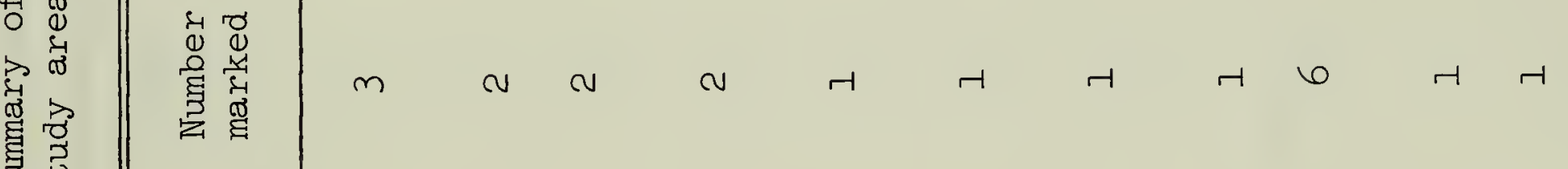

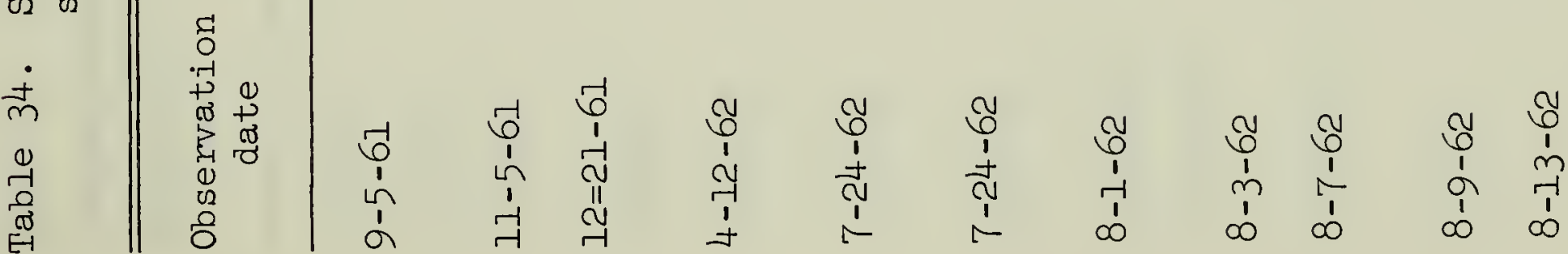





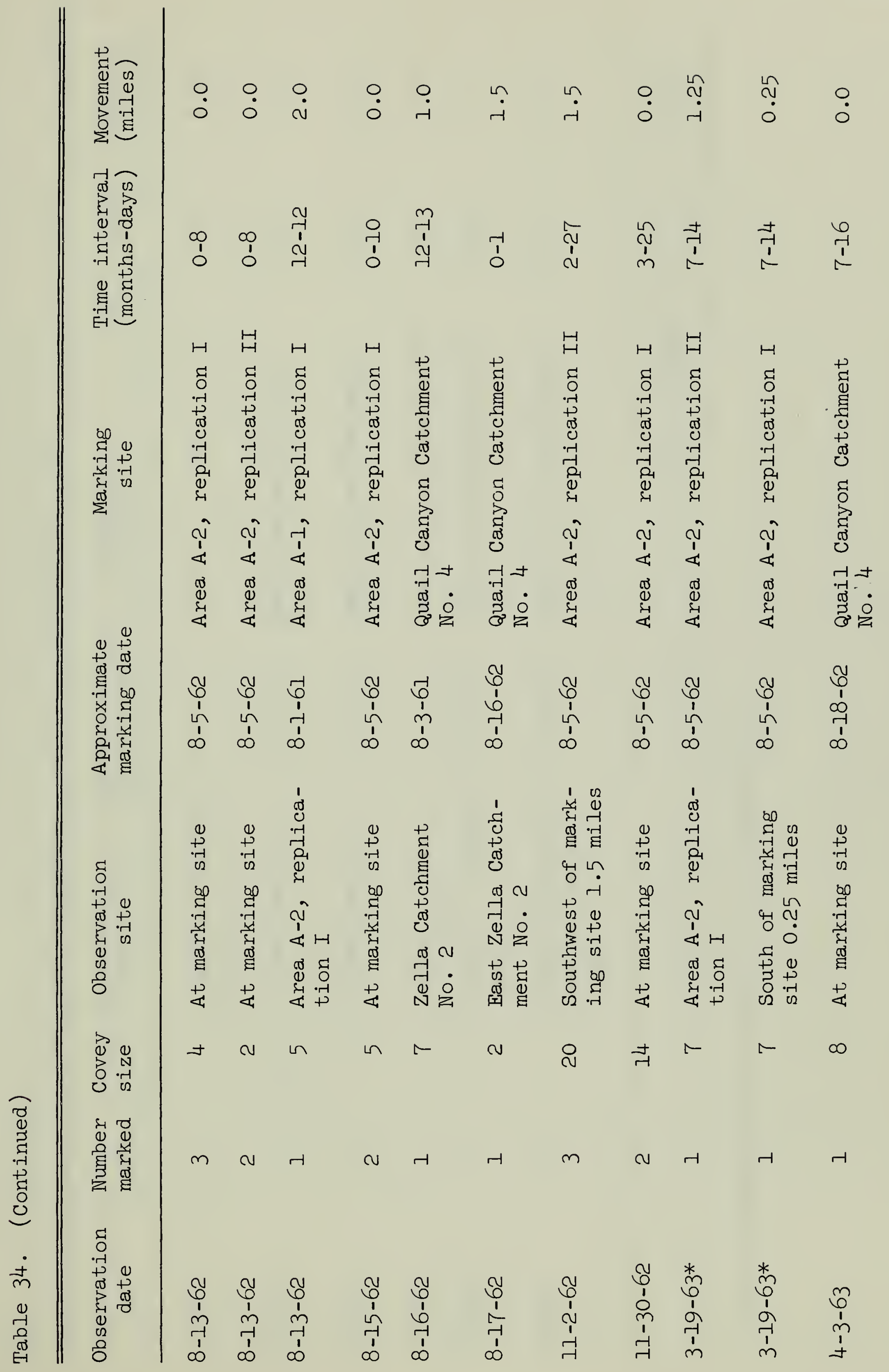





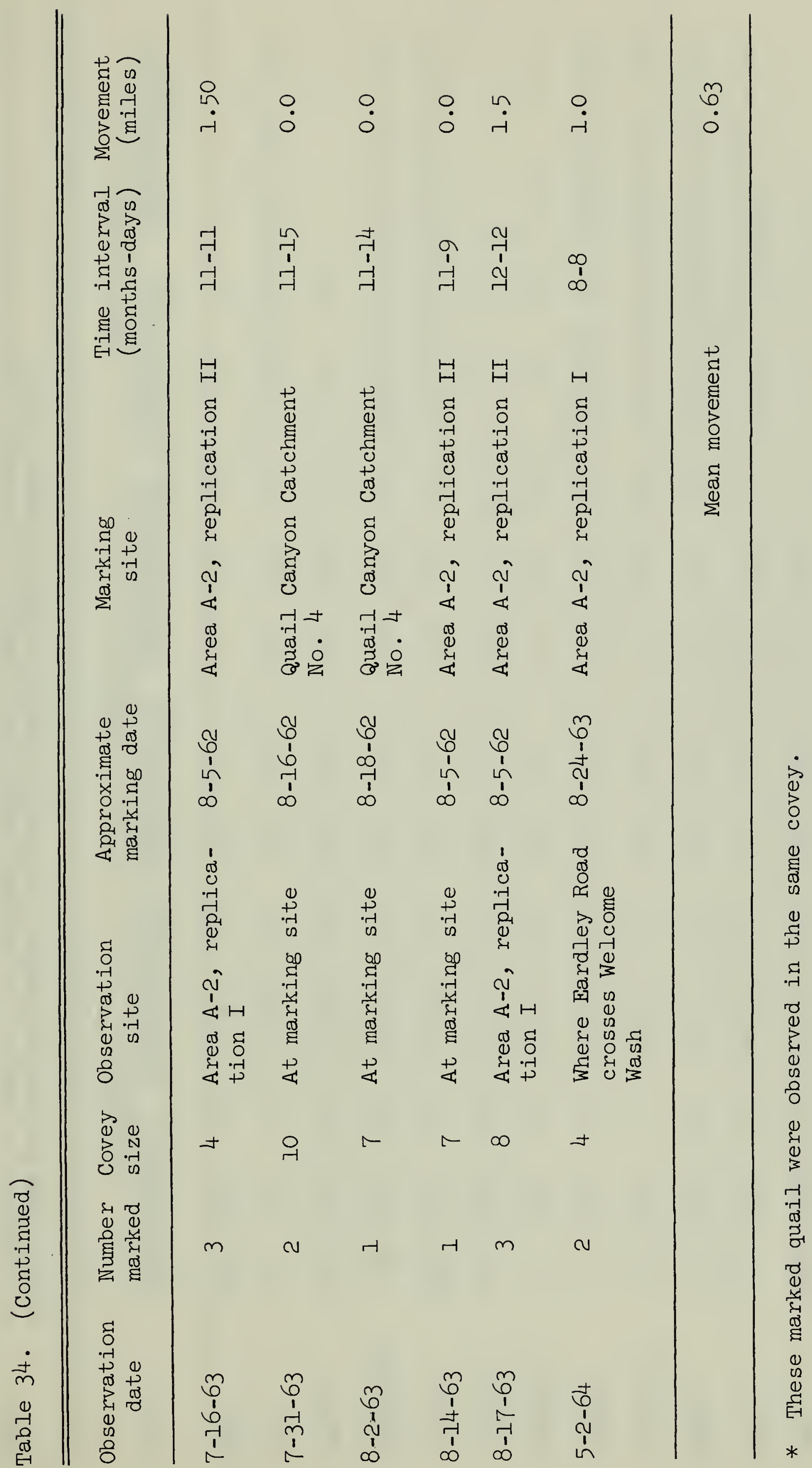



政

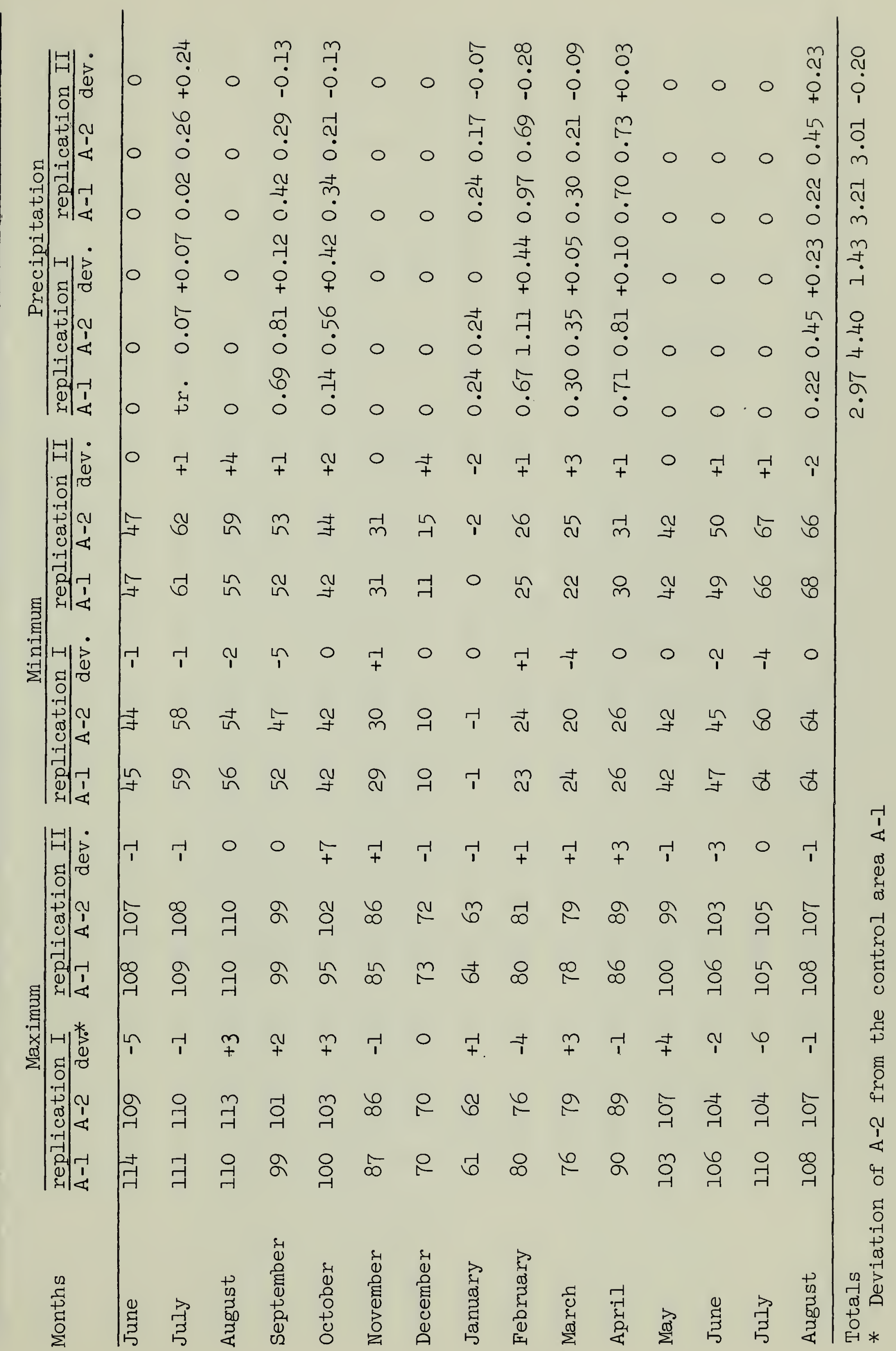





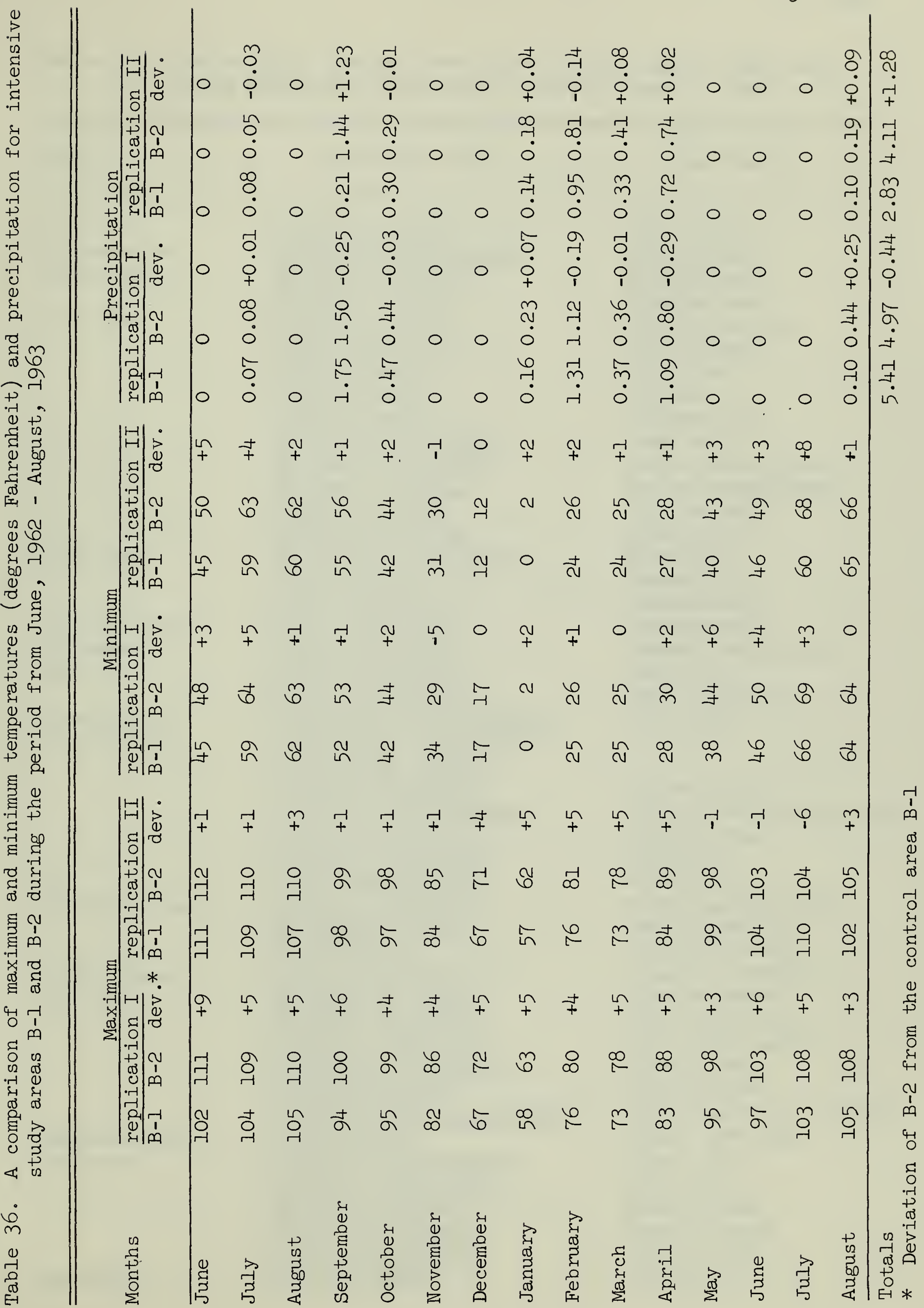



Table 37. List of plant species identified in the general study area during the period from June 15, 1961 to June 30, 1964

Family Scientific name Common name

Pinaceae

Cupressaceae

Ephedraceae

Gramineae

Liliaceae

Amaryllidaceae

Salicaceae

Fagaceae

Loranthaceae

Polygonaceae

Chenopodiaceae

Berberidaceae

Cruciferae

Capparidaceae Rosaceae

Leguminosae
Pinus monophylla

Juniperus osteosperma

Ephedra nevadensis

Ephedra viridis

Bouteloua barbata

Bromus tectorum

Bromus rubens

Hilaria jamesii

Hilaria rigida

Muhlenbergia porteri

Oryzopsis hymenoides

Schismus barbatus

Sitanion hystrix

Tridens pulchella

Calochortus flexuosus

Yucca baccata

Yucca brevifolia

Agave utahensis

Populus fremontii

Quercus gambelii

Quercus turbinella

Phoradendron californicum

Chorizanthe brevicornu

Chorizanthe rigida

Eriogonum deflexum

Eriogonum fasciculatum

Eriogonum inflatum

Eriogonum maculatum

Rumex hymenosepalus

Atriplex canescens

Chenopodium album

Salsola kali

Berberis fremontii

Descurainia sophia

Lepidium fremontii

Lepidium lasiocarpum

Lesquerella gordoni

Stanleya pinnata

Streptanthella longirostris

Cleome lutea

Coleogyne ramosissima

Cowania stansburiana

Fallugia paradoxá

Prunus fasciculatus

Purshia glandulosa

Acacia greggii
Pinyon pine

Utah juniper

Brigham tea

Brigham tea

Six-weeks grama

Cheat grass

Red brome

Galleta

Big galleta

Bush muhly

Indian rice grass

Mediterranean grass

Squirrel tail

Fluff grass

Mariposa

Banana yucca

Joshua-tree

Century-plant

Fremont cottonwood

Gambel oak

Shrub live-oak

Mistletoe

Skeleton-weed

Flat-top buckwheat-brush

Bladder-stem

Buckwheat

Wild-rhubarb

Four-wing salt-bush

Lambs-quarters

Russian-thistle

Fremont barberry

Tansy-mustard

Desert àlyssum

Sand pepper-grass

Bladder-pod

Desert-plume

Long-beaked twist-flower

Yellow bee-plant

Black-brush

Cliff-rose

Apache-plume

Desert-almond

Bitter-brush :

Cat-claw 

Table 37. (Continued)

Family

Scientific name

Common name

Leguminosae

Geraniaceae

Linaceae

Zygophyllaceae

Rutaceae

Euphorbiaceae

Anacardiaceae

Rhamnaceae

Malvaceae

Loasaceae

Cactaceae

Onagraceae

Ericaceae

Oleaceae

Polemoniaceae

Hydrophyllaceae
Astragalus flarus

Astragalus lentiginosus

Astragalus nuttallianus

Dalea fremontii

Dalea polyadenia

Krameria parviflora

Lupinus sparsiflorus

Prosopis juliflora

Prosopis pubescens

Eriodium cicutarium

Iinum aristatum

Larrea divaricata

Thamnosma montana

Euphorbia albomarginata

Rhus trilobata

Ceanothus greggii

Sphaeralcea grossulariaefolia

Mentzelia albicaulis

Mentzelia multiflora

Echinocereus engelmannii

Ferocactus lecontei

Mammillaria chlorantha

Opuntia acanthocarpa

Opuntia basilaris

Opuntia echinocarpa

Opuntia phaeacantha

Opuntia polycantha

opuntia ursina

Gaura coccinea

Oenothera caespitosa

Oenothera deltoides

Oenothera multijuga

Arctostaphylos patula

Arctostaphylos pungens

Fraxinus anomala

Fraxinus velutina

Eriastrum eremicum

Eriastrum sparsiflorum

Gilia leptomeria

Gilia polycladon

Gilia sinuata

Langloisia setosissima

Phlox longifolia

Eriodictyon angustifolium

Nama demissum

Phacelia crenulata

Phacelia fremontii
Milk-vetch

Milk-vetch

Dwarf milk-vetch

Indigo-bush

Indigo-bush

Range ratany

Iupine

Mesquite

Screwbean mesquite

Filaree

Flax

Creosote-bush

Turpentine-broom

Spurge

Squaw-bush

Buckbrush

Globe-mallow

Stick-leaf

Stick-leaf

Hedgehog cactus

Barrel cactus

Pincushion cactus

Buckhorn cholla

Beavertail cactus

Cholla

Prickly-pear

Prickly-pear

Grizzly bear cactus

Gaura

Evening-primrose

Evening-primrose

Evening-primrose

Green-leaf manzanita

Point-leaf manzanita

Single-leaf ash

Velvet ash

Gilia

Gilia

Gilia

Phlox

Mountain-balm

Purplemat

Water-ledf

Fremont phacelia 
Table 37. (Continued)

\begin{tabular}{|c|c|c|}
\hline Family & Scientific name & Common name \\
\hline \multirow[t]{9}{*}{ Boraginaceae } & 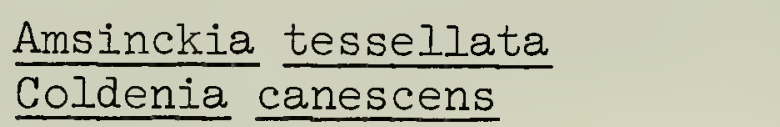 & Checker fiddle-neck \\
\hline & Cryptantha barbigera & Forget-me-not \\
\hline & Cryptantha circumcissa & Forget-me-not \\
\hline & Cryptantha micrantha & Forget-me-not \\
\hline & Cryptantha nevadensis & Forget-me-not \\
\hline & Cryptantha pterocarya & Forget-me-not \\
\hline & Cryptantha virginensis & Forget-me-not \\
\hline & Pectocarya setosa & Stiff-stemmed comb-bur \\
\hline & Plagiobothrys arizonicus & Popcorn flower \\
\hline \multirow[t]{2}{*}{ Labiatae } & Salazaria mexicana & Bladder-sage \\
\hline & $\frac{\text { Salvia }}{\text { Salvia }} \frac{\text { carnosa }}{\text { columbariae }}$ & $\begin{array}{l}\text { Desert sage } \\
\text { Chia }\end{array}$ \\
\hline \multirow[t]{3}{*}{ Solanaceae } & Datura meteloides & Sacred datura \\
\hline & $\overline{\text { Lycium andersonii }}$ & Wolf-berry \\
\hline & Nicotiana trigonophylla & Desert tobacco \\
\hline \multirow[t]{2}{*}{ Scrophulariaceae } & Castille ja chromosa & Indian paint-brush \\
\hline & Penstemon palmeri & Beardtongue \\
\hline Bignoniaceae & Chilopsis linearis & Desert-willow \\
\hline \multirow{2}{*}{ Plantaginaceae } & Plantago insularis & Plantain \\
\hline & Plantago purshii & Plantain \\
\hline Cucurbitaceae & Cucurbita foetidissima & Buffalo-gourd \\
\hline \multirow[t]{19}{*}{ Compositae } & Acamptopappus spaerocephalus & Golden-head \\
\hline & Artemisia ludoviciana & Wormwood \\
\hline & Artemisia tridentata & Big sagebrush \\
\hline & Aster abatus & Desert aster \\
\hline & Baccharis sergiloides & Desert baccharis \\
\hline & Baccharis viminea & Mule-fat \\
\hline & $\frac{\text { Baileya multiradiata }}{\text { Chaenactis macrantha }}$ & Desert-marigold \\
\hline & $\begin{array}{l}\text { Chrysothamnus paniculatus } \\
\text { Encelia frutescens }\end{array}$ & Rabbit-brush \\
\hline & Erigeron concinnus & Flea-bane \\
\hline & Eriophyllum wallacei & Woolly-daisy \\
\hline & Franseria dumosa & Bur-sage \\
\hline & Franseria eriocentra & Bur-sage \\
\hline & Gaillardia arizonica & Blanket-flower \\
\hline & Gutierrezia sarothrae & Snake-weed \\
\hline & Haplopappus Iinearifolius & Golden-bush \\
\hline & Hymenoclea salsola & Burro-brush \\
\hline & Malacothrix glabrata & Desert-dendelion \\
\hline & Psilostrophe cooperi & Paper-daisy \\
\hline & Senecio multicapitatus & Groundsel \\
\hline
\end{tabular}



Phylogenetic order of families listed follows Kearney and Peebles (1960) Arizona Flora. Genera and species with in families are listed in alphabetical $\overline{\text { order. }}$.

Common names were derived from the Arizona Flora, Jaeger's (1944) Desert Wildflowers, Arnberger's (1954) Flowers of the Southwest Mountains, Dodge's (1958) Flowers of the Southwest Deserts and Patraw's (1959) Flowers of the Southwest Mesas.

All plants collected were identified by Arthur H. Holmgren, Curator of the Intermountain Herbarium at Utah State University, Logan, Utah. 


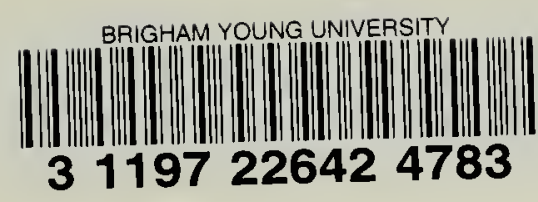


